\title{
Experiment Design and Analysis Guide - Neutronics \& Physics
}

June 2014

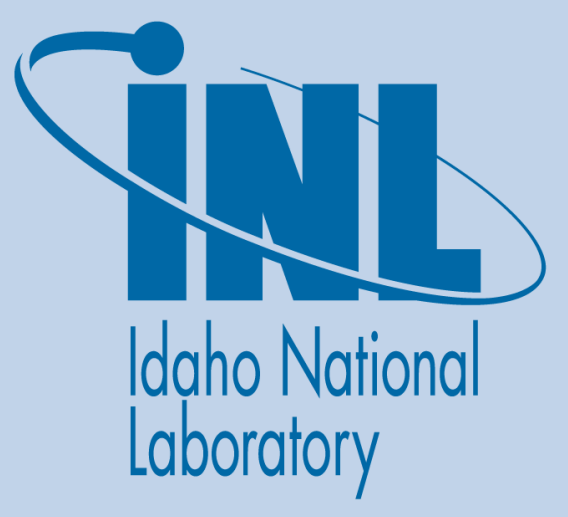




\section{DISCLAIMER}

This information was prepared as an account of work sponsored by an agency of the U.S. Government. Neither the U.S. Government nor any agency thereof, nor any of their employees, makes any warranty, expressed or implied, or assumes any legal liability or responsibility for the accuracy, completeness, or usefulness, of any information, apparatus, product, or process disclosed, or represents that its use would not infringe privately owned rights. References herein to any specific commercial product, process, or service by trade name, trade mark, manufacturer, or otherwise, does not necessarily constitute or imply its endorsement, recommendation, or favoring by the U.S. Government or any agency thereof. The views and opinions of authors expressed herein do not necessarily state or reflect those of the U.S. Government or any agency thereof. 
INL/EXT-14-32504

GDE-594

\section{Experiment Design and Analysis Guide - Neutronics \& Physics}

June 2014

Idaho National Laboratory Idaho Falls, Idaho 83415

http://www.inl.gov

Prepared for the U.S. Department of Energy Under DOE Idaho Operations Office Contract DE-AC07-05ID14517 
Guide

\section{Experiment Design and Analysis Guide - Neutronics \& Physics}

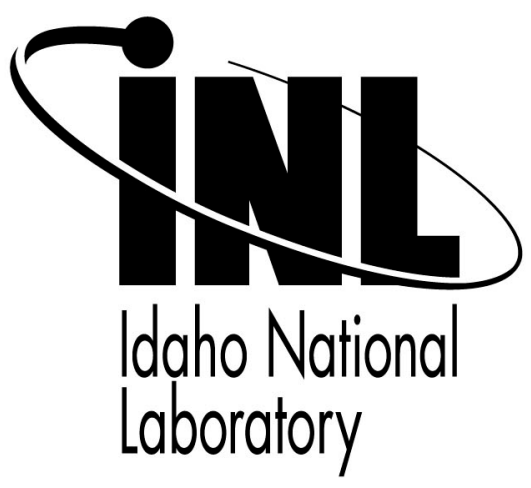

The INL is a U.S. Department of Energy National Laboratory operated by Battelle Energy Alliance. 


\begin{tabular}{|c|lll|}
\hline EXPERIMENT DESIGN AND ANALYSIS & Identifier: & GDE-594 & \\
GUIDE - NEUTRONICS \& PHYSICS & Revision: & 1 & \\
& Effective Date: & $06 / 26 / 2014$ & Page: 2 of 67 \\
\hline
\end{tabular}

\section{REVISION LOG}

\begin{tabular}{|c|c|c|l|}
\hline Rev. & Date & Affected Pages & \multicolumn{1}{c|}{ Revision Description } \\
\hline 0 & $09 / 27 / 2013$ & All & See eCR 609642. Create. \\
\hline 1 & $06 / 26 / 2014$ & All & See eCR 623888. \\
\hline & & & \\
\hline & & & \\
\hline & & & \\
\hline & & & \\
\hline & & & \\
\hline & & & \\
\hline & & & \\
\hline & & & \\
\hline & & & \\
\hline
\end{tabular}




\begin{tabular}{|c|lll|}
\hline $\begin{array}{c}\text { EXPERIMENT DESIGN AND ANALYSIS } \\
\text { GUIDE - NEUTRONICS \& PHYSICS }\end{array}$ & Revision: & GDE-594 & \\
& Effective Date: & $06 / 26 / 2014$ & Page: 3 of 67 \\
\hline
\end{tabular}

\section{CONTENTS}

1. PURPOSE

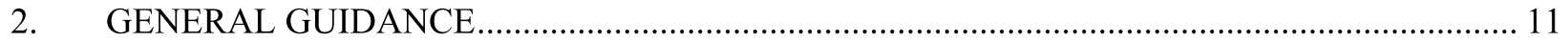

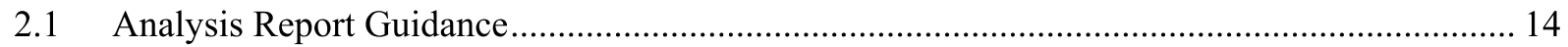

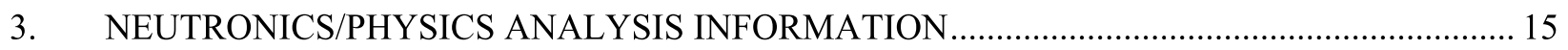

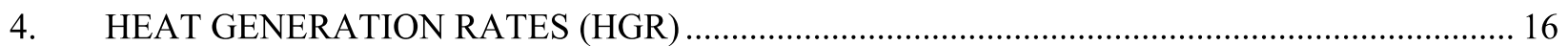

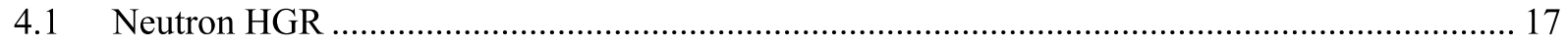

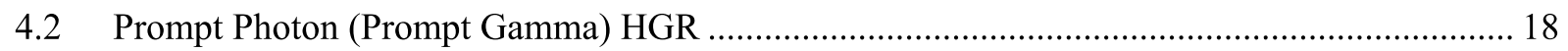

4.3 Delayed Photon (Delayed Fission Product Gamma) HGR …................................................. 18

5. EXPERIMENT/BACKUP EXPERIMENT REACTIVITY WORTH .................................... 21

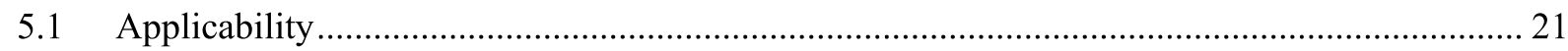

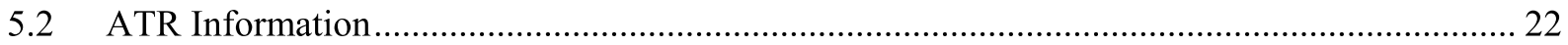

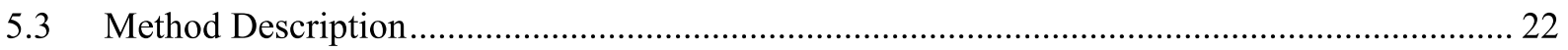

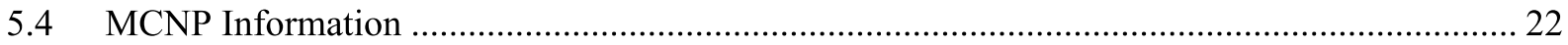

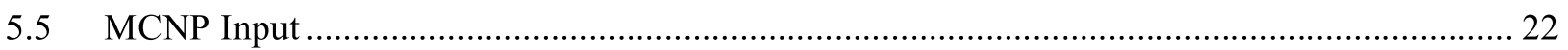

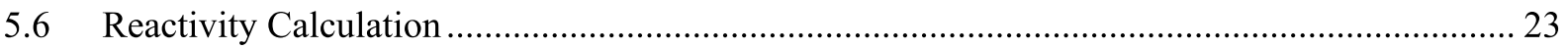

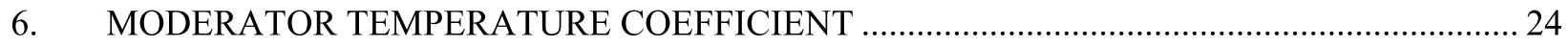

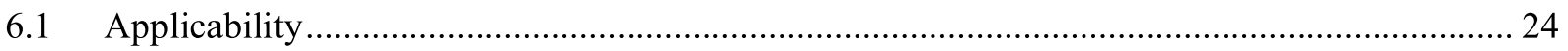

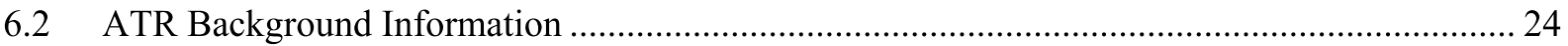

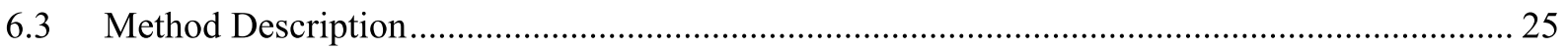

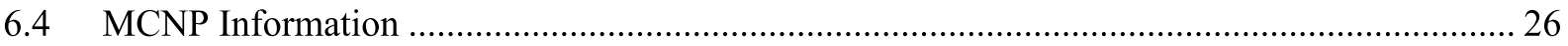

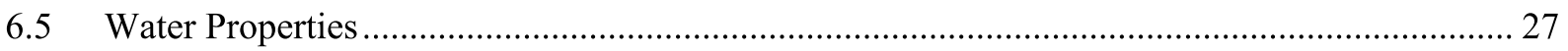

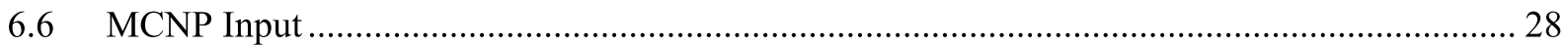

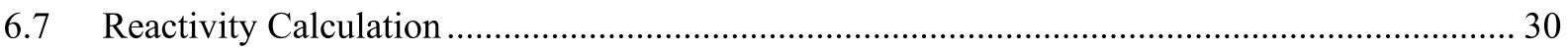

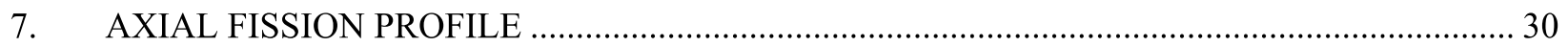

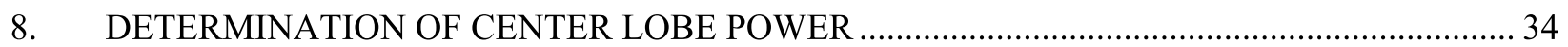

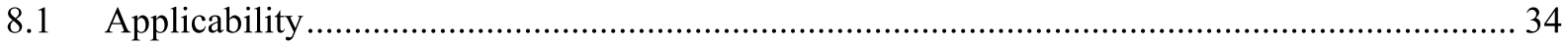

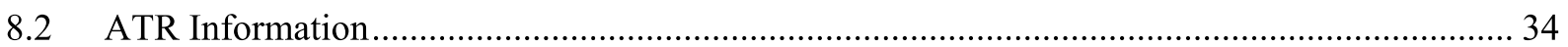

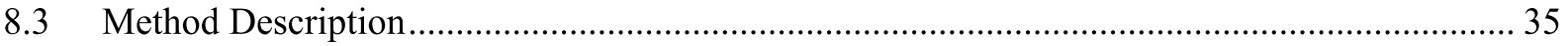

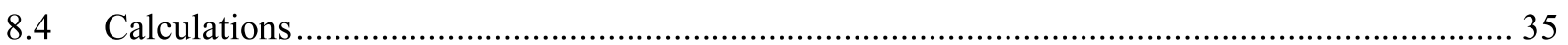

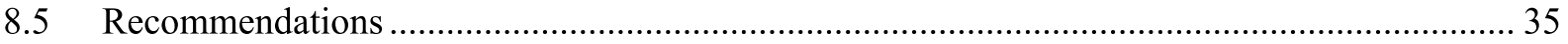

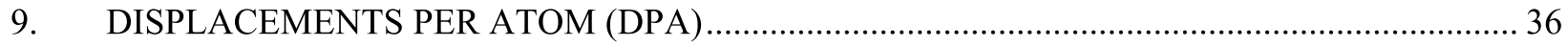

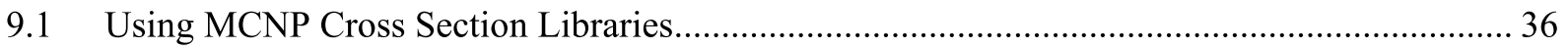

9.2 Using existing Tabulated Cross Sections …............................................................................. 39 


\begin{tabular}{|c|c|c|c|}
\hline $\begin{array}{l}\text { EXPERIMENT DESIGN AND ANALYSIS } \\
\text { GUIDE - NEUTRONICS \& PHYSICS }\end{array}$ & $\begin{array}{l}\text { Identifier: } \\
\text { Revision: } \\
\text { Effective Date: }\end{array}$ & $\begin{array}{l}\text { GDE-594 } \\
1 \\
06 / 26 / 2014\end{array}$ & Page: 4 of 67 \\
\hline
\end{tabular}

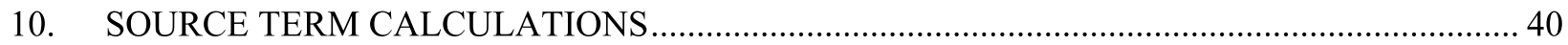

10.1 MCNP Neutron Flux and Cross-Section Calculations ......................................................... 41

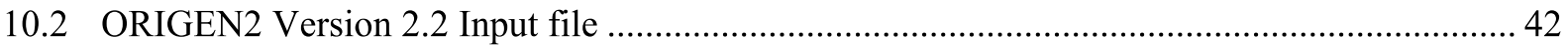

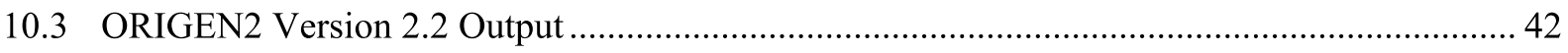

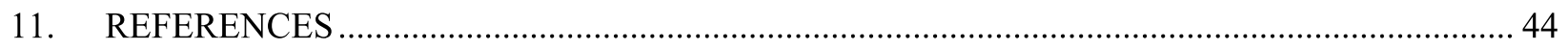

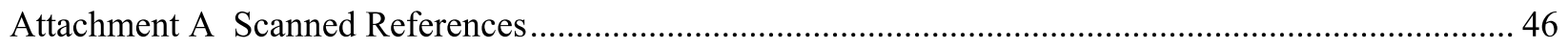

Attachment B Water Properties for Primary Coolant Used in Moderator Temperature Coefficient

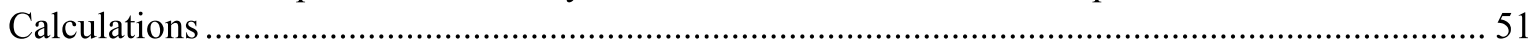

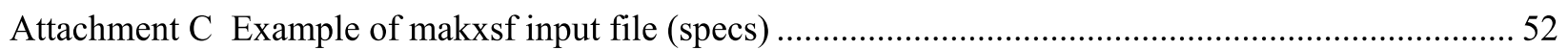

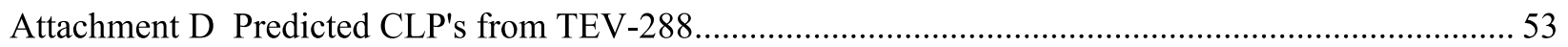

Attachment E Comparison Using Average CLPM vs. TEV-288 Method .............................................. 54

Attachment F Comparison Using Average CLPM vs. TEV-288 Method, PALM Cycles ........................ 57

Attachment G ATR Power History Through Cycle 133B-1, DEH-05-04 ............................................. 58

Attachment H ATR Power History Through Cycle 150B-1, Revision 1, DEH-05-11, Rev.1.................. 64 


\begin{tabular}{|c|c|c|c|}
\hline $\begin{array}{l}\text { EXPERIMENT DESIGN AND ANALYSIS } \\
\text { GUIDE - NEUTRONICS \& PHYSICS }\end{array}$ & $\begin{array}{l}\text { Identifier: } \\
\text { Revision: } \\
\text { Effective Date: }\end{array}$ & $\begin{array}{l}\text { GDE-594 } \\
1 \\
06 / 26 / 2014\end{array}$ & Page: 5 of 67 \\
\hline
\end{tabular}

\section{ACRONYMS}

AF

ANSI

ASME

ASTM

ASUDAS

ATR

ATRC (ATR-C)

BA

BEA

$\mathrm{BF}$

BOC

$\mathrm{BU}$

$\mathrm{C}$

CAES

CDIPT

CFR

CIC

$\mathrm{CHF}$

CLOFA

CSAP

DAC

DBR

DNBR

DOE

DPA

DPHGR

DPHNF

DWG

E

ECAR

ECP

eCR

EDF

EFIS

EFPD

EOC

EPP

EPRI
Aluminum Filler

American National Standards Institute

American Society of Mechanical Engineers

American Society for Testing and Materials

ATR Surveillance Data Acquisition System

Advanced Test Reactor

Advanced Test Reactor Critical Facility

Burnable Absorber

Battelle Energy Alliance

Beryllium Filler

Beginning-of-Cycle

Back Up (also used for burnup)

Center (flux trap or lobe)

Center for Advanced Energy Studies

Chopped Dummy In Pile Tube

Code of Federal Regulations

Core Internal Change out

Critical Heat Flux

Complete Loss of Flow Accident

Core Safety Assurance Package

Data Acquisition and Control

Design Basis Report - ATR PPS and Technical Specifications

Departure from Nucleate Boiling Ratio

Department of Energy

Displacements Per Atom

Delayed Photon Heat Generation Rate

Delayed Photon Heating Normalization Factor

Drawing

East (flux trap)

Engineering Calculations and Analysis Report

Emergency Coolant Pump(s)

Electronic Change Request

Engineering Design File (ECAR and TEV are a type of EDF)

Emergency Firewater Injection System

Effective Full Power Day

End-of-Cycle

Effective Plate Power

Electric Power Research Institute 


\begin{tabular}{|c|lll|}
\hline $\begin{array}{c}\text { EXPERIMENT DESIGN AND ANALYSIS } \\
\text { GUIDE - NEUTRONICS \& PHYSICS }\end{array}$ & $\begin{array}{l}\text { Revision: } \\
\text { Effective Date: }\end{array}$ & $\begin{array}{l}\text { 06/26/2014 } \\
\text { Page: } 6 \text { of } 67\end{array}$ \\
\hline
\end{tabular}

ESA

ESAP

FE

FIMA

FIR

FT

GDC

GDE

GPD

HEU

HFEF

HGR

HSA

HSIS

HPC

IA

IHA

INL

IPT

ISOP

ITV

L2AR

LDRD

LEU

LHGR

LIPT

LOCA

LSA

LWP

MCNP

MCWO

MFC

MOC

MT

MTCR

$\mathrm{N}$

NE

NHGR

NNSA

NR
Experiment Safety Analysis

Experiment Safety Assurance Package

Fuel Element

Fissions per Initial heavy Metal Atom

Flow Instability Ratio

Flux Trap

General Design Criteria

Guide

Gamma Production Data

High Enriched Uranium

Hot Fuel Examination Facility

Heat Generation Rate

High Specific Activity

Hydraulic Shuttle Irradiation System

High Performance Computing

Inboard A position

Irradiation Housing Assembly

Idaho National Laboratory

In-Pile Tube

Integrated Strategic Operational Plan

Irradiation Test Vehicle

Local-to-Average Ratio

Lab Directed Research and Development

Low Enriched Uranium

Linear Heat Generation Rate

Large In Pile Tube

Loss Of Coolant Accident

Low Specific Activity

Lab Wide Procedure

Monte Carlo N-Particle (transport code)

MCNP Coupled With ORIGEN2

Materials and Fuels Complex

Middle-of-Cycle

Empty

Moderator Temperature Coefficient of Reactivity

North (flux trap)

Northeast (flux trap or lobe)

Neutron Heat Generation Rate

National Nuclear Security Administration

Naval Reactors (Program) 


\begin{tabular}{|c|lll|}
\hline $\begin{array}{c}\text { EXPERIMENT DESIGN AND ANALYSIS } \\
\text { GUIDE - NEUTRONICS \& PHYSICS }\end{array}$ & $\begin{array}{l}\text { Revision: } \\
\text { Effective Date: }\end{array}$ & $\begin{array}{l}\text { 06/26/2014 } \\
\text { Page: } 7 \text { of } 67\end{array}$ \\
\hline
\end{tabular}

NRC

NSUF

NS

NW

OA

OGK

OP

ONB

ORIGEN

OSCC

PALM

PCP

PCS

PDD

PEP

PHNF

PIE

PISA

PLN

PPC

PPHGR

PPHNF

PPS

PRA

QA

RDAS

R\&D

RIA

RR

RSICC

RSS

RTC

$\mathrm{S}$

SAR

SARP

SE

SIHA

SIPT

SOPL

SORC
Nuclear Regulatory Commission

National Scientific User Facility

Neck Shim

Northwest (flux trap or lobe)

Outboard A position

O.G. Kelly and Company (can refer to cask made by O.G. Kelly)

Operating Procedure

Onset of Nucleate Boiling

Oak Ridge Isotope Generation code

Outer Shim Control Cylinder

Powered Axial Locator Mechanism

Primary Coolant Pump(s)

Primary Coolant System

Projected Description Document

Project Execution Plan

Prompt Heating Normalization Factor

Post Irradiation Examination

Potentially Inadequate Safety Analysis

Plan (document type)

Plant Protection Criteria

Prompt Photon Heat Generation Rate

Prompt Photon Heating Normalization Factor

Plant Protection System

Probabilistic Risk Assessment

Quality Assurance

Reactor Data Acquisition System

Research and Development

Reactivity Insertion Accident

Regulating Rod

Radiation Safety Information Computational Center

Reactor Shutdown System

Reactor Technology Complex (now ATR Complex)

South (flux trap)

Safety Analysis Report

Safety Analysis Report for Packaging

Southeast (flux trap or lobe)

Standard Irradiation Housing Assembly

Standard In-Pile Tube

Standard Out-of-Pile Loop

Safety and Operations Review Committee 


\begin{tabular}{|c|lll|}
\hline $\begin{array}{c}\text { EXPERIMENT DESIGN AND ANALYSIS } \\
\text { GUIDE - NEUTRONICS \& PHYSICS }\end{array}$ & $\begin{array}{l}\text { Revision: } \\
\text { Effective Date: }\end{array}$ & $\begin{array}{l}\text { 06/26/2014 } \\
\text { Page: } 8 \text { of } 67\end{array}$ \\
\hline
\end{tabular}

$\begin{array}{ll}\text { SR } & \text { Safety Rod } \\ \text { SSC } & \text { Structures Systems and Components } \\ \text { SW } & \text { Southwest (flux trap or lobe) } \\ \text { TCR } & \text { Temperature Coefficient of Reactivity } \\ \text { TEV } & \text { Technical Evaluation } \\ \text { TFR } & \text { Technical and Functional Requirements } \\ \text { TRA } & \text { Test Reactor Area (now ATR Complex) } \\ \text { TSR } & \text { Technical Safety Requirements } \\ \text { UFSAR } & \text { Upgraded Final Safety Analysis Report } \\ \text { USQ } & \text { Unreviewed Safety Question } \\ \text { W } & \text { West (flux trap) } \\ \text { V\&V } & \text { Verification and Validation } \\ \text { ZPPR } & \text { Zero Power Physics Reactor }\end{array}$

\section{Program Specific Acronyms}

AFC

AFCI

AGR

AGC

AFIP

DBRP

FCRD

GTRI

LEP

LWRS

MICE

NGNP

RERTR

SPICE

Basket

Bucket

Capsule

Capsule Assembly

Cell
Advanced Fuel Cycle

Advanced Fuel Cycle Initiative (now FCRD)

Advanced Gas Reactor

Advanced Graphite Creep

ATR Full-size plate In center flux trap Position

Design Basis Reconstitution Program (now LEP)

Fuel Cycle Research and Development

Global Threat Reduction Initiative

Life Extension Program

Light Water Reactor Sustainability

Multiple Irradiation Capsule Experiment

Next Generation Nuclear Plant

Reduced Enrichment for Research and Test Reactors (now GTRI)

South Position Irradiation Capsule Experiment

\section{DEFINITIONS}

Holder used to arrange and situate test hardware such as capsules and spacers; typically used for drop-in type tests

Holder used to move and store experiment hardware such as test assemblies

A component of the experiment assembly that serves as a primary boundary to isolate the test specimens from the ATR primary coolant system.

Any test/experiment that is in contact with the ATR primary coolant system MCNP defined volume containing a single material composition. This may or may not represent a physical volume within the model. 


\begin{tabular}{|c|lll|}
\hline $\begin{array}{c}\text { EXPERIMENT DESIGN AND ANALYSIS } \\
\text { GUIDE - NEUTRONICS \& PHYSICS }\end{array}$ & $\begin{array}{l}\text { Revision: } \\
\text { Effective Date: }\end{array}$ & $\begin{array}{l}\text { 06/26/2014 } \\
\text { Page: } 9 \text { of } 67\end{array}$ \\
\hline
\end{tabular}

Envelope Tube

Experiment Hardware

Irradiation Facility

Fixtures

Flow Tube

Flux Trap (FT)

Fuel Compact

Fuel Pellet

Heat Generation Rate (HGR)

Inboard A

In-Pile Tube (IPT)

Large B

Large I

Lead Out

Lobe

Loop

Medium I

Neck Shim (NS)

Outboard A

Outer Shim Control Cylinder (OSCC)

Pressure Tube

Regulating Rod (RR)

Rodlet

Safety Rod (SR)

Small B

Small I

Snubber Tube
Containment of the pressure tube.

All physical items, excluding test specimen(s), associated with the location and fixture(s) for a given experiment configuration.

Test location or test position in the ATR.

Any of various devices for holding parts or components in position

Redirects flow through an experiment in a loop.

Irradiation facility that is surrounded by at least 4 driver fuel elements. These facilities are the NW, N, NE, E, SE, S, SW, W and Center positions.

A holder containing the fuel pellets.

A small spherical or cylindrical piece of fuel with some type of cladding.

The energy deposited in a specimen or material when it is irradiated in a nuclear reactor (i.e. subject to nuclear reactions). Typical units for HGR reporting are: W (Power), W/cc (Power Density), W/g, W/cm² (Heat Flux), W/cm (LHGR)

ATR irradiation positions A-1 through A-8

The envelope tube and pressure tube assembly.

ATR irradiation positions B-9 through B-12

ATR irradiation positions I-1, I-6, I-11 and I-16

Drop in capsule experiment with instrumentation lines that exit the experiment and the reactor vessel.

Irradiation facility that is surrounded by 8 driver fuel elements. These facilities are the NW, NE, SE, SE and Center positions.

Irradiation facility that isolates the experiment from the primary reactor coolant. These facilities are located in the N, NW, SE, SW and W positions.

ATR irradiation positions I-2 through I-5, I-7 through I-10, I-12 through I-15, I-17 through I-20

Control elements located in the NW, NE, SW, SE quadrants of the ATR. There are 6 NS per quadrant. The number 4 NS in SE and SW quadrants serve as either the RR, or the backup RR.

AR irradiation positions A-9 through A-16

Control drums located around the perimeter of the ATR fuel. Each quadrant has four OSCCs ganged together as a bank of OSCCs used to control the corner lobe power (NW, NE, SW, and SE)

Containment for the loop.

Neck shim number 4 in the SE or SW quadrant. Both south NS serve as either the RR or the backup RR for the ATR.

A tubular component of the experiment that contains fuel or material specimens and provides an interface with the capsule.

Located in the N, W, E, SW, S, and SE flux trap positions.

ATR irradiation positions B-1 through B-8

ATR irradiation positions I-21 through I-24

Located in the reflector tank and is used to slow down the safety rods. 
EXPERIMENT DESIGN AND ANALYSIS GUIDE - NEUTRONICS \& PHYSICS

$\begin{array}{ll}\text { Identifier: } & \text { GDE-594 } \\ \text { Revision: } & 1 \\ \text { Effective Date: } & 06 / 26 / 2014\end{array}$

Specimen

Structural Material

Test Train Assembly
Sample being irradiated for research or production purposes.

Any material in the core that carries a load.

All experiment components configured for placement into the ATRC or ATR core irradiation facility, including the basket. May consist of individual or multiple capsules, may be fitted with multiple thermocouples and with separate gas supply and return lines. Test trains may be pressure tested and leak tested during and after assembly. 


\begin{tabular}{|c|c|c|c|}
\hline $\begin{array}{l}\text { EXPERIMENT DESIGN AND ANALYSIS } \\
\text { GUIDE - NEUTRONICS \& PHYSICS }\end{array}$ & $\begin{array}{l}\text { Identifier: } \\
\text { Revision: } \\
\text { Effective Date: }\end{array}$ & $\begin{array}{l}\text { GDE-594 } \\
1 \\
06 / 26 / 2014\end{array}$ & Page: 11 of 67 \\
\hline
\end{tabular}

\begin{tabular}{|l|l|l|l|}
\hline ATR & Guide & & eCR Number: 623888 \\
\hline
\end{tabular}

\section{PURPOSE}

The purpose of this guide is to provide a consistent, standardized approach to performing neutronics/physics analysis for experiments inserted into the Advanced Test Reactor (ATR). This document provides neutronics/physics analysis guidance to support experiment design and analysis needs for experiments irradiated in the ATR. This guide addresses neutronics/physics analysis in support of experiment design, experiment safety, and experiment program objectives and goals.

The intent of this guide is to provide a standardized approach for performing typical neutronics/physics analyses. Deviation from this guide is allowed provided that neutronics/physics analysis details are properly documented in an analysis report.

\section{GENERAL GUIDANCE}

Experiments inserted into ATR are designed and evaluated to meet programmatic objectives and goals, to support experiment design requirements, and to help demonstrate compliance with the ATR safety basis. Neutronics/physics analysis results may be used to support the following:

- planning and scheduling of experiment irradiations,

- experiment engineering design,

- thermal hydraulic analysis,

- Experiment Safety Assurance Package (ESAP) preparation,

- ATR Critical (ATRC) Facility measurements,

- experiment shipping and handling,

- experiment post irradiation examination (PIE), and

- experiment program objectives and goals.

The type of neutronics/physics analysis performed for each experiment depends upon experiment parameters and conditions. The following questions identify some of these experiment parameters and conditions.

- What materials are being used in this experiment (e.g., fissile material, burnable neutron absorber, isotope producing material, or structural material)?

- What is the ATR in-pile irradiation position for this experiment (e.g, flux trap, neckshim housing, beryllium block, fuel element (FE) position, or other position)?

- What type of experiment is it (e.g., drop-in capsule, lead-out capsule, loop experiment, demonstration FE, or other)?

- What are the experiment goals or objectives (e.g., \% depletion, temperatures, displacements per atom (DPA), peak heating rates, isotope production, fluence, or other)?

- What are the ATR operating conditions for this experiment (number of cycle(s), lobe powers/core power, cycle duration, or other)? 


\begin{tabular}{|c|lll|}
\hline $\begin{array}{c}\text { EXPERIMENT DESIGN AND ANALYSIS } \\
\text { GUIDE - NEUTRONICS \& PHYSICS }\end{array}$ & Revision: & \multicolumn{1}{l|}{ GDE-594 } & \\
& Effective Date: & $06 / 26 / 2014$ & Page: 12 of 67 \\
\hline
\end{tabular}

The neutronics/physics analysis results that are most often used include:

- material heat generation rates (prompt neutron, prompt gamma, delayed gamma) for materials within experiment,

- experiment reactivity worth and backup experiment reactivity worth relative to a water-filled position,

- axial fission profile within ATR FE water channels,

- depletion of fissile or burnable materials within experiment, and

- radionuclide inventory source term (isotopic activity and decay heat).

Table 1 lists ATR irradiation test positions and identifies the neutronics/physics analyses typically performed.

Table 1 also identifies test positions that are affected by the movement of ATR control elements. The neck shims (NS) and outer shim control cylinders (OSCC) are used to control ATR core power and maintain the lobe power splits. These shim positions can significantly affect the local thermal neutron flux within the ATR. Thus, for an experiment in an irradiation position physically near NS or OSCC, the experiment neutron heat generation rate (HGR) evaluations should include NS withdrawal effects or OSCC rotation effects, respectively. NS withdrawal effects are most relevant to experiments in the inner and outer A positions as well as $\mathrm{H}$ positions. The OSCC rotation effects are most relevant to experiments in the large B and small B positions and all I positions, with lesser effects to the FT positions. Refer to EDF-7326 and ECAR-341 for additional information regarding OSCC rotation effects. Refer to ECAR2070 as an example regarding NS withdrawal effects for an experiment in an outer A position.

In order to ensure a clear understanding of the analysis scope and associated risk factors, prior to performing an analysis that supports the ESA or experiment design, perform a technical pre-job briefing utilizing form RP-6003 or equivalent. The briefing shall include the Manager (or designee) of NS\&T Experiment Design and Analysis Department. The briefing should also include other analysts (Neutronics, Thermal, Structural) performing analysis in support of the same ESA or experiment design as well as the design engineer, Experiment Manager and the ESA author. The agreed upon detailed scope of the analysis shall be documented in an analysis request, an analysis plan, or equivalent. The technical pre-job briefing form should be included as an attachment to the analysis request or the analysis plan (or equivalent). 


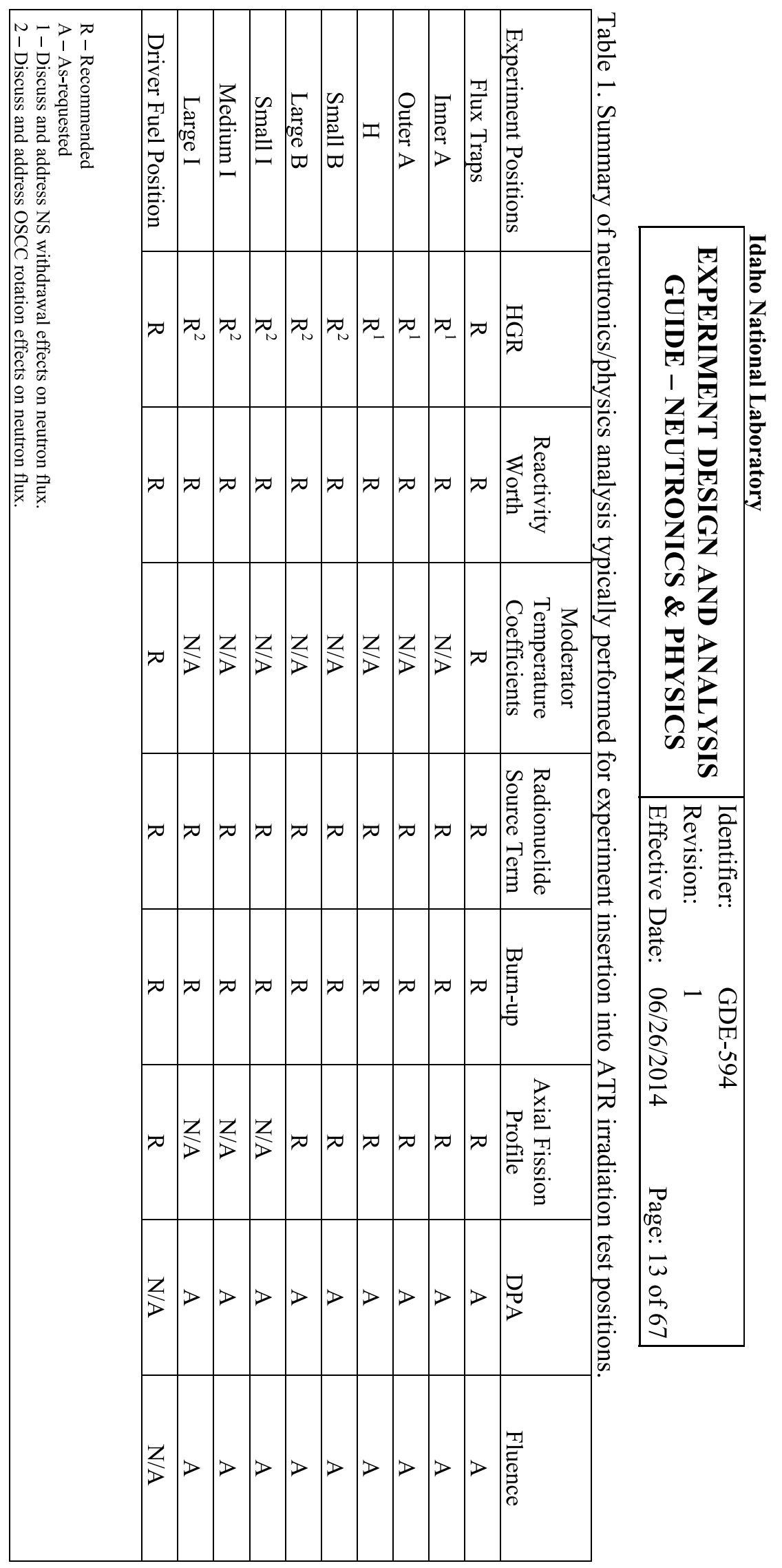




\begin{tabular}{|c|lll|}
\hline $\begin{array}{c}\text { EXPERIMENT DESIGN AND ANALYSIS } \\
\text { GUIDE - NEUTRONICS \& PHYSICS }\end{array}$ & Revision: & \multicolumn{1}{l|}{ GDE-594 } & \\
& Effective Date: & $06 / 26 / 2014$ & Page: 14 of 67 \\
\hline
\end{tabular}

\subsection{Analysis Report Guidance}

The neutronics/physics analysis results are typically documented in an Engineering Calculations and Analysis Report (ECAR). The analyst should refer to LWP-10200 for generating an ECAR.

A neutronics/physics ECAR should always be technically checked either by another neutronics/physics analyst or an engineer with applicable experience. Guidance for performing a technical check is given below.

\section{ECAR Technical Check Guidance}

1. Read ECAR

- understand purpose and scope of analysis

- understand technical content

- understand technical approach

- ensure completeness of report

- ensure accuracy of report

- ensure report satisfies purpose and scope of analysis

2. Check all input models, all output files, all calculations, and all values reported by ECAR.

A. MCNP - check/verify the input/output files for the following:

- experiment geometry (cells, surfaces)

- experiment materials/compositions/densities (cells, materials)

- experiment position(s) in ATR

- experiment configuration(s)

- modeled shim positions

- modeled lobe power splits

- cross-sections used

- output files for reported failures, errors, lost particles, status for 10 statistical checks, etc...

B. ORIGEN - check/verify input/output files for the following:

- experiment material compositions

- cross-sections being used (LPU and LIB commands)

- output files for failures, errors, etc...

- fluxes and durations used (IRF command)

- decay durations used (DEC Command)

- vector transfers and output vector request (IRF, DEC, MOV, and OUT commands)

- output table types and cutoff (OPTL, OPTA, OPTF, and CUT commands)

3. Independently calculate all values which have been manipulated outside of verified and validated software (i.e. use tallies, eigenvalues, etc... to calculate reported values)

4. Verify applicability and appropriateness

- Assumptions

- Constants and Normalization Factors

- Software V\&V records

- QLD level and QLD reference

- References

- Drawings

- Analysis Plan

- Analysis Purpose

- Analysis Conclusions

5. Check planned cycle lobe powers 


\begin{tabular}{|c|lll|}
\hline $\begin{array}{c}\text { EXPERIMENT DESIGN AND ANALYSIS } \\
\text { GUIDE - NEUTRONICS \& PHYSICS }\end{array}$ & $\begin{array}{l}\text { Revision: } \\
\text { Effective Date: }\end{array}$ & $\begin{array}{l}\text { 06/26/2014 } \\
\text { Page: } 15 \text { of } 67\end{array}$ \\
\hline
\end{tabular}

6. Check planned cycle irradiation duration

7. Check experiment cooling times (source term and decay heat)

8. Check limiting values

9. Refer to LWP-10200 and LWP-10106 for additional requirements and information.

Suggested Technical Check Deliverables

1. Document a summary of your technical check.

2. Print, sign and date your technical check summary document.

3. Provide the "tech checked" electronic track changes version or red-line markup copy of the ECAR and the signed hard copy technical check document to the performer/author for comment resolution.

Once comments are resolved, concur with the final ECAR as technical checker.

\section{NEUTRONICS/PHYSICS ANALYSIS OVERVIEW}

This guide provides information and methods for performing neutronics and physics analysis in support of irradiation testing of experiments in the ATR. These analyses may be performed to support various activities such as scoping studies, experiment design and review, thermal analysis, safety analysis, measurement and testing, programmatic goals, irradiation, shipping, and PIE. Additionally, projection, asbuilt, and as-run neutronics/physics calculations and analyses are performed.

HGRs are calculated for all experiments. The HGRs are used as input data for the thermal hydraulic analysis of the experiment. MCNP is used to calculate experiment HGRs as described in Section 4. The HGR calculations address material heating as the result of both prompt and delayed neutrons and prompt and delayed gammas.

For each experiment, the reactivity worth of the experiment should be calculated relative to the reactivity worth of the proposed backup experiment. The ATR cycle specific core safety assurance package (CSAP) uses the experiment reactivity worth to determine key operating parameters and limits. Thus, if an experiment cannot be inserted, an approved backup prevents re-work of the CSAP and potential delays in start-up of the reactor. Reference 5 suggests that the experiment backup have a reactivity worth relative to the experiment of no more than $0.25 \$$ core wide. That is, that the sum of each experiment backup is less than $0.25 \$$ relative to experiments. Therefore, backup experiments should be designed or selected to ensure the difference in reactivity worth of the backup relative to the experiment is minimal, but under no circumstances be greater than $0.25 \$$. MCNP is used to calculate experiment reactivity worth as summarized in Section 5.

The flux trap positions in ATR have a positive moderator temperature coefficient. Safety of the reactor is maintained by limiting the reactivity cascading effects as the result of reactivity transients. Additionally, voiding of an In-Pile Tube (IPT) must be evaluated to ensure that failure of an IPT does not result in a reactivity transient that cannot be controlled. The results for the IPT voiding reactivity calculations and the moderator temperature coefficient calculations are used to support experiment thermal hydraulic analysis. Section 6 presents the MCNP method used to calculate moderator temperature coefficients. MCNP is also used to calculate the void worth of an IPT. The void worth calculation uses the calculated reactivity worth of an experiment in an IPT with water (Section 4) and the calculated reactivity worth for an experiment in an IPT with the water replaced with a void.

The methods used to develop the CSAP for each cycle evaluates a 2-D ATR core. The analysis assumes a chopped cosine shaped axial flux over the length of the ATR core. This is key to estimating 


\begin{tabular}{|c|lll|}
\hline $\begin{array}{c}\text { EXPERIMENT DESIGN AND ANALYSIS } \\
\text { GUIDE - NEUTRONICS \& PHYSICS }\end{array}$ & Revision: & \multicolumn{1}{l|}{ GDE-594 } & \\
& Effective Date: & $06 / 26 / 2014$ & Page: 16 of 67 \\
\hline
\end{tabular}

burn-up and fissile content of driver FEs that may be used in future cycles. Therefore, an experiment may not perturb the axial fission profile that has been established and is documented in Reference 18. This requirement applies to all experiment positions except for the I-positions, which are located outside of the outer shim control cylinders. For many experiments, the axial fission profile will be measured in ATRC prior to insertion. The design of the experiment should be evaluated for possible perturbation of the axial fission profile to ensure that the requirement is met prior to construction of the experiment. The method for calculating the axial fission profile is provided in Section 6.

Experiments containing structural materials may require calculation of fluence and DPA. These values are dependent upon irradiation test position in ATR, fast flux, and duration of irradiation. The methods for calculating these values are presented in Section 8.

Fueled experiments typically require burn-up analysis and projection of the fission density. The methods for calculating these values are presented in Section 9. The burn-up analysis may be used to demonstrate programmatic goals, but may also be used to demonstrate compliance with the ESAP. Some fueled experiments may experience higher heating rates at times other than beginning-of-cycle (BOC). As an example an experiment with a neutron filter such as a cadmium $(\mathrm{Cd})$ shroud may experience higher heat rates towards the end-of-cycle (EOC) as the $\mathrm{Cd}$ burns out, becoming a less effective neutron filter.

Each experiment should be evaluated for its projected radionuclide inventory radioactivity source term. A projected radioactivity source term allows for experiment managers and principle investigators to plan for shipment of the experiment from ATR and for PIE. It is important to realize that a projected source term should not be considered "bounding" but should represent a source term for nominal operating conditions based on planned core power, lobe power splits, and cycle length for the proposed irradiation cycles. A bounding source term may be difficult to define and produce since isotopes of concern may be burned out faster at higher powers or the peak may occur earlier in a cycle rather than later. In other words assuming higher operating powers and longer cycles may not necessarily provide the most conservative results. Therefore, for some experiments, as-run analysis may be required for future shipping. PIE activities may require additional radionuclide inventory radioactivity source term calculations. A description of the method to provide a source term is presented in Section 10.

\section{HEAT GENERATION RATES (HGR)}

HGR evaluations are performed for planned experiment irradiations within the ATR. Calculated HGR values are typically used as input data for the thermal hydraulic analysis of the experiment. The calculated HGR values are reported using the following units.

- Specimens that deplete $-\mathrm{W} / \mathrm{cc}$

- Specimens that do not deplete $-\mathrm{W} / \mathrm{g}$

- $\quad$ Structural materials $-\mathrm{W} / \mathrm{g}$

The three region MCNP model is used to evaluate HGRs due to neutron interactions at steady state, prompt photon interactions and delayed photon interactions within specimens and materials irradiated in specified ATR test facilities/locations. For example:

- Stainless steel 316 in the center flux trap (CFT),

- Gadolinium-153 in an outboard A position, A-13,

- Boron Carbide (B4C) in a large B Position, B-12, and

- Metallic Fuels in the E-3 position of the east flux trap (EFT) small irradiation housing assembly (SIHA). 


\begin{tabular}{|c|c|c|c|}
\hline $\begin{array}{l}\text { EXPERIMENT DESIGN AND ANALYSIS } \\
\text { GUIDE - NEUTRONICS \& PHYSICS }\end{array}$ & $\begin{array}{l}\text { Identifier: } \\
\text { Revision: } \\
\text { Effective Date: }\end{array}$ & $\begin{array}{l}\text { GDE-594 } \\
1 \\
06 / 26 / 2014\end{array}$ & Page: 17 of 67 \\
\hline
\end{tabular}

Shim positions for both NS and OSCC are used to control ATR core power and maintain the lobe power splits. These shim positions can significantly affect the local thermal neutron flux within the ATR. Thus, for an experiment in an irradiation position physically near the NS or the OSCC, the experiment neutron HGR evaluations should include NS withdrawal effects or OSCC rotation effects, respectively. NS withdrawal effects are applicable to experiments in the inner and outer A positions as well as the $\mathrm{H}$ positions. The OSCC rotation effects are applicable to experiments in the large $\mathrm{B}$ and small B positions and all I positions, with lesser effects to the FT positions. Refer to EDF-7326 and ECAR-341 for additional information regarding OSCC rotation effects. Refer to ECAR-2070 as an example regarding NS withdrawal effects for an experiment in an outer A position.

\subsection{Neutron HGR}

Neutron HGR is the heat/energy generated and deposited within the specimen or material due to neutron interactions at steady state within that specimen or material. The MCNP models should use the following input specifications to evaluate neutron heating at steady state. 2

- MCNP tally type $\mathrm{f} 7$ for fissile specimen cells (f7:n). The $\mathrm{f} 7$ tally provides the cell-averaged fission energy deposition and cell mass.

- $\quad$ MCNP tally type $\mathrm{f} 6$ for non-fissile material cells ( $\mathrm{f} 6: \mathrm{n})$. The $\mathrm{f} 6$ tally provides the cell-averaged neutron energy deposition and cell mass.

- MCNP tally type $\mathrm{f4}$ for the same sets of cells specified by the $\mathrm{f7}$ and f6 tallies (f4:n). The f4 tally provides the cell-averaged neutron flux and cell volume.

- MCNP "mode n p".

MCNP reports tally results normalized per source particle. The neutron heating tallies have units of $\mathrm{MeV} / \mathrm{g}$ per fission neutron. The prompt heating normalization factor (PHNF) used to calculate prompt neutron heating due to fission neutrons is given by equation (1).

$$
\begin{gathered}
\text { PHNF }=\left(\frac{2.43 \text { fission neutrons }}{\text { fission }}\right)\left(\frac{\text { fission }}{200 \mathrm{MeV}}\right)\left(\frac{1 \times 10^{6} \mathrm{~W}}{\mathrm{MW}}\right) \\
\text { PHNF }=1.215 \times 10^{4} \frac{\text { fission neutrons }-\mathrm{W}}{\mathrm{MeV}-\mathrm{MW}}
\end{gathered}
$$

The neutron HGR (NHGR) values are calculated using the MCNP neutron tally results (f7:n for fissile specimens and f6:n for non-fissile specimens), the PHNF, and the ATR core power. The MCNP $\mathrm{f} 7: \mathrm{n}$ tally tallies all fission energy generated in a cell. The MCNP f6:n tally tallies all neutron energy generated in a cell. The $\mathrm{f} 7$ or f6 neutron tally results are used to calculate NHGR values for fissile or nonfissile material compositions. The NHGR is calculated using equation (2) for fissile specimens and equation (3) for non-fissile specimens.

$$
\begin{gathered}
\mathrm{NHGR}=\left(\mathrm{f} 6 \text { or f7 neutron tally } \frac{\mathrm{MeV}}{\mathrm{g}-\text { fission neutron }}\right)\left(1.215 \times 10^{4} \frac{\text { fission neutrons }-\mathrm{W}}{\mathrm{MeV}-\mathrm{MW}}\right) \text { (Core Power MW) } \\
\mathrm{NHGR}_{\text {fissile }}=(\mathrm{f7}: \mathrm{n})(\mathrm{PHNF})(\text { Core Power })=\frac{\mathrm{W}}{\mathrm{g}}
\end{gathered}
$$




\begin{tabular}{|c|c|c|c|}
\hline $\begin{array}{l}\text { EXPERIMENT DESIGN AND ANALYSIS } \\
\text { GUIDE - NEUTRONICS \& PHYSICS }\end{array}$ & $\begin{array}{l}\text { Identifier: } \\
\text { Revision: } \\
\text { Effective Date: }\end{array}$ & $\begin{array}{l}\text { GDE-594 } \\
1 \\
06 / 26 / 2014\end{array}$ & Page: 18 of 67 \\
\hline
\end{tabular}

$$
\mathrm{NHGR}_{\text {non-fissile }}=(\mathrm{f} 6: \mathrm{n})(\mathrm{PHNF})(\text { Core Power })=\frac{\mathrm{W}}{\mathrm{g}}
$$

\subsection{Prompt Photon (Prompt Gamma) HGR}

Prompt photon HGR (PPHGR) is the heat/energy generated and deposited within the specimen or material due to prompt photon (gamma) interactions, respectively. The MCNP models should use the following input specifications for prompt neutron and prompt photon heating.2.3

- Verify MCNP material cross-sections specified and used by the MCNP model for the experiment materials have gamma production data (GPD) available (see MCNP Manuals Appendix G Table G.2, Continuous-Energy and Discrete Neutron Data Libraries GPD column).

- MCNP tally type f6, photons, for non-fueled materials (f6:p). The f6 tally provides the cell-averaged photon energy deposition and cell mass. Note the sum of f6:n and f6:p tallies will be equal to the $\mathrm{f} 6: \mathrm{n}, \mathrm{p}$ tally. It is recommended that individual neutron and photon tallies are specified.

- MCNP tally type f4 for the same set of cells specified by the f6 tally (f4:p). The f4 tally provides the cell averaged photon flux and cell volume.

- MCNP "mode n p".

MCNP reports tally results normalized per source particle. The prompt photon heating tallies have units of $\mathrm{MeV} / \mathrm{g}$ per fission neutron. The PHNF given by equation (1) is also used to calculate prompt photon heating.

The PPHGR values are calculated using the MCNP photon tally results (f6:p), the HNF, and ATR core power. The MCNP f6:p tally tallies all prompt photon energy generated in a cell. The f6 tally results are used to calculate PPHGR values for material compositions. The PPHGR is calculated using equation (4).

$$
\begin{gathered}
\text { PPHGR }=\left(\mathrm{f} 6 \text { photon tally } \frac{\mathrm{MeV}}{\mathrm{g}-\text { fission neutron }}\right)\left(1.215 \times 10^{4} \frac{\text { fission neutrons }-\mathrm{W}}{\mathrm{MeV}-\mathrm{MW}}\right)(\text { Core Power MW }) \\
\text { PPHGR }=(\mathrm{f} 6: \mathrm{p})(\mathrm{PHNF})(\text { Core Power })=\frac{\mathrm{W}}{\mathrm{g}}
\end{gathered}
$$

\subsection{Delayed Photon (Delayed Fission Product Gamma) HGR}

Delayed photon HGR (DPHGR) is the heat/energy generated and deposited within the specimen or material due to delayed photon (gamma) interactions. The MCNP models should use the following input specifications for delayed photon heating.2:3

- Verify MCNP material cross-sections specified and used by the MCNP model for the experiment materials have GPD available.

- Verify MCNP material cross-sections specified and used by the MCNP model for all materials use extension “04p" (see MCNP Manuals Appendix G Table G.4, Continuous-Energy Photoatomic Data Libraries).

- $\quad$ MCNP tally type f6, photons, for non-fueled materials (f6:p). The f6 tally provides the cell-averaged photon energy deposition and cell mass. 


\begin{tabular}{|c|lll|}
\hline $\begin{array}{c}\text { EXPERIMENT DESIGN AND ANALYSIS } \\
\text { GUIDE - NEUTRONICS \& PHYSICS }\end{array}$ & Revision: & \multicolumn{1}{l|}{ GDE-594 } & \\
& Effective Date: & $06 / 26 / 2014$ & Page: 19 of 67 \\
\hline
\end{tabular}

- $\quad$ MCNP tally type $\mathrm{f} 4$ for the same set of cells specified by the f6 tally (f4:p). The f4 tally provides the cell averaged photon flux and cell volume.

- MCNP "mode p".

- Change MCNP source definition (sdef) to use a fission product photon energy spectrum for delayed photons (sc2, si2, and sp2).

MCNP reports tally results normalized per source particle. The delayed photon heating tallies have units of $\mathrm{MeV} / \mathrm{g}$ per photon. The delayed photon heating normalization factor (DPHNF) used to calculate heating due to delayed fission product gammas (DFP $\gamma$ ) is given by equation (5).

$$
\begin{gathered}
\text { DPHNF }=\left(\frac{8.9603 \mathrm{DFP} \gamma}{\text { fission }}\right)\left(\frac{\text { fission }}{200 \mathrm{MeV}}\right)\left(\frac{1 \times 10^{6} \mathrm{~W}}{\mathrm{MW}}\right) \\
\text { DPHNF }=4.48015 \times 10^{4} \frac{\mathrm{DFP} \gamma-\mathrm{W}}{\mathrm{MeV}-\mathrm{MW}}
\end{gathered}
$$

The DPHGR values are calculated using the MCNP photon tally results (f6:p), the DPHNF, and ATR core power. The MCNP f6:p tally tallies all photon energy generated in a cell. The f6 tally results are used to calculate DPHGR values for material compositions. The DPHGR is calculated using equation (6).

$$
\begin{gathered}
\text { DPHGR }=\left(\mathrm{f} 6 \text { photon tally } \frac{\mathrm{MeV}}{\mathrm{g}-\text { photon }}\right)\left(4.48015 \times 10^{4} \frac{\mathrm{DFP} \gamma-\mathrm{W}}{\mathrm{MeV}-\mathrm{MW}}\right)(\text { Core Power MW }) \\
\text { DPHGR }=(\mathrm{f} 6: \mathrm{p})(\text { DPHNF })(\text { Core Power })=\frac{\mathrm{W}}{\mathrm{g}}
\end{gathered}
$$

There are two delayed fission product gamma yield spectra that may be used with MCNP to calculate the delayed photon heating. The analyst can use either the delayed fission product gamma yield spectrum from the ZPPR experiments9 listed in Table 2 and plotted in Figure 1 or the MCNPX-calculated delayed fission product gamma yield spectrum for ATR FE also plotted in Figure 1.

Table 2. ZPPR delayed fission product gamma spectrum.9

\begin{tabular}{|c|c|c|c|c|}
\hline \multicolumn{3}{|c|}{} & \multicolumn{2}{c|}{ Gamma/Fission } \\
\hline Group & \multicolumn{2}{|c|}{ Energy, MeV } & \multirow{2}{*}{$\begin{array}{c}\text { Prompt } \\
\text { Fission }\end{array}$} & $\begin{array}{c}\text { Fission } \\
\text { Product }\end{array}$ \\
\hline & Upper & Lower & 0.001 & 0 \\
\hline 1 & 10 & 8 & 0.0005 & 0 \\
\hline 2 & 8 & 7 & 0.0093 & 0 \\
\hline 3 & 7 & 6 & 0.0197 & 0 \\
\hline 4 & 6 & 5 & 0.0586 & 0 \\
\hline 5 & 5 & 4 & 0.0805 & 0 \\
\hline 6 & 4 & 3.5 & 0.0805 & 0 \\
\hline 7 & 3.5 & 3 & 0.248 & 0.2554 \\
\hline 8 & 3 & 2.5 & 0.248 & 0.2554 \\
\hline 9 & 2.5 & 2 & 0.4997 & 0.4455 \\
\hline 10 & 2 & 1.6 & 0.6425 & 0.5728 \\
\hline 11 & 1.6 & 1.2 & & \\
\hline
\end{tabular}




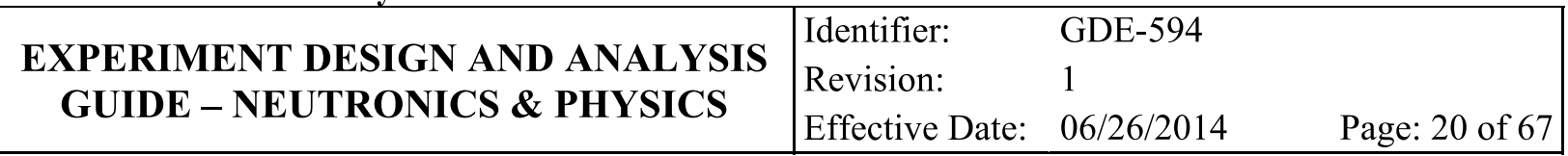

\begin{tabular}{|c|c|c|c|c|}
\hline 12 & 1.2 & 0.9 & 0.6425 & 0.5728 \\
\hline 13 & 0.9 & 0.6 & 1.112 & 1.3783 \\
\hline 14 & 0.6 & 0.4 & 1.6685 & 2.0681 \\
\hline 15 & 0.4 & 0.21 & 2.7528 & 3.412 \\
\hline 16 & 0.21 & 0.12 & 0 & 0 \\
\hline 17 & 0.12 & 0.07 & 0 & 0 \\
\hline 18 & 0.07 & 0.01 & 0 & 0 \\
\hline Total & -- & -- & 8.0641 & 8.9603 \\
\hline
\end{tabular}

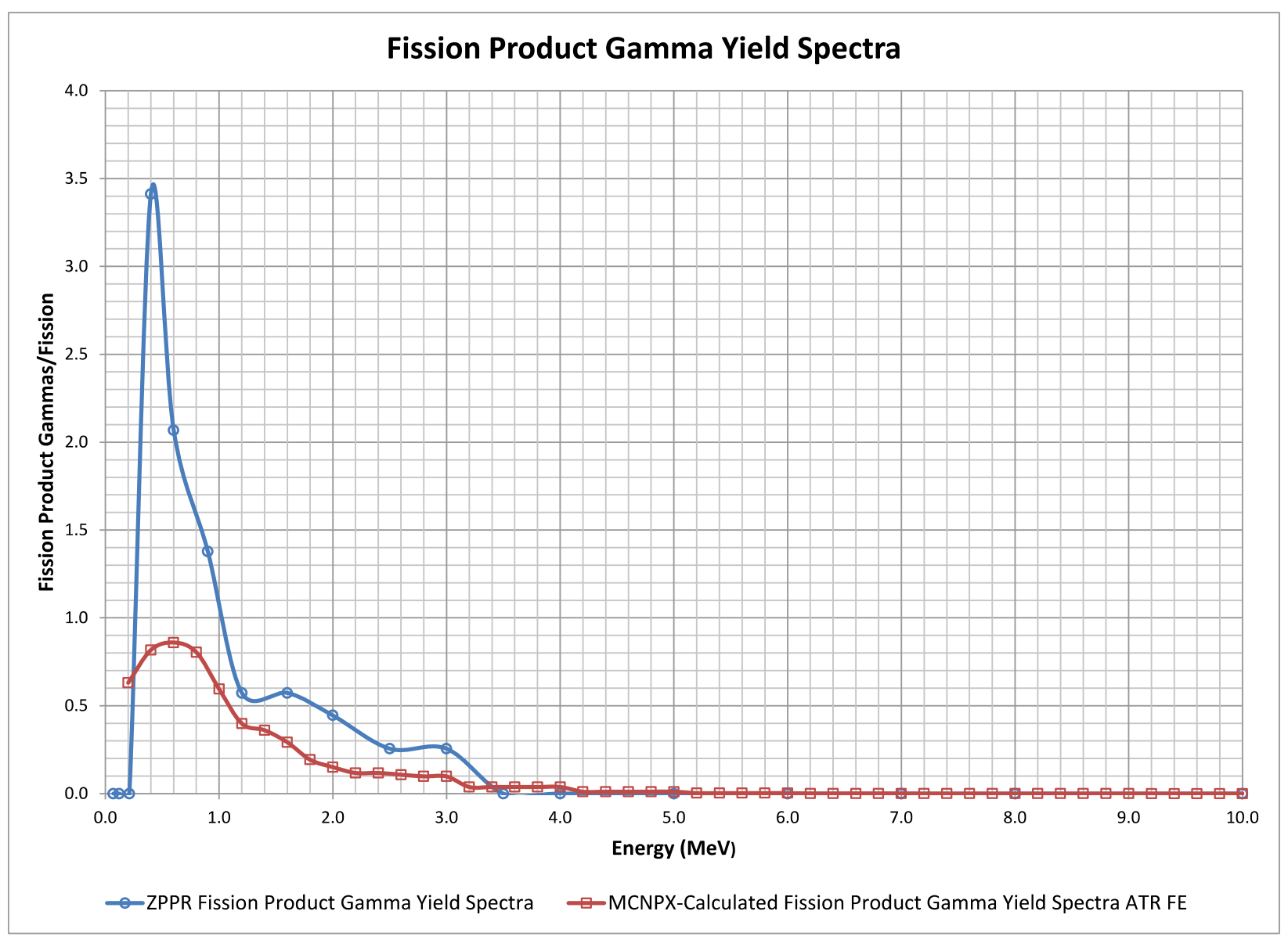

Figure 1. Delayed fission product gamma spectra.

The BASH script (genPhotonInput.sh) will modify an MCNP input file with an existing "sp2 -3" sdef card to use a delayed fission product gamma spectrum instead of fission neutrons. The "genPhotonInput.sh" script changes the following cards within an MCNP input file:

1. Replaces "sp2 -3" card with "sc2 .. si2 ... sp2 ... for the ZPPR delayed gamma spectrum".

2. Replaces the specification of all isotope cross section libraries with $.04 \mathrm{p}$ libraries for all materials.

3. Removes the use of $s(a, B)$ libraries (i.e. deletes "mt" cards).

4. Changes "mode ..." card to "mode p". 


\section{EXPERIMENT DESIGN AND ANALYSIS GUIDE - NEUTRONICS \& PHYSICS}

Identifier: Revision:

Effective Date: $06 / 26 / 2014$
GDE-594

1 Page: 21 of 67

The following BASH script, genPhotonInput.sh, may be used to generate the MCNP delayed fission product gamma heating model from an existing MCNP prompt neutron/gamma heating model.

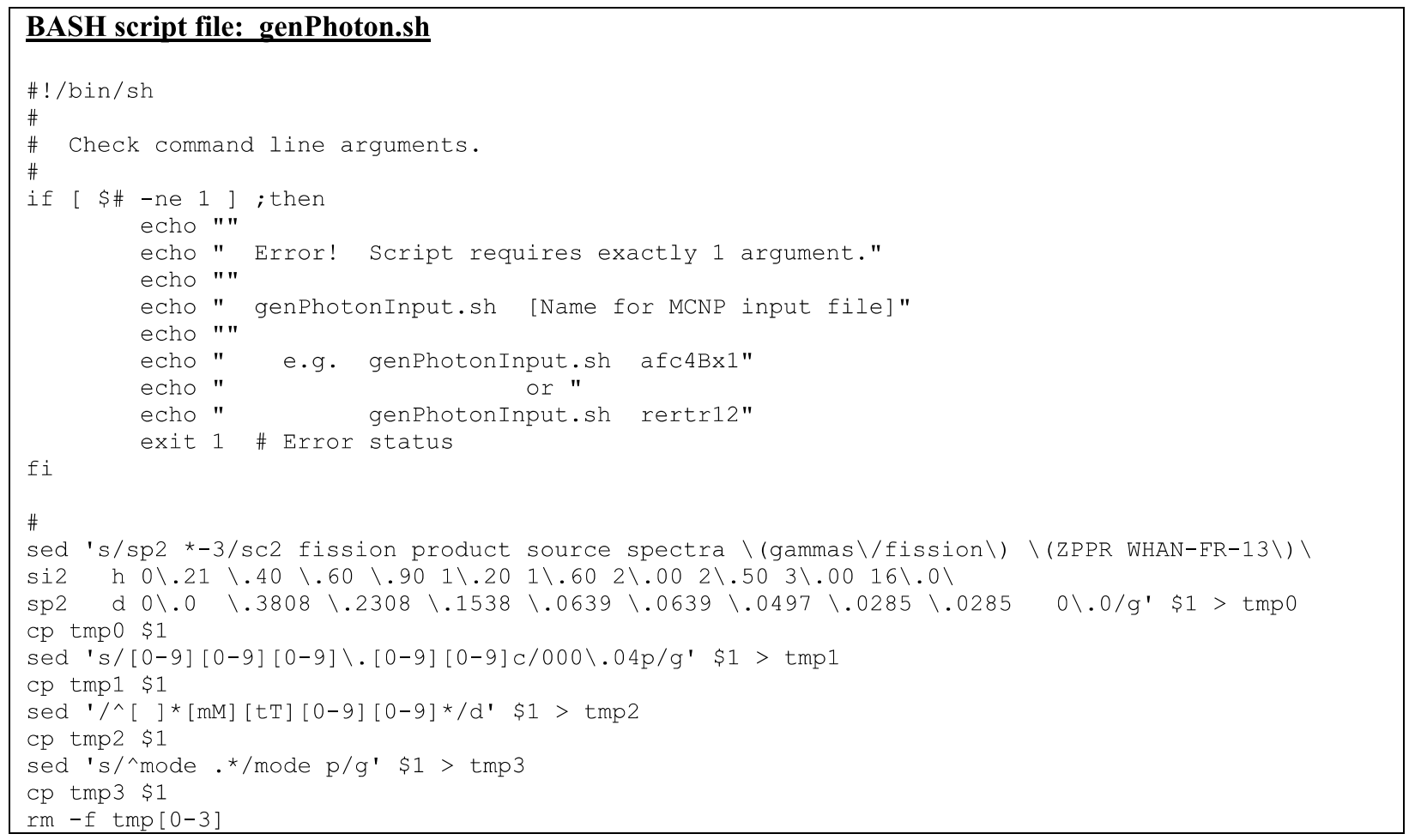

The MCNP cards below represent the MCNPX-generated delayed fission product gamma spectrum for ATR FE. These MCNP cards may be used to replace the "sc2", "si2", and "sp2" for the ZPPR delayed fission product gamma spectrum cards generated by the BASH script "genPhotonInput.sh".

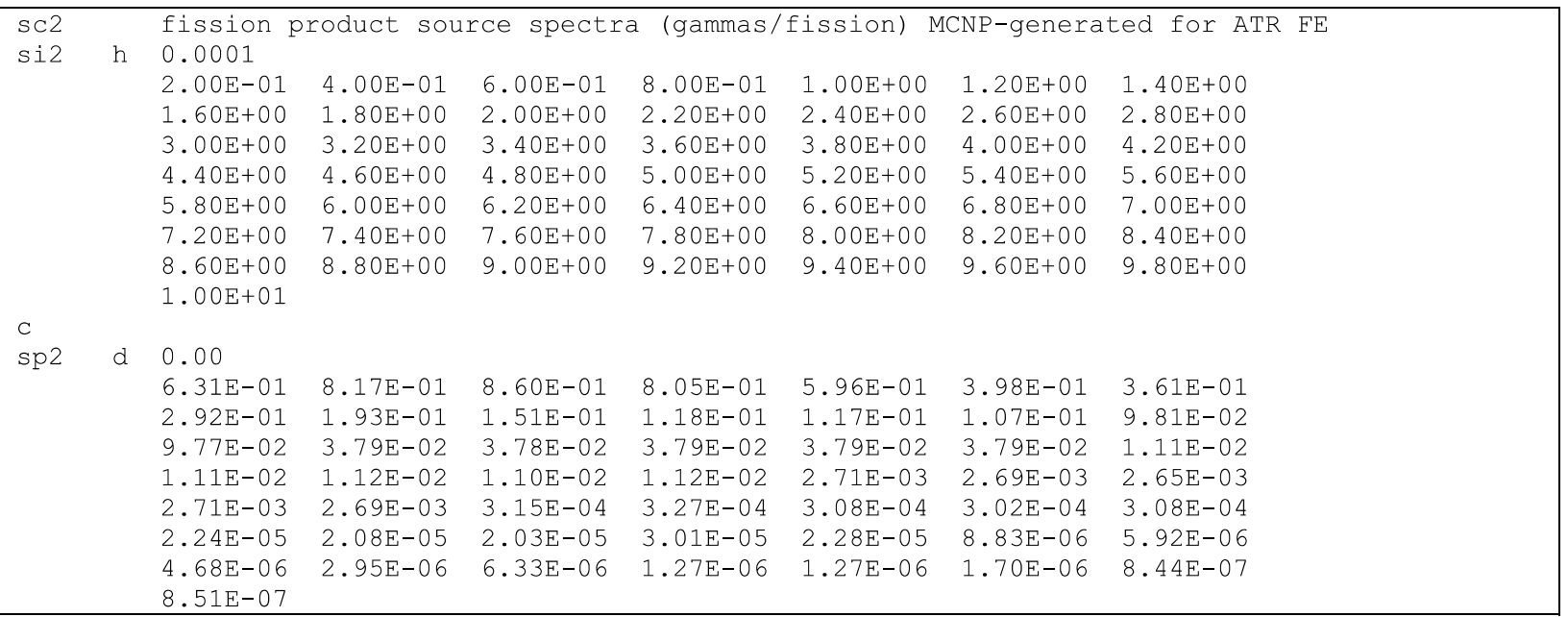

\section{EXPERIMENT/BACKUP EXPERIMENT REACTIVITY WORTH}

\subsection{Applicability}

The reactivity change caused by the insertion of an experiment or a backup experiment into any irradiation test position of the ATR is the reactivity worth of that experiment or backup experiment. 


\begin{tabular}{|c|c|c|c|}
\hline $\begin{array}{l}\text { EXPERIMENT DESIGN AND ANALYSIS } \\
\text { GUIDE - NEUTRONICS \& PHYSICS }\end{array}$ & $\begin{array}{l}\text { Identifier: } \\
\text { Revision: } \\
\text { Effective Date: }\end{array}$ & $\begin{array}{l}\text { GDE-594 } \\
1 \\
06 / 26 / 2014\end{array}$ & Page: 22 of 67 \\
\hline
\end{tabular}

Reactivity worth is a relative value. Typically, the experiment reactivity worth is reported relative to the water-filled test position, but reactivity worth may need to be reported relative to another configuration (e.g. beryllium-filled, aluminum-filled, backup-filled, etc...). Reactivity worth measurements are conducted in the ATRC facility to support ESAP and CSAP preparation. To support experiment design

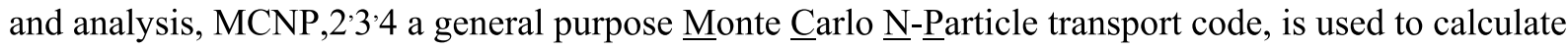
experiment reactivity worth.

\subsection{ATR Information}

The reactivity worth of an experiment or backup experiment planned for insertion into an ATR test position is used by ATR Nuclear Engineering5 and is reported in the CSAP for each ATR operating cycle. ATR Nuclear Engineering also uses the experiment reactivity worth to support ATR fuel selection, 6 to prepare shim predictions, 7 and to calculate the hold-down reactivity margin. 8 Reactivity worth can be measured in the ATRC in all test positions except for A-13 through A-16, the large B positions (B-09 through B-12), and the small I positions (I-21 through I-24). Requirements for ATRC experiment reactivity worth measurements are summarized in Appendix B of Reference 5. Since the reactivity worth for experiments in the large B positions and small I positions cannot be measured, calculated reactivity worth values are used. Calculated reactivity worth values may also be used to estimate experiment reactivity worth for experiment design and analysis activities.

\subsection{Method Description}

MCNP input parameters are defined for experiments or backup experiments loaded in specific core locations of the validated ATR full core 19-plate MCNP input model. ${ }^{11}$ MCNP input parameters depend upon experiment and backup experiment loading (i.e. cell geometry, material compositions and densities, cross-section data, etc...). Using experiment-specific input parameters MCNP $k$ code (criticality eigenvalue) calculations are run to generate $\mathrm{k}$-effective values as a function of experiment loading. The resultant MCNP-calculated k-effective values are used to calculate the change in reactivity associated with the change in experiment loading. In addition to the k-effective values, the MCNP-calculated relative lobe power splits (NW-NE-C-SW-SE) are reported for each corresponding kcode calculation.

\subsection{MCNP Information}

The scientific/engineering software MCNP is used to calculate k-effective values for experiment specific loadings in ATR core locations. The resultant k-effective values are used to evaluate the reactivity worth for the experiment loading. The kcode parameters specified in the validated ATR full core 19-plate MCNP input model are shown below.

$$
\text { kcode } 10000 \quad 1.005 \quad 250 \quad 3750
$$

The kcode parameters used to evaluate eigenvalues for reactivity worth calculations may differ from these parameters. The statistical error for each calculation may require adjusting these $k c o d e$ parameters.

\subsection{MCNP Input}

The MCNP input parameters that are typically used to evaluate experiment reactivity worth are listed below. Perform these steps for all experiment and backup experiment configurations.

1. Specify MCNP input parameters for the experiment (cells, surfaces, materials, etc...) in the appropriate test position of the validated ATR full core 19-plate MCNP input model ${ }^{11}$ to generate experiment input model.

2. Specify kcode parameters in experiment input model. 


\begin{tabular}{|c|c|c|c|}
\hline $\begin{array}{l}\text { EXPERIMENT DESIGN AND ANALYSIS } \\
\text { GUIDE - NEUTRONICS \& PHYSICS }\end{array}$ & $\begin{array}{l}\text { Identifier: } \\
\text { Revision: } \\
\text { Effective Date: }\end{array}$ & $\begin{array}{l}\text { GDE-594 } \\
1 \\
06 / 26 / 2014\end{array}$ & Page: 23 of 67 \\
\hline
\end{tabular}

3. Specify $\mathrm{f} 7$ tallies for the ATR driver fuel in experiment input model that are used to obtain the relative core power splits.

4. Execute MCNP using the experiment input model.

5. Extract the "final estimated k-effective" value from the MCNP output file. ${ }^{a}$

6. Repeat steps 1-5 for the backup experiment.

7. Repeat steps 1-5 for the water-filled test position.

8. Repeat steps 1-5 for any additional experiment configurations.

\subsection{Reactivity Calculation}

The MCNP-calculated k-effective values for the experiment and the water-filled test position are used to calculate the experiment reactivity worth relative to a water-filled test position. Equation (7) defines core reactivity, $\rho \$,,^{13,14}$ and equation (8) defines change in core reactivity, $\Delta \rho \$^{13,14}$ for different experiment configurations.

$$
\begin{array}{r}
\rho \$=\frac{1}{\beta_{\mathrm{eff}}} \cdot\left(\frac{\mathrm{k}-1}{\mathrm{k}}\right) \\
\Delta \rho \$=\frac{1}{\beta_{\mathrm{eff}}} \cdot\left(\frac{\mathrm{k}_{2}-\mathrm{k}_{1}}{\mathrm{k}_{2} \mathrm{k}_{1}}\right)
\end{array}
$$

where

$\mathrm{k}=$ calculated eigenvalue.

$\mathrm{k}_{1}=$ calculated eigenvalue for experiment loading.

$\mathrm{k} 2=$ calculated eigenvalue for water-filled experiment position.

$\beta_{\text {eff }}=$ delayed neutron fraction for the ATR, $\beta_{\text {eff }}=0.0072 .{ }^{15}$

Using the MCNP-calculated error values $\left(\sigma_{\mathrm{k}_{1}}\right.$ and $\left.\sigma_{\mathrm{k}_{2}}\right)$ reported with the MCNP-calculated k-effective values $\left(\mathrm{k}_{1}\right.$ and $\left.\mathrm{k}_{2}\right)$, the change in reactivity error $\left(\sigma_{\Delta \rho \$}\right)$ within a $95 \%$ confidence interval $(2 \sigma)$ is calculated using the error propagation formula ${ }^{16}$ given by equation (9).

$$
\sigma_{\mathrm{u}}^{2}=\left(\frac{\partial \mathrm{u}}{\partial \mathrm{x}}\right)^{2} \sigma_{\mathrm{x}}^{2}+\left(\frac{\partial \mathrm{u}}{\partial \mathrm{y}}\right)^{2} \sigma_{\mathrm{y}}^{2}
$$

For the error associated with each k-effective value, equation (9)is rewritten in terms of $\mathrm{k}_{1}$ and $\mathrm{k}_{2}$, given by equation (10), which is also defined to be the variance of the change in reactivity, $\Delta \rho$.

$$
\sigma_{\mathrm{u}}^{2}=\left(\frac{\partial \mathrm{u}}{\partial \mathrm{k}_{1}}\right)^{2} \sigma_{\mathrm{k}_{1}}^{2}+\left(\frac{\partial \mathrm{u}}{\partial \mathrm{k}_{2}}\right)^{2} \sigma_{\mathrm{k}_{2}}^{2}
$$

\footnotetext{
${ }^{a}$ In some cases, the MCNP output file may not report a final estimated k-effective value. At the judgment of the analyst, the keff estimator "col/abs/trk len" values for keff and standard deviation from "the estimated average keffs" table in the output file may be used instead.
} 


\begin{tabular}{|c|c|c|c|}
\hline $\begin{array}{l}\text { EXPERIMENT DESIGN AND ANALYSIS } \\
\text { GUIDE - NEUTRONICS \& PHYSICS }\end{array}$ & $\begin{array}{l}\text { Identifier: } \\
\text { Revision: } \\
\text { Effective Date: }\end{array}$ & $\begin{array}{l}\text { GDE-594 } \\
1 \\
06 / 26 / 2014\end{array}$ & Page: 24 of 67 \\
\hline
\end{tabular}

Now, define $u$ in terms of $\mathrm{k}_{1}$ and $\mathrm{k}_{2}$ and substitute the values for $\mathrm{u}$ into equation (10), producing equation (11).

$$
\begin{aligned}
\mathrm{u} & =\frac{\mathrm{k}_{2}-\mathrm{k}_{1}}{\mathrm{k}_{2} \mathrm{k}_{1}}=\frac{1}{\mathrm{k}_{1}}-\frac{1}{\mathrm{k}_{2}} \\
\sigma_{\mathrm{u}}^{2} & =\frac{1}{\mathrm{k}_{1}{ }^{4}} \sigma_{\mathrm{k}_{1}}^{2}+\frac{1}{\mathrm{k}_{2}{ }^{4}} \sigma_{\mathrm{k}_{2}}^{2}
\end{aligned}
$$

Equation (11) reduces to equation (12), yielding the formula for standard deviation, $\sigma$.

$$
\sigma_{\mathrm{u}}=\sqrt{\frac{\sigma_{\mathrm{k}_{1}}^{2}}{\mathrm{k}_{1}^{4}}+\frac{\sigma_{\mathrm{k}_{2}}^{2}}{\mathrm{k}_{2}^{4}}}
$$

The standard deviation formula for the change in reactivity error, $\sigma_{\Delta \rho \$}$, is given by equation (13) with the $95 \%$ confidence interval being twice the change in reactivity error value $\left(95 \%\right.$ Confidence $\left.=2 \times \sigma_{\Delta \rho \varsigma}\right)$.

$$
\sigma_{\Delta \rho \$}=\frac{1}{\beta_{\text {eff }}} \cdot \sqrt{\frac{\sigma_{\mathrm{k}_{1}}^{2}}{\mathrm{k}_{1}^{4}}+\frac{\sigma_{\mathrm{k}_{2}}^{2}}{\mathrm{k}_{2}^{4}}}
$$

See Attachment A for the derivation of "reactivity worth error propagation" and supporting references.

\section{MODERATOR TEMPERATURE COEFFICIENT 6.1 Applicability}

For both experiments and backup experiments inserted into a flux trap (FT) position of the ATR, the reactivity feedback caused by changes in reactor coolant density/temperature conditions are evaluated to support ESAP preparation and ultimately to demonstrate compliance with the Chapter 15, "Accident

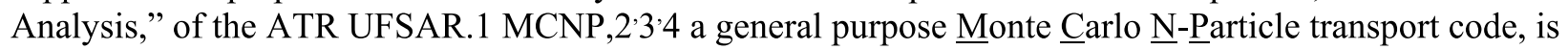
used to evaluate the TCR for ATR primary coolant system (PCS) water.

\subsection{ATR Background Information}

The reactivity coefficient for the PCS water in the ATR fuel region is referred to as the moderator temperature coefficient of reactivity (MTCR) for the fuel region, which is the reactivity change as a function of moderator density/temperature change within the cooling channels of the ATR FEs. By design, the MTCR for the ATR fuel region is strongly negative (i.e., negative reactivity insertion is a function of water density decrease/temperature increase). The ATR UFSAR ${ }^{\mathrm{b}}$ reports the calculated representative MTCR for the fuel region to be $-0.0067 \$ /{ }^{\circ} \mathrm{F} \pm 0.0004 \$ /^{\circ} \mathrm{F}$. ${ }^{\mathrm{c}}$ ATR UFSAR also reports the calculated nominal MTCR for the fuel region at a near balanced 60/40 MW lobe power split condition and nominal moderator temperature of $160^{\circ} \mathrm{F}$ to be $-0.0092 \$ /{ }^{\circ} \mathrm{F}$ at BOC and $-0.0069 \$ /{ }^{\circ} \mathrm{F}$ at EOC. ${ }^{\mathrm{d}}$ The dominant effect on the MTCR for the fuel region over the duration of an operating cycle is the change in neutron leakage from the core as the reactivity control elements are withdrawn.

\footnotetext{
b. SAR-153, Chapter 4, Section 4.3.2.3 Reactivity Coefficients.

c. SAR-153, Chapter 4, Table 4.3-11, Reactivity coefficient values.

d. SAR-153, Chapter 4, Table 4.3-3, Nominal nuclear parameters.
} 


\begin{tabular}{|c|lll|}
\hline $\begin{array}{c}\text { EXPERIMENT DESIGN AND ANALYSIS } \\
\text { GUIDE - NEUTRONICS \& PHYSICS }\end{array}$ & Revision: & \multicolumn{1}{l|}{ GDE-594 } & \\
& Effective Date: & $06 / 26 / 2014$ & Page: 25 of 67 \\
\hline
\end{tabular}

The reactivity coefficient for the PCS water within a FT position is referred to as the MTCR for a specified experiment for that FT position. The MTCR for a FT position loaded with an experiment is the reactivity change as a function of the PCS water density/temperature change within that loaded FT position. The MTCR for the PCS water in a FT is typically positive and small in magnitude (i.e., positive reactivity inserted for PCS water density decrease/temperature increase).

To evaluate the MTCR for the ATR, nominal PCS operating conditions are used. The nominal maximum ATR core inlet and outlet coolant temperatures are $125^{\circ} \mathrm{F}$ and $170^{\circ} \mathrm{F}$, respectively. Part of the primary coolant flow is directed through the FEs with the remainder directed through the reactor internals. The reactor has a core inlet pressure (top of FEs) of nominally $360 \mathrm{psig}$ and a core outlet pressure of nominally 260 psig for three primary coolant pump (PCP) operation and a core inlet pressure of nominally 360 psig and a core outlet pressure of nominally 283 psig for 2 PCP operation.e Table 3 summarizes the ATR nominal core PCS conditions.

Table 3. ATR nominal core PCS conditions.

\begin{tabular}{|l|c|c|c|}
\hline \multicolumn{1}{|c|}{ Location } & $\begin{array}{c}\text { Nominal PCS Pressure } \\
\text { 2 PCP Operation } \\
(\mathrm{psig})\end{array}$ & $\begin{array}{c}\text { Nominal PCS Pressure } \\
\text { 3 PCP Operation } \\
(\mathrm{psig})\end{array}$ & $\begin{array}{c}\text { Nominal PCS Temperature } \\
\left({ }^{\circ} \mathrm{F}\right)\end{array}$ \\
\hline Core inlet & 360 & 360 & 125 \\
\hline Core outlet & 283 & 260 & 170 \\
\hline Average $^{\mathrm{a}}$ & 321.5 & 310 & 147.5 \\
\hline a. The average value for pressure is used to evaluate water properties. \\
\hline
\end{tabular}

\subsection{Method Description}

Water properties at specified temperatures and a nominal average pressure representative of the ATR PCS operating conditions are used to define input parameters for PCS water in specific core locations of the validated ATR full core 19-plate MCNP input model. ${ }^{11}$ These MCNP input parameters for PCS water include cross-section data, composition density, and temperature treatment. Varying these input parameters as a function of PCS water temperature and running MCNP kcode (criticality eigenvalue) calculations generates k-effective values as a function of PCS water temperature for a specified experiment in a specified FT location. The resultant MCNP-calculated temperature-dependent k-effective values are then used to calculate the change in reactivity associated with the change in PCS water temperature $(\Delta \rho / \Delta \mathrm{T})$ in units of $\$ /{ }^{\circ} \mathrm{F}$ for a specified experiment in a specified FT position. At least two water temperatures are specified and evaluated. The results are plotted on an X-Y plot with the X-axis representing temperature in ${ }^{\circ} \mathrm{F}$ the $\mathrm{Y}$-axis representing reactivity in $\$ \rho$. If more than two temperatures are evaluated, a curve fit for the data is generated. Typically, for the ATR operating temperature range, the data is linear. For Microsoft Excel, add a trendline and display the equation and $\mathrm{R}^{2}$ value for the trendline on the plot. The $\mathrm{R}^{2}$ value should be very close to 1.0 for a good linear fit of the data. If the $\mathrm{R}^{2}$ value is not very close to $1.0(<0.95)$, then verify the statistics for the MCNP-calculated eigenvalues being used, consider adding calculations for other temperatures within the range, and address the source(s) for uncertainty when reporting the calculated results.

In addition to the k-effective values, the MCNP-calculated relative lobe power splits (NW-NE-C-SW$\mathrm{SE}$ ) are reported for each corresponding kcode calculation. The MCNP-calculated relative lobe power splits are generated using an $\mathrm{f7}$ tally for the driver fuel cells in the MCNP model. Table 4 summarizes the FEs used for the relative lobe power split calculation.

e. SAR-153, Chapter 4, Section 4.1 Summary Description 


\begin{tabular}{|c|lll|}
\hline $\begin{array}{c}\text { EXPERIMENT DESIGN AND ANALYSIS } \\
\text { GUIDE - NEUTRONICS \& PHYSICS }\end{array}$ & Revision: & \multicolumn{1}{l|}{ GDE-594 } & \\
& Effective Date: & $06 / 26 / 2014$ & Page: 26 of 67 \\
\hline
\end{tabular}

Table 4. MCNP-calculated Relative Lobe Powers.

\begin{tabular}{|l|l|l|l|}
\hline Lobe & \multicolumn{1}{|c|}{ ATR FEs per Lobe } & \multicolumn{1}{|c|}{ f7 tally } & \multicolumn{1}{|c|}{ Relative Lobe Power (\%) } \\
\hline NE & $2,3,4,5,6,7,8,9$ & Fuel cells FE 2-9 & f7 NE/f7 Total =\% NE \\
\hline SE & $12,13,14,15,16,17,18,19$ & Fuel cells FE 12-19 & f7 SE/f7 Total =\% SE \\
\hline SW & $22,23,24,25,26,27,28,29$ & Fuel cells FE 22-29 9 & f7 SW/f7 Total =\% SW \\
\hline NW & $32,33,34,35,36,37,38,39$ & Fuel cells FE 32-39 & f7 NW/f7 Total = \% NW \\
\hline Center & $1,10,11,20,21,30,31,40$ & Fuel cells $1,10,11,20,21,30,31,40$ & f7 Center/f7 Total = \% Center \\
\hline Total & $1-40$ & Fuel cells $1-40$ & f7 Total/f7 Total = 100\% \\
\hline
\end{tabular}

\subsection{MCNP Information}

MCNP is used to calculate k-effective values at different PCS water temperatures for specific ATR core locations. The resultant k-effective values are used to evaluate the MTRC for PCS water within specific ATR core locations (e.g. FE coolant channels or loaded FT positions). The kcode parameters specified in the validated ATR full core 19-plate MCNP input model ${ }^{11}$ are shown below.

kcode $10000 \quad 1.005 \quad 250 \quad 3750$

The kcode parameters used in TCR evaluations may differ from these parameters. The statistical error for each calculation may require adjusting these kcode parameters.

The cross-section libraries provided with MCNP are evaluated at discrete temperatures. Table 5 lists the MCNP52'3 default ENDF/B-VII Release 0 cross-section library information for hydrogen, oxygen, and water.

Table 5. MCNP52:3 Default ENDF/B-VII Release 0 Cross-Section Library Information for Hydrogen, Oxygen, and Water

\begin{tabular}{|l|c|c|c|c|}
\hline \multirow{2}{*}{\begin{tabular}{|} 
Isotope/Material Name \\
Continuous-Energy Neutron Cross-Section Libraries
\end{tabular}} & $\begin{array}{c}\text { MCNP5 ENDF/B-VII } \\
\text { Library }\end{array}$ & $\begin{array}{c}\text { Temp. } \\
(\mathrm{K})\end{array}$ & $\begin{array}{c}\text { Temp. } \\
\left({ }^{\circ} \mathrm{F}\right)\end{array}$ \\
\hline \multirow{2}{*}{ Hydrogen } & $1001.70 \mathrm{c}$ & endf70a & 293.6 & 68.8 \\
\cline { 2 - 5 } & $1001.71 \mathrm{c}$ & endf70a & 600 & 620.3 \\
\hline \multirow{2}{*}{ Oxygen } & $8016.70 \mathrm{c}$ & endf70a & 293.6 & 68.8 \\
\cline { 2 - 5 } & $8016.71 \mathrm{c}$ & endf70a & 600 & 620.3 \\
\hline \multirow{2}{*}{$\mathrm{S}(\alpha, \beta)$ Thermal Neutron Scattering Cross-Section Libraries } & \multicolumn{2}{|c|}{} \\
\hline \multirow{2}{*}{ Hydrogen in light water } & lwtr.10t & endf70sab & 293.6 & 68.8 \\
\cline { 2 - 5 } & lwtr.11t & endf70sab & 350 & 170.3 \\
\cline { 2 - 5 } & lwtr.12t & endf70sab & 400 & 260.3 \\
\cline { 2 - 5 } & lwtr.13t & endf70sab & 450 & 350.3 \\
\hline
\end{tabular}

In order to properly model and evaluate the TCR for the ATR PCS water, cross-section datasets must be created for specific temperatures. The makxsf $f^{12}$ code, which is transmitted as part of the standard MCNP2' 3 code package, is used to create temperature-dependent, continuous-energy, neutron crosssection datasets for hydrogen and oxygen as well as temperature-dependent thermal neutron scattering cross-section datasets for hydrogen in light water. The makxsf $f^{2}$ code creates new temperature-dependent cross-section libraries based on existing cross-section libraries and user specifications. Creation of a nuclide dataset at a new temperature addresses three basic issues:

1. Doppler broadening the resolved resonance data to a higher temperature. 


\begin{tabular}{c|lll|} 
EXPERIMENT DESIGN AND ANALYSIS & Identifier: & GDE-594 & \\
GUIDE - NEUTRONICS \& PHYSICS & Revision: & 1 & \\
& Effective Date: & $06 / 26 / 2014$ & Page: 27 of 67 \\
\hline
\end{tabular}

2. Interpolate any unresolved resonance probability tables to the new temperature.

3. Interpolate $S(\alpha, \beta)$ thermal scattering kernel data to the new temperature.

\subsection{Water Properties}

The water properties used to generate the MCNP input data are provided in Attachment B. The conversion factors and constants used to generate the MCNP input parameters are tabulated in Table 6 . The atomic mass for hydrogen and oxygen, and the molecular mass for water are listed in Table 7.

Table 6. Conversion factors and constants used to calculate MCNP input values for water.

\begin{tabular}{|l|l|l|}
\hline \multicolumn{1}{|c|}{ Parameter } & \multicolumn{1}{c|}{$\begin{array}{c}\text { Conversion Factors or } \\
\text { Constants }\end{array}$} & \multicolumn{1}{c|}{ Units } \\
\hline Mass & 453.59237 & $\mathrm{gm} / \mathrm{lb}$ \\
\hline Volume & $28,316.84659$ & $\mathrm{~cm}^{3} / \mathrm{ft}^{3}$ \\
\hline Area & $1.00 \mathrm{E}+24$ & $\mathrm{barns} / \mathrm{cm}^{2}$ \\
\hline Temperature & +459.67 & ${ }^{\circ} \mathrm{F}$ to ${ }^{\circ} \mathrm{R}$ \\
\hline Temperature & +273.15 & ${ }^{\circ} \mathrm{C}$ to ${ }^{\circ} \mathrm{K}$ \\
\hline Thermal Temperature & $4.787 \mathrm{E}-11$ & $\mathrm{MeV} /{ }^{\circ} \mathrm{R}$ \\
\hline Avogadro's Constant $\left(\mathrm{N}_{\mathrm{A}}\right)$ & $6.02214179 \mathrm{E}+23$ & $\begin{array}{l}\text { atoms } / \mathrm{mole} \\
\text { atoms-cm } / \mathrm{mole}-\mathrm{barn}\end{array}$ \\
\hline
\end{tabular}

Table 7. Atomic mass for hydrogen and oxygen, molecular mass for water.

\begin{tabular}{|ll|c|c|}
\hline $\begin{array}{c}\text { Hydrogen } \\
(\mathrm{gm} / \mathrm{mole})\end{array}$ & $\begin{array}{c}\text { Oxygen }^{\mathrm{a}} \\
(\mathrm{gm} / \mathrm{mole})\end{array}$ & $\begin{array}{c}\text { Water }^{\mathrm{b}} \\
(\mathrm{gm} / \mathrm{mole})\end{array}$ \\
\hline \multicolumn{2}{|c|}{1.00794} & 15.9994 & 18.01528 \\
\hline a. & $\begin{array}{l}\text { Atomic mass values obtained from "Nuclides and Isotopes, Chart of the Nuclides, } \\
\text { Seventeenth Edition, Revised 2009," Bechtel Marine Propulsion Corporation, 2010. }\end{array}$ \\
b. & Molecular mass value calculated using atomic mass values. \\
\hline
\end{tabular}

The evaluated water properties used to generate MCNP input data are provided in Table 8 . Note that the evaluated water properties reported by Table 8 are nearly constant over the applicable temperature and pressure range. The water density in $\mathrm{lb} / \mathrm{ft}^{3}$ is calculated using the specific gravity data from Attachment $\mathrm{B}$. The conversion factors used to calculate the water density in units of $\mathrm{g} / \mathrm{cm}^{3}$ are from Table 6 . The MCNP definition for thermal temperature of a cell is $\mathrm{kT}$, where $\mathrm{kT}=4.787 \times 10^{-11}(\mathrm{~T}+459.67) \mathrm{MeV}$ for $\mathrm{T}$ in ${ }^{\circ} \mathrm{F} .3$ The atom densities and molecular densities were calculated using the atomic masses and molecular mass given in Table 7, and Avogadro's constant and conversion factors given in Table 6 . 


\begin{tabular}{|c|lll|}
\hline $\begin{array}{c}\text { EXPERIMENT DESIGN AND ANALYSIS } \\
\text { GUIDE - NEUTRONICS \& PHYSICS }\end{array}$ & Revision: & \multicolumn{1}{l|}{ GDE-594 } & \\
& Effective Date: & $06 / 26 / 2014$ & Page: 28 of 67 \\
\hline
\end{tabular}

Table 8. Temperature-dependent water properties for use in MCNP input models (see Attachment B).

\begin{tabular}{|c|c|c|c|c|c|c|c|}
\hline $\begin{array}{l}\text { PCS } \\
\text { Temp. } \\
\left({ }^{\circ} \mathrm{F}\right)\end{array}$ & $\begin{array}{l}\text { Specific } \\
\text { Gravity, v } \\
\left(\mathrm{ft}^{3} / \mathrm{lb}\right)\end{array}$ & $\begin{array}{c}\text { Density, } \rho \\
\left(\mathrm{lb} / \mathrm{ft}^{3}\right)\end{array}$ & $\begin{array}{c}\text { Density, } \rho \\
\left(\mathrm{g} / \mathrm{cm}^{3}\right)\end{array}$ & $\begin{array}{c}\text { kT, Thermal } \\
\text { Temperature } \\
(\mathrm{MeV})\end{array}$ & $\begin{array}{c}\text { Hydrogen } \\
\text { Atom Density } \\
\text { (atom/b-cm) }\end{array}$ & $\begin{array}{c}\text { Oxygen } \\
\text { Atom Density } \\
(\text { atom } / \mathrm{b}-\mathrm{cm})\end{array}$ & $\begin{array}{l}\text { Water Atom } \\
\text { Density } \\
\text { (atom/b-cm) }\end{array}$ \\
\hline \multicolumn{8}{|c|}{ PCS Pressure at $260 \mathrm{psig}$} \\
\hline 125 & 0.01621 & 61.69 & 0.9882 & $2.7988 \mathrm{E}-08$ & $6.6066 \mathrm{E}-02$ & $3.3033 \mathrm{E}-02$ & $9.9099 \mathrm{E}-02$ \\
\hline 175 & 0.01646 & 60.75 & 0.9732 & $3.0382 \mathrm{E}-08$ & $6.5063 \mathrm{E}-02$ & $3.2531 \mathrm{E}-02$ & $9.7594 \mathrm{E}-02$ \\
\hline 225 & 0.01679 & 59.56 & 0.9540 & $3.2775 \mathrm{E}-08$ & $6.3784 \mathrm{E}-02$ & $3.1892 \mathrm{E}-02$ & $9.5676 \mathrm{E}-02$ \\
\hline 275 & 0.01720 & 58.14 & 0.9313 & $3.5169 \mathrm{E}-08$ & $6.2263 \mathrm{E}-02$ & $3.1132 \mathrm{E}-02$ & $9.3395 \mathrm{E}-02$ \\
\hline \multicolumn{8}{|c|}{ PCS Pressure at $283 \mathrm{psig}$} \\
\hline 125 & 0.01621 & 61.69 & 0.9882 & $2.7988 \mathrm{E}-08$ & $6.6066 \mathrm{E}-02$ & $3.3033 \mathrm{E}-02$ & $9.9099 \mathrm{E}-02$ \\
\hline 175 & 0.01646 & 60.75 & 0.9732 & $3.0382 \mathrm{E}-08$ & $6.5063 \mathrm{E}-02$ & $3.2531 \mathrm{E}-02$ & $9.7594 \mathrm{E}-02$ \\
\hline 225 & 0.01679 & 59.56 & 0.9540 & $3.2775 \mathrm{E}-08$ & $6.3784 \mathrm{E}-02$ & $3.1892 \mathrm{E}-02$ & $9.5676 \mathrm{E}-02$ \\
\hline 275 & 0.01720 & 58.14 & 0.9313 & $3.5169 \mathrm{E}-08$ & $6.2263 \mathrm{E}-02$ & $3.1132 \mathrm{E}-02$ & $9.3395 \mathrm{E}-02$ \\
\hline \multicolumn{8}{|c|}{ PCS Pressure at $310 \mathrm{psig}$} \\
\hline 125 & 0.0 & & 0.9882 & $2.7988 \mathrm{E}-08$ & $6.6066 \mathrm{E}-02$ & -02 & $9.9099 \mathrm{E}-02$ \\
\hline 175 & 0.01646 & 60.75 & 0.9732 & $3.0382 \mathrm{E}-08$ & $6.5063 \mathrm{E}-02$ & $3.2531 \mathrm{E}-02$ & $9.7594 \mathrm{E}-02$ \\
\hline 225 & 0.01679 & 59.56 & 0.9540 & $3.2775 \mathrm{E}-08$ & $6.3784 \mathrm{E}-02$ & 3.1892E-02 & $9.5676 \mathrm{E}-02$ \\
\hline 275 & 0.01720 & 58.14 & 0.9313 & $3.5169 \mathrm{E}-08$ & $6.2263 \mathrm{E}-02$ & $3.1132 \mathrm{E}-02$ & $9.3395 \mathrm{E}-02$ \\
\hline \multicolumn{8}{|c|}{ PCS Pressure at $321.5 \mathrm{psig}$} \\
\hline 125 & 0.01621 & 61.69 & 0.9882 & $2.7988 \mathrm{E}-08$ & $6.6066 \mathrm{E}-02$ & $3.3033 \mathrm{E}-02$ & $9.9099 \mathrm{E}-02$ \\
\hline 175 & 0.01646 & 60.75 & 0.9732 & $3.0382 \mathrm{E}-08$ & $6.5063 \mathrm{E}-02$ & $3.2531 \mathrm{E}-02$ & $9.7594 \mathrm{E}-02$ \\
\hline 225 & 0.01679 & 59.56 & 0.9540 & $3.2775 \mathrm{E}-08$ & $6.3784 \mathrm{E}-02$ & 3.1892E-02 & $9.5676 \mathrm{E}-02$ \\
\hline 275 & 0.01720 & 58.14 & 0.9313 & $3.5169 \mathrm{E}-08$ & $6.2263 \mathrm{E}-02$ & $3.1132 \mathrm{E}-02$ & $9.3395 \mathrm{E}-02$ \\
\hline \multicolumn{8}{|c|}{ PCS Pressure at $360 \mathrm{psig}$} \\
\hline 125 & 0.01621 & 61.69 & 0.9882 & $2.7988 \mathrm{E}-08$ & $6.6066 \mathrm{E}-02$ & $3.3033 \mathrm{E}-02$ & $9.9099 \mathrm{E}-02$ \\
\hline 175 & 0.01646 & 60.75 & 0.9732 & $3.0382 \mathrm{E}-08$ & $6.5063 \mathrm{E}-02$ & 3.2531E-02 & $9.7594 \mathrm{E}-02$ \\
\hline 225 & 0.01679 & 59.56 & 0.9540 & $3.2775 \mathrm{E}-08$ & $6.3784 \mathrm{E}-02$ & $3.1892 \mathrm{E}-02$ & $9.5676 \mathrm{E}-02$ \\
\hline 275 & 0.01719 & 58.17 & 0.9318 & $3.5169 \mathrm{E}-08$ & $6.2300 \mathrm{E}-02$ & $3.1150 \mathrm{E}-02$ & $9.3449 \mathrm{E}-02$ \\
\hline
\end{tabular}

\subsection{MCNP Input}

Typical MCNP input parameters that are used to evaluate the TCR of the ATR PCS water are listed below. Perform these steps for all experiment and backup experiment configurations.

1. Define at least two PCS water temperatures to be evaluated.

2. Calculate the density $(\mathrm{g} / \mathrm{cc})$ for water at the defined temperatures.

3. Use makxsf $f^{2}$ with specs file (see Attachment C), to generate temperature-dependent cross-section data sets for hydrogen and oxygen for each defined temperature or use an existing library with temperature-dependent cross-section data sets for hydrogen and oxygen.

4. Use makxsf ${ }^{12}$ with specs file (see Attachment C), to generate temperature-dependent cross-section data sets for the $S(\alpha, \beta)$ thermal neutron treatment of hydrogen in light water for each defined temperature or use an existing library with temperature-dependent cross-section data sets for $S(\alpha, \beta)$ thermal neutron treatment of hydrogen in light water. 


\begin{tabular}{|c|lll|}
\hline $\begin{array}{c}\text { EXPERIMENT DESIGN AND ANALYSIS } \\
\text { GUIDE - NEUTRONICS \& PHYSICS }\end{array}$ & Revision: & \multicolumn{1}{l|}{ GDE-594 } & \\
& Effective Date: & $06 / 26 / 2014$ & Page: 29 of 67 \\
\hline
\end{tabular}

5. Change the water density value for the MCNP cell card(s) corresponding with the water in the specific FT location to the density value at a defined temperature. Repeat this step at each defined temperature, generating temperature-specific input models.

6. Change the material number for the MCNP cell card(s) corresponding with the water in the specific FT location to the material number for water at a defined temperature. Repeat this step at each defined temperature, for each temperature-specific input model.

7. Change or specify the corresponding water temperature for each defined temperature using the TMP (free-gas thermal temperature treatment) parameter on the MCNP cell cards corresponding with the water in the specific FT location. Repeat this step at each defined temperature, for each temperaturespecific input model.

8. Specify temperature-dependent cross-section data for hydrogen and oxygen using the MCNP material cards corresponding with the water in the specific FT location. Repeat this step at each defined temperature, for each temperature-specific input model.

9. Specify temperature-dependent cross-section data for the $S(\alpha, \beta)$ thermal neutron treatment of hydrogen in light water using the material treatment (MT) card corresponding with the water in the specific FT location. Repeat this step at each defined temperature, for each temperature-specific input model.

10. Specify kcode parameters.

11. Specify $\mathrm{f} 7$ tallies for the ATR driver fuel to obtain the relative core power splits.

The existing cross-section datasets used to generate the new cross-section datasets for the ATR PCS at $125^{\circ} \mathrm{F}, 175^{\circ} \mathrm{F}, 225^{\circ} \mathrm{F}$, and $275^{\circ} \mathrm{F}$ are listed in Table 9 .

The MCNP input data for the material compositions, material treatment and thermal temperature treatment specifications at each evaluated water temperature are provided in Table 10.

Temperatures for an MCNP cell may be verified in the MCNP output file using Table 72.

Table 9. Temperature-dependent cross-section datasets created with makxsf $f^{2 .}$

\begin{tabular}{|c|c|c|c|c|c|}
\hline Nuclide & \multicolumn{2}{|c|}{ Evaluated Temperature $^{\mathrm{a}}$} & \multicolumn{2}{|c|}{$\begin{array}{l}\text { MCNP5 Default ENDF/B-VII } \\
\text { ZAID } \\
\end{array}$} & $\begin{array}{c}\text { Temperature-Dependent } \\
\text { ZAID }\end{array}$ \\
\hline \multicolumn{6}{|c|}{ Continuous-Energy Neutron Cross-Section Libraries } \\
\hline \multirow[t]{4}{*}{ Hydrogen } & 125 & 324.82 & $1001.70 \mathrm{c}$ & $1001.71 \mathrm{c}$ & $1001.11 \mathrm{c}$ \\
\hline & 175 & 352.59 & $1001.70 \mathrm{c}$ & $1001.71 \mathrm{c}$ & $1001.12 \mathrm{c}$ \\
\hline & 225 & 380.37 & $1001.70 \mathrm{c}$ & $1001.71 \mathrm{c}$ & $1001.13 \mathrm{c}$ \\
\hline & 275 & 408.15 & $1001.70 \mathrm{c}$ & $1001.71 \mathrm{c}$ & $1001.14 \mathrm{c}$ \\
\hline \multirow[t]{4}{*}{ Oxygen } & 125 & 324.82 & $8016.70 \mathrm{c}$ & $8016.71 \mathrm{c}$ & $8016.11 \mathrm{c}$ \\
\hline & 175 & 352.59 & $8016.70 \mathrm{c}$ & $8016.71 \mathrm{c}$ & $8016.12 \mathrm{c}$ \\
\hline & 225 & 380.37 & $8016.70 \mathrm{c}$ & $8016.71 \mathrm{c}$ & $8016.13 c$ \\
\hline & 275 & 408.15 & $8016.70 \mathrm{c}$ & $8016.71 \mathrm{c}$ & $8016.14 \mathrm{c}$ \\
\hline \multicolumn{6}{|c|}{$S(\alpha, \beta)$ Libraries } \\
\hline \multirow{4}{*}{$\begin{array}{l}\text { Hydrogen in } \\
\text { light water }\end{array}$} & 125 & 324.82 & lwtr.10t & lwtr.11t & lwtr.30t \\
\hline & 175 & 352.59 & lwtr.11t & lwtr.12t & lwtr.31t \\
\hline & 225 & 380.37 & lwtr.11t & lwtr.12t & lwtr.32t \\
\hline & 275 & 408.15 & lwtr.12t & lwtr.13t & lwtr.33t \\
\hline
\end{tabular}




\begin{tabular}{|c|lll|}
\hline EXPERIMENT DESIGN AND ANALYSIS & Identifier: & GDE-594 & \\
GUIDE - NEUTRONICS \& PHYSICS & Revision: & 1 & \\
& Effective Date: & $06 / 26 / 2014$ & Page: 30 of 67 \\
\hline
\end{tabular}

Table 10. MCNP Input Data for Material Compositions, Material Treatment, and Thermal Temperature Treatment for Water-filled Cells in FT

\begin{tabular}{|c|c|c|}
\hline $\begin{array}{l}\text { Temperature of } \\
\text { Water in FT } \\
\left({ }^{\circ} \mathrm{F}\right)\end{array}$ & $\begin{array}{c}\text { MCNP Input Data } \\
\text { Material Compositions \& } \\
\text { Material Treatment for Water in FT }\end{array}$ & $\begin{array}{c}\text { MCNP TMP } \\
\text { Thermal Temperature } \\
\text { Treatment for Water in FT }\end{array}$ \\
\hline 125 & $\begin{array}{llr}\text { c Water } & \text { in EFT at } & 125 \mathrm{~F} \\
\text { m130 } & 1001.11 \mathrm{c} & 0.666666666 \\
& 8016.11 \mathrm{c} & 0.333333333 \\
\text { mt130 } & \text { lwtr.30t } & \\
\end{array}$ & $\mathrm{TMP}=2.7988 \mathrm{E}-08$ \\
\hline 175 & $\begin{array}{llr}\text { C Water } & \text { in EFT at } & 175 \mathrm{~F} \\
\text { m130 } & 1001.12 \mathrm{C} & 0.666666666 \\
& 8016.12 \mathrm{C} & 0.333333333 \\
\text { mt130 } & \text { lwtr.31t } & \\
\end{array}$ & $\mathrm{TMP}=3.0382 \mathrm{E}-08$ \\
\hline 225 & $\begin{array}{llr}\text { C Water } & \text { in EFT at } & 225 \mathrm{~F} \\
\text { m130 } & 1001.13 \mathrm{C} & 0.666666666 \\
& 8016.13 \mathrm{C} & 0.333333333 \\
\text { mt130 } & \text { lwtr.32t } & \\
\end{array}$ & $\mathrm{TMP}=3.2775 \mathrm{E}-08$ \\
\hline 275 & $\begin{array}{llr}\text { c Water } & \text { in EFT at } & 275 \mathrm{~F} \\
\text { m130 } & 1001.14 \mathrm{C} & 0.666666666 \\
& 8016.14 \mathrm{C} & 0.333333333 \\
\text { mt130 } & \text { lwtr.33t } & \end{array}$ & $\mathrm{TMP}=3.5169 \mathrm{E}-08$ \\
\hline
\end{tabular}

\subsection{Reactivity Calculation}

The MCNP-calculated temperature-dependent k-effective values are used to calculate the change in reactivity associated with the change in PCS water temperature for the experiment in the FT. Refer to the reactivity calculation in section 5.6 of this guide and use equations (7) through (13) to calculate the reactivity change as a function of PCS water temperature.

\section{AXIAL FISSION PROFILE}

The ATR Core Safety Assurance Package (CSAP) uses a 2D-diffusion code (PDQ) to perform burnup calculations for the ATR driver fuel. The PDQ analysis assumes that the axial fission profile is a cosine shape. New experiments are typically measured in ATRC to ensure the axial fission profile is not significantly perturbed from the established baseline. The established baseline criteria for the axial fission profile measurements are documented in EDF TRA-ATRC-1546. ${ }^{18}$ The established criteria for measurements was used to develop a similar criteria for MCNP calculated axial fission profiles.

Measurements for the axial flux profile are typically taken in Channels 2, 6, 11, 15, and 19 of an ATRC FE. Flux wands are inserted into each of the elements and U/Al fission wires are placed every two inches axially in the flux wands. A diagram of the fission wire channel placement is presented in Figure 2. The ATRC reactor is brought critical and the wires are irradiated for 20 minutes at a core power of approximately 600 Watts. The flux wands and wires are removed and the counted at the Radiological Monitoring Laboratory (RML). The point-to-average values are calculated for each set of wires in their respective channels. 


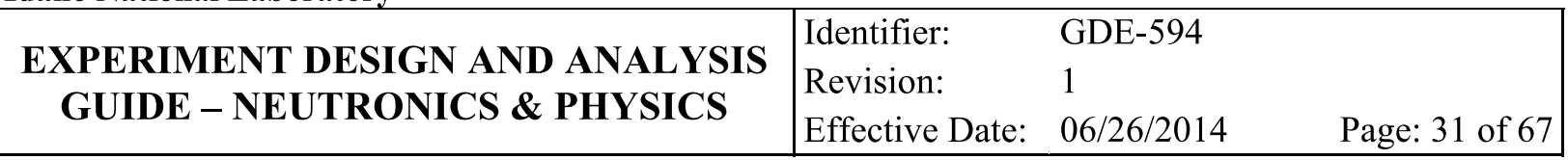

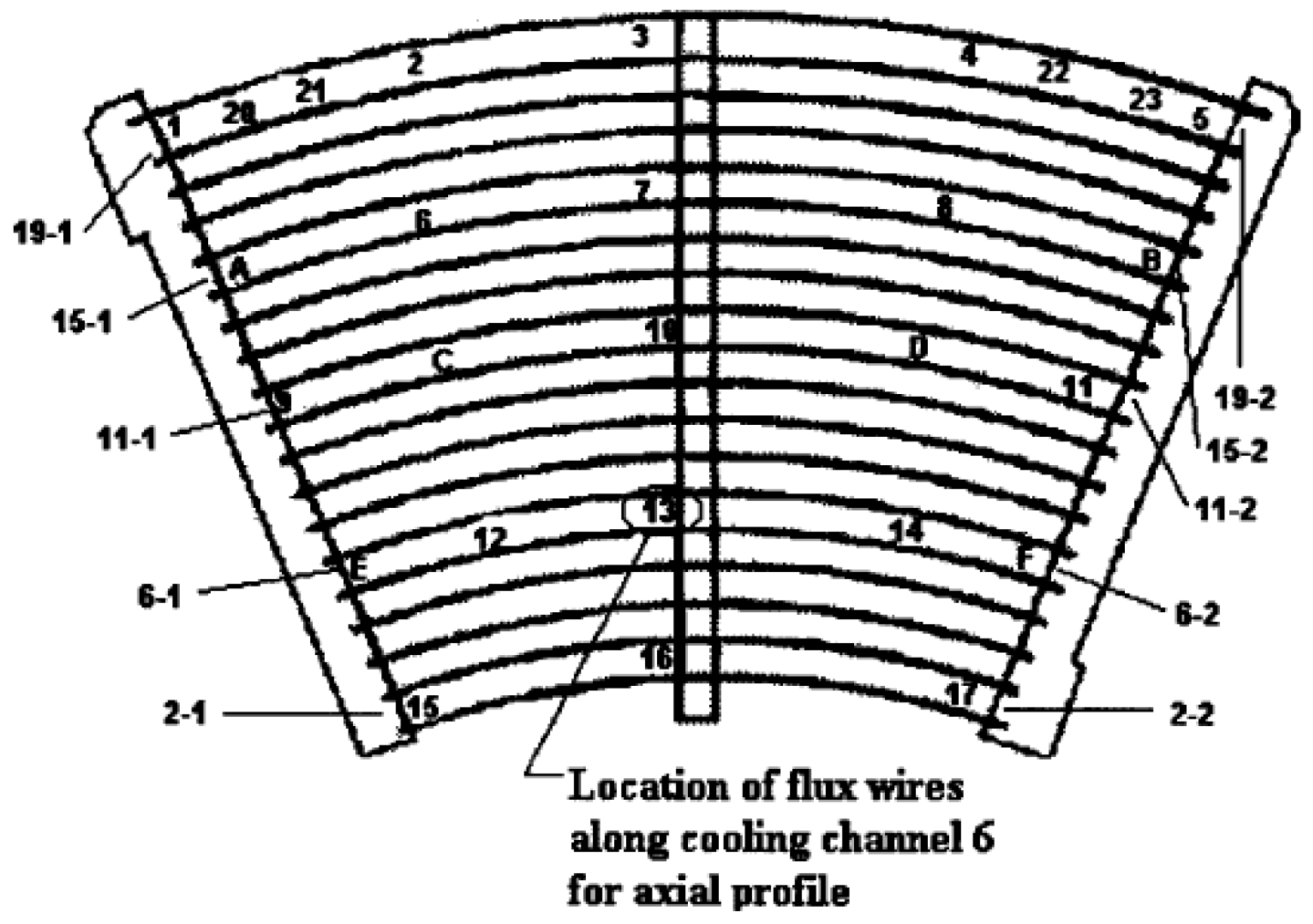

Figure 2. Location of the fission wires for axial fission profile measurements.

As part of experiment design, the potential for axial fission profile perturbation should be evaluated to ensure the experiment does not perturb the axial flux, affecting the assumptions used in the core physics analysis. The fission profile perturbation is evaluated using the ATR full core 19-plate MCNP model. The MCNP model "baseline" should consist of an axial homogenous configuration, such as an aluminum filler (AF) or a water-filled experiment position. The surrounding positions that could affect the FE of interest should also be axially homogenous. The MCNP tally cards are used to calculate the fission rate in each of the water channels of interest. The fission rate is calculated using and f4 type tally with a tally multiplier. The tally is multiplied by the fission cross-section for U-235 to give the fission rate in the channel. The channels are segmented into 232 -inch axial segments symmetric about the core-midplane with 1-inch segments on each end. The average fission rate in each segment is used. The segment tally is divided by the overall channel average to obtain the point to average for that particular 2-inch segment.

The point-to-average ratio for the axial fission flux profile is calculated using equation (14):

$$
\left(\frac{P}{A}\right)_{i}=\frac{P_{i}}{A}
$$

Where $\mathrm{P}_{\mathrm{i}}$ is the tally for segment " $\mathrm{i}$ " and $\mathrm{A}$ is the MCNP-calculated average of the tallies for all of the segments (cells) within the particular channel.

Convergence of the tallies is important in ensuring the calculated results are valid. The number of histories that are used in the MCNP simulation should be enough to complete the MCNP statistical 


\begin{tabular}{|c|c|c|c|}
\hline $\begin{array}{l}\text { EXPERIMENT DESIGN AND ANALYSIS } \\
\text { GUIDE - NEUTRONICS \& PHYSICS }\end{array}$ & $\begin{array}{l}\text { Identifier: } \\
\text { Revision: } \\
\text { Effective Date: }\end{array}$ & $\begin{array}{l}\text { GDE-594 } \\
1 \\
06 / 26 / 2014\end{array}$ & Page: 32 of 67 \\
\hline
\end{tabular}

checks and the tallies are properly converged. The analyst should evaluate the MCNP output files to ensure proper convergence of the calculated results.

In TRA-ATRC-1546, ${ }^{18}$ a measured "baseline" is established by averaging the point-to-average fission rate of several FEs from 10 different test configurations that were deemed by Reference 18 to be essentially axially uniform adjacent to the FE being evaluated. The standard deviation of the average values for the 10 different measurements was then used to establish an acceptance band. If the measured values of an experiment fell within that band, then the experiment was deemed to not perturb the axial flux. When a data point fell outside that band, then the error in the flux wire measurements assumed to be $3 \%,{ }^{18}$ was taken into consideration and applied towards the direction of acceptability. If the value fell within the "baseline" band, then the experiment was determined to be acceptable.

The values for standard deviation in percent (\%) of the "baseline" reported by Table 5 of EDF TRAATRC- $1546,{ }^{18}$ vary from $1.9 \%$ to $9.9 \%$. It was proposed that for each MCNP axial segment, the MCNPcalculated point-to-average fission rate for an experiment must fall within $\pm 2 \%$ of the corresponding MCNP-calculated "baseline" point-to-average fission rate. ${ }^{19}$ With properly converged MCNP tallies, the error in the MCNP values will be considerably less than $2 \%$. The uncertainty in the MCNP results only account for statistical uncertainty associated with the Monte Carlo method and do not reflect modeling uncertainty.

If the MCNP-calculated experiment point-to-average fission rate does not fall within $\pm 2 \%$ of the MCNP-calculated "baseline" acceptance band, then 3\% of the value of the MCNP point-to-average may be included towards the direction of acceptability. The $3 \%$ corresponds to the acceptable measured uncertainty in the fission wires, which have been deemed to be acceptable.

To ensure statistical acceptability for the MCNP-calculated standard deviations of the tallies, it should be verified that all 10 statistical checks for the MCNP calculation have been passed. The 10 statistical checks are reported in the MCNP output files.

Since the "baseline" values in EDF TRA-ATRC- $1546{ }^{18}$ have larger standard deviations for data points near the top and bottom of the core, the MCNP-calculated values near the top and bottom of the core that fail to meet either criteria ( $\pm 2 \%$ MCNP-calculated "baseline" and $( \pm) 3 \%$ of the MCNP calculated value) may be evaluated on a case-by-case basis to ensure that the axial fission profile will not be significantly perturbed. It is proposed that no more than $4 \mathrm{MCNP}$-calculated point-to-average fission rate values for a FE channel may fall outside of the first two acceptance criteria. ${ }^{19}$

This graded approach to acceptance criteria should be allowed since the band of acceptability narrows as the MCNP-calculated values become smaller at the top and bottom of the core.

\section{Summary of Acceptance Criteria for MCNP-Calculated Axial Fission Profiles}

1. MCNP-calculated axial point-to-average fission rate value for an experiment must fall within $\pm 2 \%$ of the MCNP-calculated "baseline" axial point-to-average fission rate value.

2. The $\pm 3 \%$ of the MCNP-calculated point-to-average value may be included towards the direction of acceptability. It is recommended that all 10 statistical checks are passed for the MCNP calculation.

3. No more than $4 \mathrm{MCNP}$-calculated point-to-average fission rate values for a single FE channel may fall outside of the first two acceptance criteria.

4. If the first three acceptance criteria for an MCNP-calculated axial fission profile for a test are not met, then on a case-by-case basis, the MCNP-calculated results may be evaluated by ATR Nuclear Safety and/or ATR Reactor Engineering and the MCNP-calculated results rejected or accepted. 


\begin{tabular}{|c|lll|}
\hline $\begin{array}{c}\text { EXPERIMENT DESIGN AND ANALYSIS } \\
\text { GUIDE - NEUTRONICS \& PHYSICS }\end{array}$ & Revision: & \multicolumn{1}{l|}{ GDE-594 } & \\
& Effective Date: & $06 / 26 / 2014$ & Page: 33 of 67 \\
\hline
\end{tabular}

An example of the comparison used to compare the axial fission profile for an experiment and a baseline is presented in Table 11. The axial fission profile is calculated using an f4 type tally. An example of the MCNP tally card used to calculate the axial fission profile is presented in Figure 3.

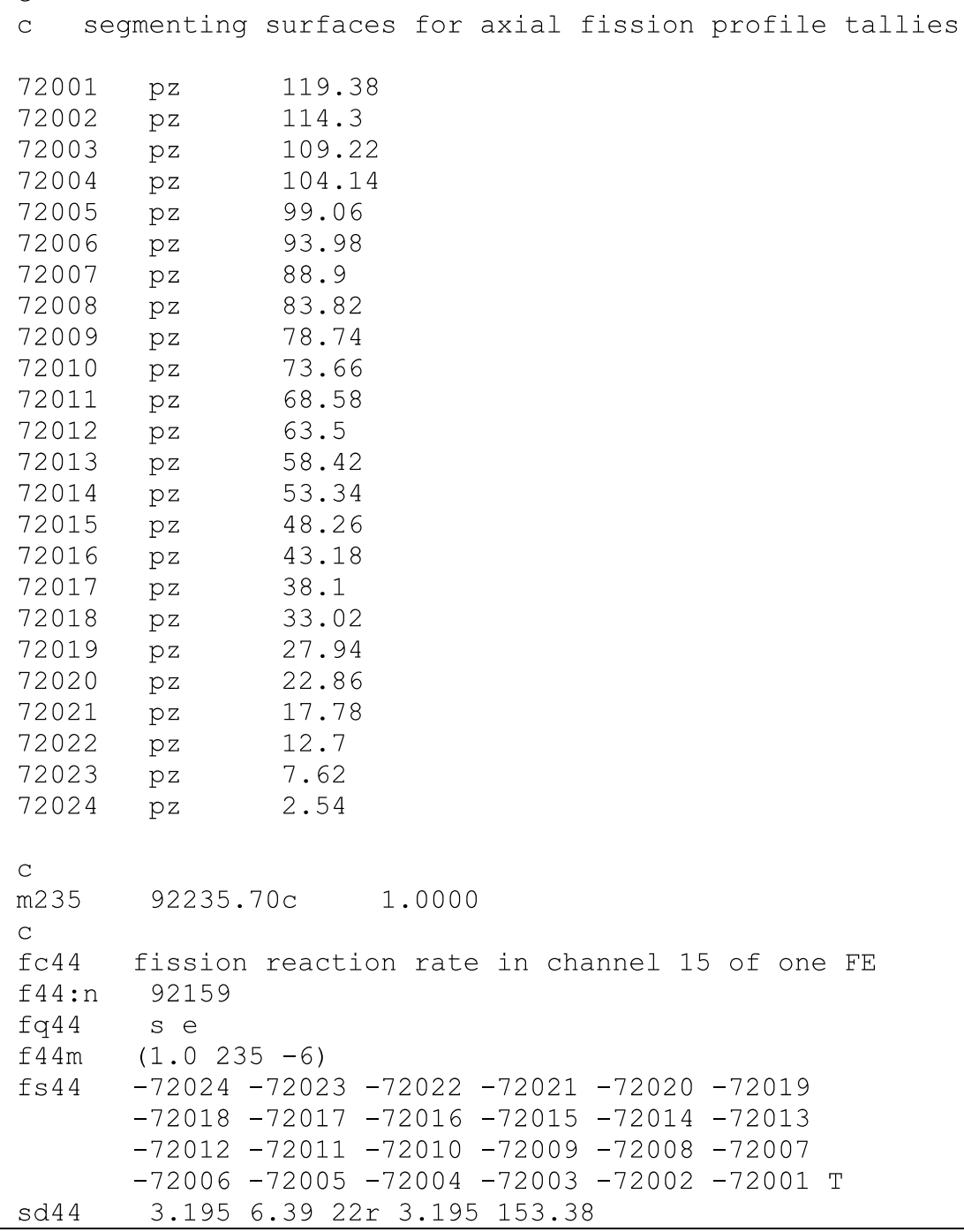

Figure 3. Example of MCNP Input for Axial Fission Profile Calculations 


\section{EXPERIMENT DESIGN AND ANALYSIS GUIDE - NEUTRONICS \& PHYSICS}

Identifier:

Revision:

Effective Date: $06 / 26 / 2014$

GDE-594

1
Page: 34 of 67

Table 11. Example of acceptance criteria check for axial fission profile analysis.

\begin{tabular}{|c|c|c|c|c|c|c|c|}
\hline $\begin{array}{c}\text { Elevation } \\
\text { (inches) }\end{array}$ & $\begin{array}{c}\text { MCNP- } \\
\text { Calculated } \\
\text { Baseline }\end{array}$ & $\begin{array}{c}\text { Baseline } \\
+2 \%\end{array}$ & $\begin{array}{c}\text { Baseline - } \\
2 \%\end{array}$ & $\begin{array}{c}\text { MCNP- } \\
\text { Calculated } \\
\text { Test }\end{array}$ & $\begin{array}{c}\text { Criteria 1 } \\
\text { Check }\end{array}$ & $\begin{array}{c}\text { Criteria 2 } \\
\pm \text { Value }\end{array}$ & $\begin{array}{c}\text { Criteria } 2 \\
\text { Check }\end{array}$ \\
\hline-22.0 & 0.490 & 0.500 & 0.480 & 0.490 & OK & 0.003 & OK \\
\hline-20.0 & 0.625 & 0.638 & 0.613 & 0.617 & OK & 0.003 & OK \\
\hline-18.0 & 0.765 & 0.781 & 0.750 & 0.761 & OK & 0.004 & OK \\
\hline-16.0 & 0.896 & 0.914 & 0.878 & 0.895 & OK & 0.004 & OK \\
\hline-14.0 & 1.015 & 1.036 & 0.995 & 1.014 & OK & 0.004 & OK \\
\hline-12.0 & 1.127 & 1.149 & 1.104 & 1.119 & OK & 0.004 & OK \\
\hline-10.0 & 1.216 & 1.241 & 1.192 & 1.212 & OK & 0.005 & OK \\
\hline-8.0 & 1.295 & 1.321 & 1.269 & 1.280 & OK & 0.005 & OK \\
\hline-6.0 & 1.349 & 1.376 & 1.322 & 1.340 & OK & 0.005 & OK \\
\hline-4.0 & 1.387 & 1.414 & 1.359 & 1.377 & OK & 0.005 & OK \\
\hline-2.0 & 1.410 & 1.438 & 1.381 & 1.393 & OK & 0.005 & OK \\
\hline 0.0 & 1.412 & 1.440 & 1.383 & 1.405 & OK & 0.005 & OK \\
\hline 2.0 & 1.390 & 1.418 & 1.362 & 1.395 & OK & 0.005 & OK \\
\hline 4.0 & 1.358 & 1.386 & 1.331 & 1.360 & OK & 0.005 & OK \\
\hline 6.0 & 1.302 & 1.328 & 1.276 & 1.304 & OK & 0.005 & OK \\
\hline 8.0 & 1.236 & 1.261 & 1.211 & 1.232 & OK & 0.005 & OK \\
\hline 10.0 & 1.143 & 1.166 & 1.120 & 1.140 & OK & 0.005 & OK \\
\hline 12.0 & 1.039 & 1.059 & 1.018 & 1.049 & OK & 0.004 & OK \\
\hline 14.0 & 0.920 & 0.939 & 0.902 & 0.922 & OK & 0.004 & OK \\
\hline 16.0 & 0.789 & 0.805 & 0.774 & 0.798 & OK & 0.004 & OK \\
\hline 18.0 & 0.643 & 0.656 & 0.630 & 0.654 & OK & 0.003 & OK \\
\hline 20.0 & 0.477 & 0.487 & 0.468 & 0.490 & high & 0.003 & fail \\
\hline 22.0 & 0.302 & 0.308 & 0.296 & 0.319 & high & 0.002 & fail \\
\hline
\end{tabular}

\section{DETERMINATION OF CENTER LOBE POWER}

\subsection{Applicability}

For experiments inserted into the CFT, inboard "A" positions, "H" positions, and for use in calculating power in the N, S, E, and W flux traps, a center lobe power (CLP) must be determined for use in experiment design and predicted physics analyses.

\subsection{ATR Information}

The ATR reactor power is controlled by manipulating the OSCCs to achieve the desired power split in the four (4) corner lobe powers (NW, NE, SW, SE) specified in the Integrated Strategic Operational Plan (ISOP). The CLP is not directly controlled by control element manipulation. It is primarily a function of the power level achieved in the adjacent corner lobes. CLP is highly sensitive to the position of the OSCCs as they are manipulated to maintain corner lobe power, along with NS movement. NS rods are withdrawn throughout a typical cycle to compensate for ATR driver fuel burnup. 


\begin{tabular}{|c|lll|}
$\begin{array}{c}\text { EXPERIMENT DESIGN AND ANALYSIS } \\
\text { GUIDE - NEUTRONICS \& PHYSICS }\end{array}$ & $\begin{array}{l}\text { Revision: } \\
\text { Effective Date: }\end{array}$ & $\begin{array}{l}\text { Gdifier: } \\
\text { - NE/2014 }\end{array}$ & Page: 35 of 67 \\
\hline
\end{tabular}

\subsection{Method Description}

As of cycle 143B-1, the primary customer of ATR stopped providing a center lobe power estimate. This estimate was reported in the ISOP for use by experimenters. This estimate has been replaced in the ISOP by one determined from the methodology described in TEV-288. ${ }^{20}$ Appendix D of TEV-288 provides predicted center lobe power for a given total corner lobe power, both nominal and worst case (maximum) startup center powers. While the predicted worst case center power from Appendix D of TEV $-288^{20}$ (see Attachment D) is recommended for use in bounding safety analyses, it is not feasible as a basis for experiment nominal design.

The predicted nominal startup powers from TEV-288 do not match power history data very well, as shown in the tables in Attachment $\mathrm{E}$ and Attachment F. For regular cycles, the table in Attachment E compares multiplying Total Corner Lobe Powers (TCLP) by the average Center Lobe Power Multiplier (CLPM - 0.28) to predict CLP versus using the nominal startup center power values from TEV-288 ${ }^{20}$. The average CLPM method for determining CLP yields closer CLPs for all but 4 of 91 cycles. A comparison of the percent differences between each CLP calculation method result and the measured value for CLP for that cycle is also given in the table in Attachment E.

Attachment F provides the same comparisons and data as Attachment E, only for the 20 Powered Axial Locator Mechanism (PALM) cycles evaluated. While using the average CLPM method isn't quite as good for PALM cycles as it is for regular cycles, it yielded CLP values closer to measured CLP values than those calculated using the method in TEV-288. ${ }^{20}$

\subsection{Calculations}

An analysis of power history data based on N-16 average lobe powers from ATR Power History Letters $^{21,22}$ going back to Cycle 103-B has been performed. For each cycle, a TCLP was calculated, and then the measured CLP was divided by the TCLP. This resulted in a CLPM for each cycle. The average CLPM over both the 91 regular (non-PALM) cycles and 20 PALM cycles is 0.28 . The data for regular cycles is tabulated in Table 12, and the data for PALM cycles is tabulated in Table 13.

Table 12. CLP and CLPM Data for Regular Cycles.

\begin{tabular}{|l|c|c|c|c|}
\hline & Average & Standard Deviation & Maximum & Minimum \\
\hline CLP (MW) & 24 & 1.4 & 27.7 & 21.4 \\
\hline CLPM & 0.28 & 0.01 & 0.32 & 0.25 \\
\hline
\end{tabular}

Table 13. CLP and CLPM Data for PALM Cycles.

\begin{tabular}{|l|c|c|c|c|}
\hline & Average & Standard Deviation & Maximum & Minimum \\
\hline CLP (MW) & 32 & 4 & 39.8 & 23.6 \\
\hline CLPM & 0.28 & 0.02 & 0.31 & 0.24 \\
\hline
\end{tabular}

\subsection{Recommendations}

The nominal CLP to use for experiment design should be calculated by multiplying the planned nominal TCLP by the average CLPM value of 0.28 , for both regular and PALM ATR operating cycles:

$$
\mathrm{CLP}=\mathrm{TCLP}^{*} 0.28
$$

The maximum CLP to use for experiment design or bounding safety analysis must to be determined on an experiment-by-experiment basis. Fueled experiments will typically have a more limiting CLP than 


\begin{tabular}{|c|lll|}
\hline $\begin{array}{c}\text { EXPERIMENT DESIGN AND ANALYSIS } \\
\text { GUIDE - NEUTRONICS \& PHYSICS }\end{array}$ & Revision: & \multicolumn{1}{l|}{ GDE-594 } & \\
& Effective Date: & $06 / 26 / 2014$ & Page: 36 of 67 \\
\hline
\end{tabular}

non-fueled experiments. Analyses will determine allowable maximum CLP for an experiment. In the event an experiment requires a CLP limit, ATR Operations and ATR Experiments should be contacted and concurrence obtained for requesting CLP limits/restrictions for the analyzed experiment irradiated in a specified ATR cycle.

\section{DISPLACEMENTS PER ATOM (DPA) \\ 9.1 Using MCNP Cross Section Libraries}

From Reference 23, "One of the damage effects of radiation is the production of lattice defects. A large cluster of lattice defects can be produced by the primary recoil nucleus of a nuclear reaction as it slows down in a lattice. It has been shown that there is an empirical correlation between the number of displaced atoms (DPA, displacements per atom) and various properties of metals, such as elasticity. The number of displaced atoms depends on the total available energy $E$, and the energy required to displace an atom from its lattice position $E_{d}$. Since the available energy is used up by producing pairs,

$$
D P A=\frac{E_{a}}{2 E_{d}}
$$

The values of $E_{d}$ used in practice are chosen to represent the empirical correlations, and a wide range of values is found in the literature (see Table 1 for some examples). The energy available to cause displacements is what HEATR calculates. It depends on the recoil spectrum and the partition of recoil energy between electronic excitations and atomic motion. The partition function used was given by Robinson based on the electronic screening theory of Lindhard (see Fig. 2).

Table 1: Typical Values for the Atomic Displacement Energy Needed to Compute DPA. ${ }^{6}$

\begin{tabular}{cccc} 
Element & $E_{d}$ in $\mathrm{eV}$ & Element & $E_{d}$ in $\mathrm{eV}$ \\
\hline $\mathrm{Be}$ & 31 & $\mathrm{Co}$ & 40 \\
$\mathrm{C}$ & 31 & $\mathrm{Ni}$ & 40 \\
$\mathrm{Mg}$ & 25 & $\mathrm{Cu}$ & 40 \\
$\mathrm{Al}$ & 27 & $\mathrm{Zr}$ & 40 \\
$\mathrm{Si}$ & 25 & $\mathrm{Nb}$ & 40 \\
$\mathrm{Ca}$ & 40 & $\mathrm{Mo}$ & 60 \\
$\mathrm{Ti}$ & 40 & $\mathrm{Ag}$ & 60 \\
$\mathrm{~V}$ & 40 & $\mathrm{Ta}$ & 90 \\
$\mathrm{Cr}$ & 40 & $\mathrm{~W}$ & 90 \\
$\mathrm{Mn}$ & 40 & $\mathrm{Au}$ & 30 \\
$\mathrm{Fe}$ & 40 & $\mathrm{~Pb}$ & 25 \\
\hline
\end{tabular}




\begin{tabular}{|c|lll|}
$\begin{array}{c}\text { EXPERIMENT DESIGN AND ANALYSIS } \\
\text { GUIDE - NEUTRONICS \& PHYSICS }\end{array}$ & $\begin{array}{l}\text { Revision: } \\
\text { Effective Date: }\end{array}$ & $\begin{array}{l}\text { G6/26/2014 } \\
\text { Page: } 37 \text { of } 67\end{array}$ \\
\hline
\end{tabular}

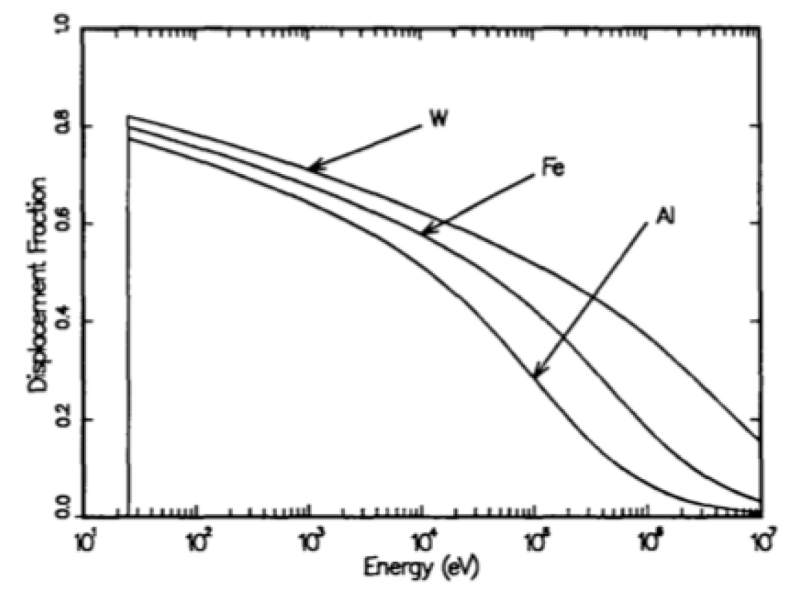

\begin{abstract}
Figure 2: Examples of the portion of the primary recoil energy that is available to cause lattice displacements in metallic lattices. The remaining energy leads to electronic excitation. The quantity plotted is $P(E)$ from Eq. (36) divided by $E$. The $25 \mathrm{eV}$ cutoff is also discussed in connection with Eq. (36).
\end{abstract}

The damage output from HEATR is the damage energy production cross section (eV-barns). As in Eq. (l), multiplying by the density and flux gives eV/s. Dividing by $2 E_{d}$ gives displacements/sec."

From Reference 24, "NJOY has long had the capability to compute "damage-energy production" in the HEATR module and pass it through GROUPR for multigroup applications. However, these numbers weren't previously available for use in Monte Carlo codes like MCNP in a convenient way. Starting with up19, we have modified the ACER module to take the existing damage cross sections (MT=444 on the PENDF tape) and include them on the ACE library file. Following the MCNP tradition, they are given in units of MeV-barns. The phenomenological treatment of radiation damage assumes that a certain "displacement energy" is required to create a particle-vacancy pair, and that the available energy is consumed in making these pairs. An efficiency factor is also normally used. Therefore, the displacements per atom (DPA) cross section is given by equation (17).

$$
\mathrm{DPA}=\eta \frac{\sigma_{\mathrm{d}}}{2 \mathrm{E}_{\mathrm{d}}}
$$

The displacement energies vary from about 25 to $90 \mathrm{eV}$. A table of typical values is given in the HEATR chapter of the NJOY report. A typical efficiency value is $80 \%$. It is up to the MCNP user to apply these two factors during the construction of a DPA tally."

Both references 23 and 24 are for the NJOY nuclear data processing system. Damage cross sections can be created from the ENDF/B nuclear data using NJOY. The ENDF/B-VII cross sections that ship with MCNP contain the damage cross sections for many isotopes. The reaction number for these cross sections is $444(\mathrm{MT}=444)$

Using MCNP with the tally multiplier card (FMn) it is possible to calculate the DPA cross sections for many materials (materials with cross section data files containing the MT-444 reaction). It is also possible to calculate the DPA rate directly with the correct multipliers. 


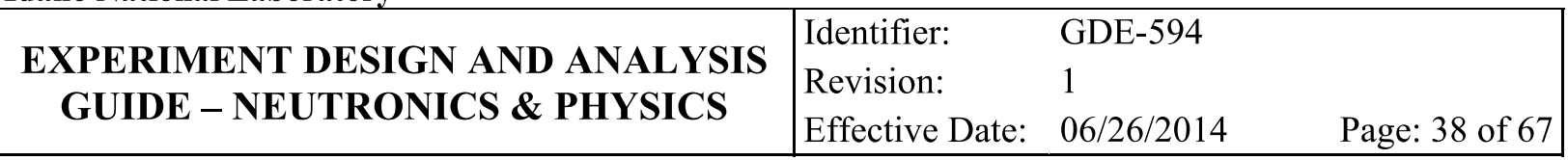

The DPA rate in a material is estimated by using a tally multiplier card with a standard flux tally in MCNP. The tally multiplier card applied to a flux tally calculates the reaction rate which is defined as the quantity:

$$
C \int \Phi(E) R_{m}(E) d E
$$

where

$$
\begin{aligned}
C & =\text { multiplicative constant } \\
\Phi(E) & =\text { energy dependent flux } \\
R_{m}(E) & =\text { energy dependent reaction rate of interest (ENDF/B-VII damage cross-section) }
\end{aligned}
$$

The quantity

$$
\int \Phi(E) R_{m}(E) d E
$$

is the total damage energy rate for the material. Assigning the quantity $\eta / 2 \mathrm{Ed}$ to the constant $\mathrm{C}$ in Equation (18) results in:

$$
\text { DPA rate }=C \int \Phi(E) R_{m}(E) d E
$$

where,

$$
C=\eta / 2 E d
$$

$\int \Phi(E) \operatorname{Rm}(E) d E=$ total damage energy.

The DPA cross section would be calculated by:

$$
\sigma_{\mathrm{DPA}}=\frac{\int \Phi(\mathrm{E}) \mathrm{R}_{\mathrm{m}}(\mathrm{E}) \mathrm{dE}}{\int \Phi(\mathrm{E}) \mathrm{dE}}
$$

The resulting cross section has units of MeV-barns per atom.

Therefore, using the MCNP tallies, the DPA rate is calculated by converting the flux multiplier result to units of $\mathrm{MeV}-\mathrm{cm}^{2}$ per atom, then multiplying by the efficiency $(\eta)$ and dividing by 2 times the cutoff energy $\left(E_{d}\right)$ then using the standard tally conversion factors:

$$
D P A \text { rate }=F M n \times \frac{\eta}{2 E_{d}} \times \text { Flux Normalization Factor } \times \text { Core Power }
$$

The DPA cross section would be calculated using MCNP tallies by:

$$
\sigma_{D P A}=\frac{F M n}{F n}
$$

The FMn card would take the form of "FMn (1.0 mat 444)". 


\begin{tabular}{|c|c|c|c|}
\hline $\begin{array}{l}\text { EXPERIMENT DESIGN AND ANALYSIS } \\
\text { GUIDE - NEUTRONICS \& PHYSICS }\end{array}$ & $\begin{array}{l}\text { Identifier: } \\
\text { Revision: } \\
\text { Effective Date: }\end{array}$ & $\begin{array}{l}\text { GDE-594 } \\
1 \\
06 / 26 / 2014\end{array}$ & Page: 39 of 67 \\
\hline
\end{tabular}

Where mat is the material number for the material needing the DPA estimate. The cutoff energies can be found in Table II of the SPECTER-ANL manual 25:

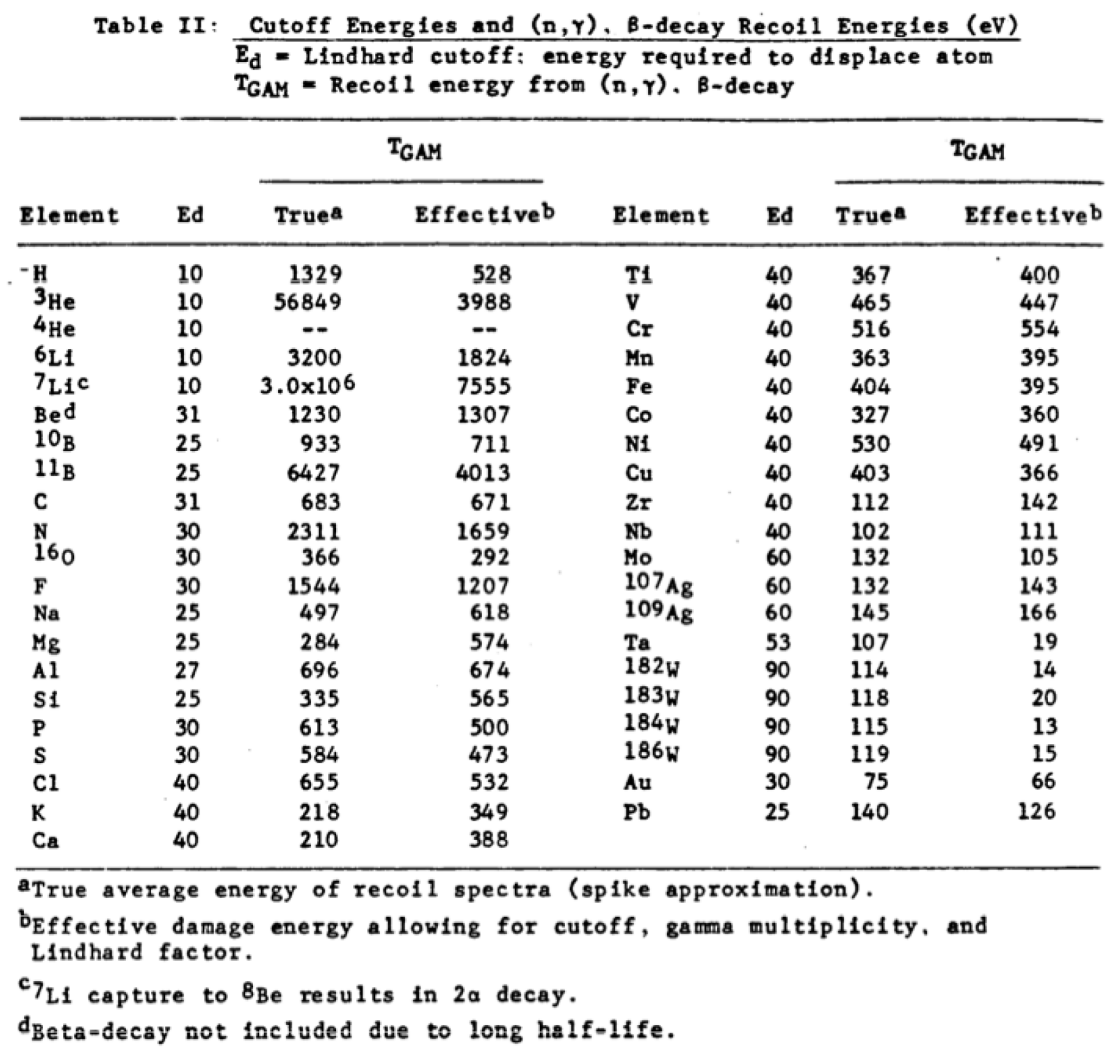

\subsection{Using existing Tabulated Cross Sections}

SPECTER-ANL is an old computer code that was used to calculate neutron damage from nuclear reactions. ${ }^{25}$ Distributed with the code are energy dependent damage cross section libraries created with the DISCS code.

The SPECTER provided cross sections can also be used in MCNP with the Energy Multiplier Card (EMn). This card scales the tally it acts on by a response function. When a tally is being recorded within energy bins the tally result is multiplied by the entry on the EMn card corresponding to that energy bin. For DPA calculations in MCNP using the EMn card, the energy bins for the type 4 tally would correspond to the energy bins for the available cross sections. Pay attention to the units of the cross sections since this will dictate the multipliers needed to get the final results.

The cross sections from Appendix A of the SPECTER ${ }^{25}$ manual are in units of KeV-b. However, the following energy bins and response function for carbon is in units of DPA-b because the cross sections from the SPECTER manual ${ }^{25}$ have already been multiplied by the efficiency factor and divided by 2 times the cutoff energy for carbon $(31 \mathrm{eV})$. The following energy bins and response function act on tally 14 (f14:n). 


\begin{tabular}{|c|lll|}
\hline $\begin{array}{c}\text { EXPERIMENT DESIGN AND ANALYSIS } \\
\text { GUIDE - NEUTRONICS \& PHYSICS }\end{array}$ & $\begin{array}{l}\text { Revision: } \\
\text { Effective Date: }\end{array}$ & $\begin{array}{l}\text { 06/26/2014 } \\
\text { Page: } 40 \text { of 67 }\end{array}$ \\
\hline
\end{tabular}

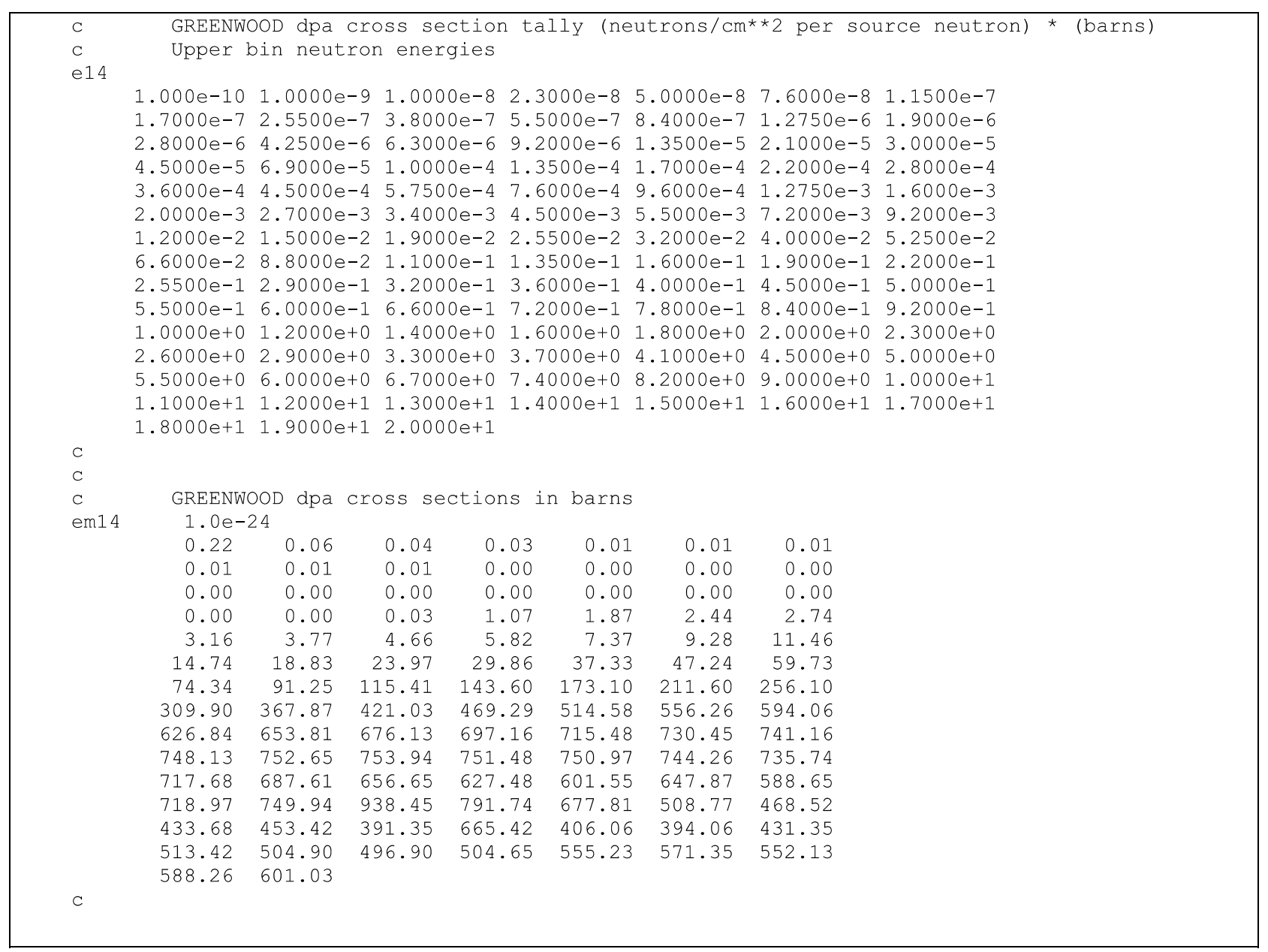

\section{SOURCE TERM CALCULATIONS}

Radionuclide inventory projections for radioactivity are typically required for each experiment. The intention is to provide an estimate of isotopic radioactivity to ensure that the experiment and hardware meet the plant protection criteria (PPC) for possible accidents as well provide assurance that the radiological waste stream created can be disposed of or removed from ATR. ORIGEN2 v2.2 is used to calculate the radionuclide source term of isotopic radioactivity for the experiments and hardware. The flux values used in the ORIGEN2 input files are obtained from MCNP calculations.

When performing projected source term calculations, the standard ATRXS library should be used. Depending upon the design of the experiment, replacement cross-section libraries can be obtained from MCNP. One-group absorption cross-sections vary from position to position within the ATR core and may also be strongly dependent upon experiment design.

Compositions that are entered into ORIGEN2 v2.2 are entered as either grams/base unit or moles/base unit. The base unit is determined by the user. The ORIGEN2 output tables report results for the base unit. For example, if the user inputs total grams of a material, the output will be Ci. If the composition is based on a single gram of material, then by virtue of the input quantity, the output will be Ci/gram, Watts/gram, etc. If a source term for total $\mathrm{Ci}$ is requested, total grams or total volume and material density must be provided to the analyst. The design engineer, the experiment manager, or the drafter can provide the total volumes and material densities to the neutronics analyst. The volumes and material densities are used to 


\begin{tabular}{|c|c|c|c|}
\hline $\begin{array}{l}\text { EXPERIMENT DESIGN AND ANALYSIS } \\
\text { GUIDE - NEUTRONICS \& PHYSICS }\end{array}$ & $\begin{array}{l}\text { Identifier: } \\
\text { Revision: } \\
\text { Effective Date: }\end{array}$ & $\begin{array}{l}\text { GDE-594 } \\
1 \\
06 / 26 / 2014\end{array}$ & Page: 41 of 67 \\
\hline
\end{tabular}

generate mass values for the source term calculations. These mass values should be listed in the physics ECAR with a reference or discussion regarding the basis and derivation of the mass values.

The radionuclide inventory radioactivity output tables (table 7) are specified in the ORIGEN2 input file using the OPTL, OPTA, and OPTF output options. The radioactivity source term has units of curies per input base unit and can be provided as $\mathrm{Ci}, \mathrm{Ci} / \mathrm{gram}$, or $\mathrm{Ci} / \mathrm{cc}$, depending the need and application. The radionuclide inventory radioactivity source should be provided isotopically.

For fueled experiments where depletion is included in the analysis, the ORIGEN2 input base unit is typically one cubic centimeter, therefore the output will have units of $\mathrm{Ci} / \mathrm{cc}$ or moles/cc, which allows for a consistent input into MCNP when coupling the two codes. In this case, the input into ORIGEN2 v2.2 is based on density of the fuel.

The decay heat for radionuclide inventory the source term can be calculated by ORIGEN2. The decay heat output tables (table 9) are generated by specifying the OPTL, OPTA, and OPTF output options in the ORIGEN2 input file. The decay heat for the radionuclide inventory source term has units of watts per the input base unit as the radionuclide inventory and can be provided as $\mathrm{W}, \mathrm{W} / \mathrm{cc}$, or W/gram. The decay heat source term should be provided for the totals only and not isotopically.

\subsection{MCNP Neutron Flux and Cross-Section Calculations}

The neutron flux for each experiment can be calculated using MCNP and the type 4 tally (f4) card in MCNP, which is average flux over a cell. The MCNP $\mathrm{f} 4$ tally has units of $1 / \mathrm{cm}^{2}$ per source neutron. The results from MCNP are then used to provide the neutron flux to ORIGEN2 v2.2 for the source term. The following normalization factor is used to calculate neutron flux from the MCNP output.

$$
\begin{gathered}
\mathrm{NFCF}=\left(\frac{2.43 \text { fission neutrons }}{\text { fission }}\right)\left(\frac{\text { fission }}{200 \mathrm{MeV}}\right)\left(\frac{\mathrm{MeV}}{1.60219 \times 10^{-13} \mathrm{~J}}\right)\left(\frac{\mathrm{J}}{\mathrm{W}-\mathrm{sec}}\right)\left(\frac{1 \times 10^{6} \mathrm{~W}}{\mathrm{MW}}\right) \\
\mathrm{NFCF}=7.583 \times 10^{16} \frac{\text { fission neutrons }}{\mathrm{MW}-\mathrm{sec}}
\end{gathered}
$$

Experiments containing significant amounts of neutron absorbing material, which could significantly alter the spectrum or fueled experiments may require modified cross-section libraries of interest. MCNP is used to calculate the one-group cross-section that may be entered into ORIGEN2 v2.2. The crosssections may be determined from MCNP using the flux tally with a multiplier card, where the reaction rate of isotope of interest is entered. The tally multiplier card applied to a flux tally calculates the reaction rate defined in MCNP as:

$$
R R=C \int \varnothing(E) R_{m}(E) d E
$$

where

$C=$ Multiplicative constant (set to 1 for cross section calculations)

$\emptyset(E)=$ Energy dependent Flux

$R_{m}=$ energy dependent reaction rate of interest

The standard MCNP flux tally calculates the quantity:

$$
\text { Flux }=\int \varnothing(E) d E
$$




\begin{tabular}{|c|lll|}
\hline $\begin{array}{c}\text { EXPERIMENT DESIGN AND ANALYSIS } \\
\text { GUIDE - NEUTRONICS \& PHYSICS }\end{array}$ & Revision: & \multicolumn{1}{l|}{ GDE-594 } & \\
& Effective Date: & $06 / 26 / 2014$ & Page: 42 of 67 \\
\hline
\end{tabular}

In order to obtain the 1-group reaction cross-section, the user simply divides the reaction rate (RR) by the flux.

\subsection{ORIGEN2 Version 2.2 Input file}

An example ORIGEN2 input file is shown in Figure 4. Users should be aware of the how material compositions and replacement cross-section libraries are entered. Compositions and cross-sections can be entered in the ORIGEN2 input file or as separate files. Compositions can be entered in the TAPE4.INP file in the same format as the ORIGEN2 v2.2 input file. The cross-sections can be entered in as a TAPEX.INP file. Users should consult the ORIGEN2 v2.2 manual for format and input requirements.

The composition output tables (table 5) are generated by specifying the OPTL, OPTA, and OPTF output options in the ORIGEN2 input file. The ORIGEN2 composition table output results should be used to verify radionuclide inventory input compositions both isotopically and total. The composition output tables have units of mass per input base unit, grams, grams/cc or gram/gram (i.e. 1 gram of material). If the ORIGEN2 input is entered as total mass, then the total mass and isotopics reported by the output should be identical. If the ORIGEN2 input has a base unit of cc, then the total ( $\mathrm{gram} / \mathrm{cc}$ ) reported by the output should match the input composition density. If the ORIGEN2 input has a base unit of 1 gram, then the total (grams/gram) reported by the output should be 1 gram.

\subsection{ORIGEN2 Version 2.2 Output}

ORIGEN2 v2.2 provides a large amount of data to the user. Curies, watts, grams, moles, and photon production are several items that may be used in the physics analysis. The output from ORIGEN2 v2.2 can be provided in a summary table, where the user specifies the fractional importance of isotopes that are reported in the summary table. Using the CUT card in ORIGEN2 v2.2, the user specifies at which fraction of the total isotopic value a specific isotope contributes. The values selected are up to the user to input into the ORIGEN2 input file, output files should be reviewed to ensure the value used is not too high. This can be done by examining the Summary Table and the SUMTOT line provides the results with the CUT card, while the OTOTAL line provides the total values. If these values differ significantly, the CUT card should be adjusted and the input model re-ran to obtain better results.

When using ORIGEN2 v2.2, the user and technical checker should review the output file to ensure time steps are consistent with the input file and the mass values reported in the output file are consistent with the input. Input errors in the ORIGEN2 input file can result in a file that will run, but may yield incorrect results that may appear to be correct. 


\begin{tabular}{|c|lll|}
\hline $\begin{array}{c}\text { EXPERIMENT DESIGN AND ANALYSIS } \\
\text { GUIDE - NEUTRONICS \& PHYSICS }\end{array}$ & Revision: & \multicolumn{1}{l|}{ GDE-594 } & \\
& Effective Date: & $06 / 26 / 2014$ & Page: 43 of 67 \\
\hline
\end{tabular}

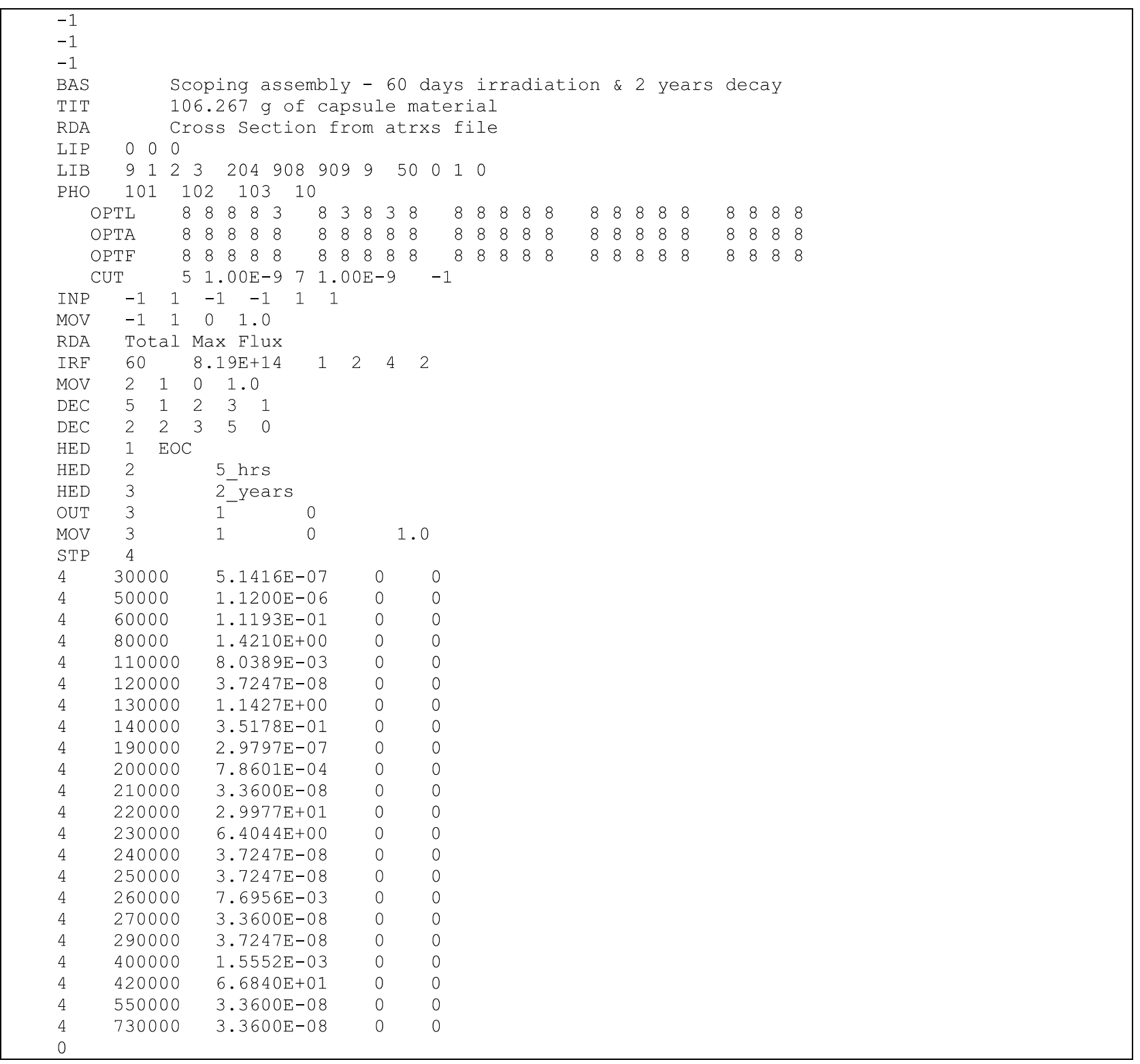

Figure 4. Sample ORIGEN2 Input File. 


\begin{tabular}{|c|c|c|c|}
\hline $\begin{array}{l}\text { EXPERIMENT DESIGN AND ANALYSIS } \\
\text { GUIDE - NEUTRONICS \& PHYSICS }\end{array}$ & $\begin{array}{l}\text { Identifier: } \\
\text { Revision: } \\
\text { Effective Date: }\end{array}$ & $\begin{array}{l}\text { GDE-594 } \\
1 \\
06 / 26 / 2014\end{array}$ & Page: 44 of 67 \\
\hline
\end{tabular}

\section{REFERENCES}

1. SAR-153, "Upgraded Final Safety Analysis Report for the Advanced Test Reactor."

2. MCNP Team, "MCNP 5.1.40 RSICC Release Notes," LA-UR-05-8617 November 2005.

3. X-5 Monte Carlo Team, "MCNP-A General Monte Carlo N-Particle Transport Code, Version 5," Volume I, LA-UR-03-1987, Los Alamos National Laboratory, April 24, 2003 (Revised 10/3/05) and Volume II, LA-CP-0245, Los Alamos National Laboratory, April 24, 2003 (Revised 10/3/05) (Vol. II is available with a licensed copy of MCNP).

4. M. A. Lillo, J. R. Mitchell, "Software Management, MCNP Version 5, Release 1.40," INL/INT-08-15171 Rev. 0, August 2010, INL Record Number 234166.

5. GDE-168, "Evaluation of Capsule Experiments," Rev. 3, September 10, 2013.

6. GDE-185, "Selection of ATR Fuel Loading," Rev. 1, May 282013.

7. GDE-186, "Shim Positions for Criticality," Rev. 0, January 10, 2012.

8. GDE-187, "Holddown Reactivity Margin," Rev. 0, June 12, 2013.

9. E. T. Boulette, W. L. Bunch, "Analysis of ZPPR/FTR Shield Experiments Gamma Distributions," WHAN-FR-13, February 1971.

10. M. A. Lillo, J. R. Mitchell, "Software Management, MCNP Version 5, Release 1.40," INL/INT-08-15171 Rev. 0, August 2010, INL Record Number 234166.

11. S. S. Kim, B. G. Schnitzler, "Advanced Test Reactor: Serpentine Arrangement of Highly Enriched Water-Moderated Uranium-Aluminide Fuel Plates Reflected by Beryllium," INL/EXT-05-00780, September 2005; published in "International Handbook of Evaluated Criticality Safety Benchmark Experiments," NEA/NSC/DOC/(95)03/II, Volume II, HEU-MET-THERM-022, September 2005 Edition.

12. Forrest Brown, "The makxsf Code with Doppler Broadening," LA-UR-06-7002, Los Alamos National Laboratory, 2006 (see Attachment C).

13. J. J. Duderstadt and L. J. Hamilton, "Nuclear Reactor Analysis," John Wiley \& Sons, New York, 1976 (see Attachment A).

14. J. R. Lamarsh, "Introduction to Nuclear Engineering, $2^{\text {nd }}$ Edition," Addison-Wesley Publishing Company, Inc., 1983 (see Attachment A).

15. ANC, 1973, E. C. Anderson, et. Al., “ATR Operating Envelope Extension,” TR-386, Volume II, Aerojet Nuclear Company, Engineering Division, May 1973.

16. G. F. Knoll, "Radiation Detection and Measurement, Second Edition," John Wiley \& Sons, New York, 1989 (see Attachment A).

17. J. R. Taylor, "An Introduction to Error Analysis, The Study of Uncertainties in Physical Measurements, Second Edition," University Science Books, 1997

18. T. A. Tomberlin, "Advanced Test Reactor Critical Facility Measurements in Support of Advanced Test Reactor Experiments," TRA-ATR-1546, Rev. 0, March 2000.

19. M. A. Lillo, J. W. Nielsen, "Validation of MCNP Axial Fission Profile Calculations with Acceptance Criteria for Axial Perturbations," ECAR-581, Rev. 0, April 2009 


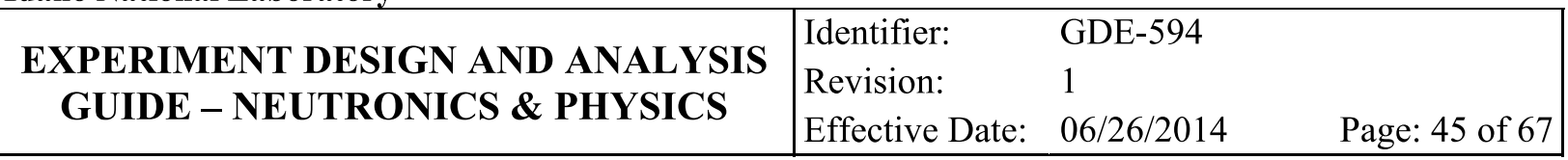

20. J. R. Jimenez, "Methodology For Determining ATR Center Lobe Power For Use In The Integrated Strategic Operational Plan (ISOP)," TEV-288 Rev. 1, June 22, 2011.

21. D. E. Hale, “Advanced Test Reactor (ATR) Power History Through Cycle 133B-1,” DEH-05-04, August 18, 2004 (see Attachment G).

22. D. E. Hale, "Advanced Test Reactor (ATR) Power History Through Cycle 150B-1, Revision 1" DEH-05-11, Rev. 1, December 1, 2011 (see Attachment H).

23. R. E. MacFarlane, D. W. Muir, "The NJOY Nuclear Data Processing System," Version 91, LA12740-M, Los Alamos National Laboratory, 1994.

24. R. E. MacFarlane, "Recent Progress on NJOY," LA-UR-96-4688, Los Alamos National Laboratory, 1996.

25. L. R. Greenwood and R. K. Smither, "SPECTER: Neutron Damage Calculations For Materials Irradiations," ANL/FPP/TM-197 (January 1985). 


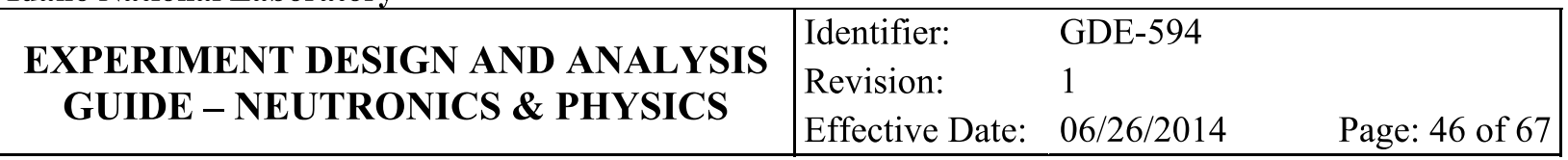

\section{Attachment A}

\section{Scanned References}

Page scanned from Reference 13, J. J. Duderstadt and L. J. Hamilton, "Nuclear Reactor Analysis," John Wiley \& Sons, New York, 1976 (see Attachment A).

\section{2 / THE ONE-SPEED DIFFUSION MODEL OF A NUCLEAR REACTOR}

define the adjoint flux $\phi^{\dagger}$ as the corresponding solution of

$$
M^{\dagger} \phi^{\dagger}=\frac{1}{k} F^{\dagger} \phi^{\dagger}
$$

(Although again we keep in mind that $M^{\dagger}=M$ and $F^{\dagger}=F$ implies that $\phi^{\dagger}=\phi$ for the one-speed diffusion model of a reactor.)

To understand the application of these concepts, let us go back to the criticality equation (5-283). Now suppose we were to perturb the macroscopic absorption cross section, say by adding a localized absorber, to a new value

$$
\Sigma_{\mathrm{a}}^{\prime}(\mathbf{r})=\Sigma_{\mathrm{a}}(\mathbf{r})+\delta \Sigma_{\mathrm{a}}(\mathbf{r}) .
$$

We will assume that this perturbation $\delta \Sigma_{\mathrm{a}}(\mathbf{r})$ is small and attempt to calculate the corresponding change in $k$ as governed by the perturbed criticality problem

$$
M^{\prime} \phi^{\prime}=\frac{1}{k^{\prime}} F \phi^{\prime} .
$$

Note here that the perturbation in the core absorption appears as a perturbation $\delta M$ in the diffusion operator

$$
M^{\prime}=M+\delta M, \quad \delta M^{\circ} \equiv \delta \Sigma_{\mathrm{a}}(\mathbf{r})^{\circ} .
$$

To calculate the change in $k$, first take the scalar product of Eq. (5-296) with the adjoint flux $\phi^{\dagger}$ characterizing the unperturbed core, that is, satisfying Eq. (5-294),

$$
\left(\phi^{\dagger}, M \phi^{\prime}\right)+\left(\phi^{\dagger}, \delta M \phi^{\prime}\right)=\frac{1}{k^{\prime}}\left(\dot{\phi}^{\dagger}, F \phi^{\prime}\right) .
$$

Now using the definition Eq. (5-285) of the adjoint operator, we find

$$
\left(\phi^{\dagger}, M \phi^{\prime}\right)=\left(M^{\dagger} \phi^{\dagger}, \phi^{\prime}\right)=\left(\frac{1}{k} F^{\dagger} \phi^{\dagger}, \phi^{\prime}\right)=\frac{1}{k}\left(\phi^{\dagger}, F \phi^{\prime}\right) \text {. }
$$

Hence we find

$$
\left(\frac{1}{k^{\prime}}-\frac{1}{k}\right)=\frac{\left(\phi^{\dagger}, \delta M \phi^{\prime}\right)}{\left(\phi^{\dagger}, F \phi^{\prime}\right)}
$$

We could now calculate $\delta k=k^{\prime}-k$. However it is far more convenient to define the core reactivity

$$
\rho \equiv \frac{k-1}{k},
$$

which essentially measures the deviation of the core multiplication from unity. Then since the perturbation in reactivity is just

$$
\Delta \rho=\rho^{\prime}-\rho=\frac{k^{\prime}-1}{k^{\prime}}-\frac{k-1}{k}=\left(\frac{1}{k}-\frac{1}{k^{\prime}}\right),
$$




\begin{tabular}{|c|lll|}
\hline $\begin{array}{c}\text { EXPERIMENT DESIGN AND ANALYSIS } \\
\text { GUIDE - NEUTRONICS \& PHYSICS }\end{array}$ & Revision: & \multicolumn{1}{l|}{ GDE-594 } & \\
& Effective Date: & $06 / 26 / 2014$ & Page: 47 of 67 \\
\hline
\end{tabular}

Page scanned from Reference 14, J. R. Lamarsh, "Introduction to Nuclear Engineering, $2^{\text {nd }}$ Edition," Addison-Wesley Publishing Company, Inc., 1983 (see Attachment A).

\section{The Time-Dependent Reactor}

tor as far as the prompt neutrons are concerned is actually $(1-\beta) k$. Therefore, when

$$
(1-\beta) k=1,
$$

the reactor is critical on prompt neutrons alone, and the reactor is said to be prompt critical. In this case, the period is very short, as it was in Example 7.2.

The reactivity corresponding to the prompt critical condition can be found by inserting $k=1 /(1-\beta)$ from Eq. (7.33) into Eq. (7.25). This, it is easy to see, gives

$$
\rho=\beta,
$$

as the condition for prompt criticality. Thus since $\beta=0.0065$ for fission induced by thermal neutrons in ${ }^{235} \mathrm{U}, a^{235} \mathrm{U}$ fueled thermal reactor becomes prompt critical with the addition of only about 0.0065 , or 0.65 percent in reactivity.

Because reactors go onto such short periods when they are prompt critical, it is normal practice to restrict (positive) reactivity additions to less than $\beta$. There are some research reactors, however, with intrinsic properties that cause them to shut down rapidly when they become supercritical. When these reactors are suddenly caused to become prompt critical, they deliver sharp pulses of neutrons.

The amount of reactivity necessary to make a reactor prompt critical, namely, $\rho=\beta$, is used to define a unit of reactivity known as the dollar. Since the value of $\beta$ varies from fuel to fuel, the dollar is not an absolute unit. Values of the delayed neutron fractions for the most important fissile and fertile isotopes are given in Table 7.2. For example, a dollar is worth 0.0065 in reactivity for a ${ }^{235} \mathrm{U}$ fueled reactor, but it is worth only $\beta=0.0026$ for a ${ }^{233} \mathrm{U}$ fueled reactor. The reactivity equivalent to one one-hundredth of a dollar is called a cent.

Example 7.5 The reactivity of the reactor in Example 7.3 is 0.001 . If the reactor is fueled with ${ }^{235} \mathrm{U}$, what is its reactivity in dollars?

Solution. The value of $\beta$ is 0.0065 . Thus $\rho$ is

$$
\begin{aligned}
\rho=\frac{0.001}{0.0065} & =0.154 \text { dollars } \\
& =15.4 \text { cents. }[\text { Ans. }]
\end{aligned}
$$

\section{The Prompt Jump (Drop)}

Following a sudden change in multiplication factor, a previously critical reactor exhibits a behavior given by Eq. (7.27), namely,

$$
\phi=A_{1} e^{\omega_{1} t}+A_{2} e^{\omega_{2} t}
$$

in the one-delayed-group model and by a sum of seven exponentials in the more realistic case of six delayed groups. As explained earlier, the second term in Eq. (7.27) dies away quickly and the flux then reduces to the first term, rising or falling 


\begin{tabular}{|c|lll|}
\hline $\begin{array}{c}\text { EXPERIMENT DESIGN AND ANALYSIS } \\
\text { GUIDE - NEUTRONICS \& PHYSICS }\end{array}$ & Revision: & \multicolumn{1}{l|}{ GDE-594 } & \\
& Effective Date: & $06 / 26 / 2014$ & Page: 48 of 67 \\
\hline
\end{tabular}

Page scanned from Reference 16, G. F. Knoll, "Radiation Detection and Measurement, Second Edition," John Wiley \& Sons, New York, 1989 (see Attachment A).

calculations and is reflected as a corresponding uncertainty in the derived quantity. It can be shown ${ }^{3}$ that if the errors are individually small and symmetric about zero, a general result can be obtained for the expected error to be associated with any quantity that is directly measured counts of any number of independent variables. If $x, y, z, \ldots$ are direch ver whow $\sigma_{x}, \sigma_{y}, \sigma_{z}, \ldots$, then the standard deviation for any quantity $u$ derived from these counts can be calculated from

$$
\sigma_{u}^{2}=\left(\frac{\partial u}{\partial x}\right)^{2} \sigma_{x}^{2}+\left(\frac{\partial u}{\partial y}\right)^{2} \sigma_{y}^{2}+\left(\frac{\partial u}{\partial z}\right)^{2} \sigma_{z}^{2}+\cdots
$$

where $u=u(x, y, z, \ldots)$ represents the derived quantity. Equation (3-37) is generally known as the error propagation formula and is applicable to almost all situations in nuclear measurements. The variables $x, y, z, \ldots$, however, must be chosen so that they are truly independent in order to avoid the effects of correlation. The same specific count should not contribute to the value of more than one such variable. The use of Eq. (3-37) can be illustrated by application to some simple cases.

\section{Case 1. Sums or Differences of Counts}

If we define

$$
u=x+y \quad \text { or } \quad u=x-y
$$

then

$$
\frac{\partial u}{\partial x}=1 \text { and } \frac{\partial u}{\partial y}= \pm 1
$$

Application of Eq. (3-37) yields

$$
\sigma_{u}^{2}=(1)^{2} \sigma_{x}^{2}+( \pm 1)^{2} \sigma_{y}^{2}
$$

or

$$
\sigma_{u}=\sqrt{\sigma_{x}^{2}+\sigma_{y}^{2}}
$$

A common application of this case arises when counts due to a radioactive source must be corrected by subtracting an appropriate background count. If we assume equal counting times, then

$$
\text { net counts }=\text { total counts }- \text { background counts }
$$

or

$$
u=x-y
$$

Because both $x$ and $y$ are directly measured numbers of counts (or successes), the expected standard deviation of each is known to be its own square root. The object is to deduce the expected standard deviation of the net counts, a derived number. Because a simple difference is involved, the answer will be given by Eq. (3-38). 


\begin{tabular}{|c|lll|}
\hline $\begin{array}{c}\text { EXPERIMENT DESIGN AND ANALYSIS } \\
\text { GUIDE - NEUTRONICS \& PHYSICS }\end{array}$ & Revision: & \multicolumn{1}{l|}{ GDE-594 } & \\
& Effective Date: & $06 / 26 / 2014$ & Page: 49 of 67 \\
\hline
\end{tabular}

Page scanned from Reference 17, J. R. Taylor, "An Introduction to Error Analysis, The Study of Uncertainties in Physical Measurements, Second Edition,” University Science Books, 1997.

\section{THE GENERAL CASE}

Having justified the error-propagation formula for the special case of a sum $x+y$, we can justify the general formula for error propagation surprisingly simply. Suppose we measure two independent quantities $x$ and $y$ whose observed values are normally distributed, and we now calculate some quantity $q(x, y)$ in terms of $x$ and $y$. The distribution of values of $q(x, y)$ is found easily by using the results from steps I through III as follows:

First, the widths $\sigma_{x}$ and $\sigma_{y}$ (the uncertainties in $x$ and $y$ ) must, as always, be small. This requirement means that we are concerned only with values of $x$ close to $X$ and $y$ close to $Y$, and we can use the approximation (3.42) to write

$$
q(x, y) \approx q(X, Y)+\left(\frac{\partial q}{\partial x}\right)(x-X)+\left(\frac{\partial q}{\partial y}\right)(y-Y) .
$$

This approximation is good because the only values of $x$ and $y$ that occur significantly often are close to $X$ and $Y$. The two partial derivatives are evaluated at $X$ and $Y$ and are, therefore, fixed numbers.

The approximation (5.61) expresses the desired quantity $q(x, y)$ as the sum of three terms. The first term $q(X, Y)$ is a fixed number, so it merely shifts the distribution of answers. The second term is the fixed number $\partial q / \partial x$ times $(x-X)$, whose distribution has width $\sigma_{x}$, so the values of the second term are centered on zero, with width

$$
\left(\frac{\partial q}{\partial x}\right) \sigma_{x}
$$

Similarly, the values of the third term are centered on zero with width

$$
\left(\frac{\partial q}{\partial y}\right) \sigma_{y}
$$

Combining the three terms in (5.61) and invoking the results already established, we conclude that the values of $q(x, y)$ are normally distributed about the true value $q(X, Y)$ with width

$$
\sigma_{q}=\sqrt{\left(\frac{\partial q}{\partial x} \sigma_{x}\right)^{2}+\left(\frac{\partial q}{\partial y} \sigma_{y}\right)^{2}}
$$

If we identify the standard deviations $\sigma_{x}$ and $\sigma_{y}$ as the uncertainties in $x$ and $y$, the result (5.62) is precisely the rule (3.47) for propagation of random errors, for the case when $q$ is a function of just two variables, $q(x, y)$. If $q$ depends on several variables, $q(x, y, \ldots, z)$, the preceding argument can be extended immediately to establish the general rule (3.47) for functions of several variables. Because the rules of Chapter 3 concerning propagation of random errors can be derived from (3.47), they are all now justified. 


\begin{tabular}{|c|lll|}
\hline EXPERIMENT DESIGN AND ANALYSIS & Identifier: & GDE-594 & \\
GUIDE - NEUTRONICS \& PHYSICS & Revision: & 1 & \\
& Effective Date: & $06 / 26 / 2014$ & Page: 50 of 67 \\
\hline
\end{tabular}

Page scanned from J. R. Parry MCNP Notebook.

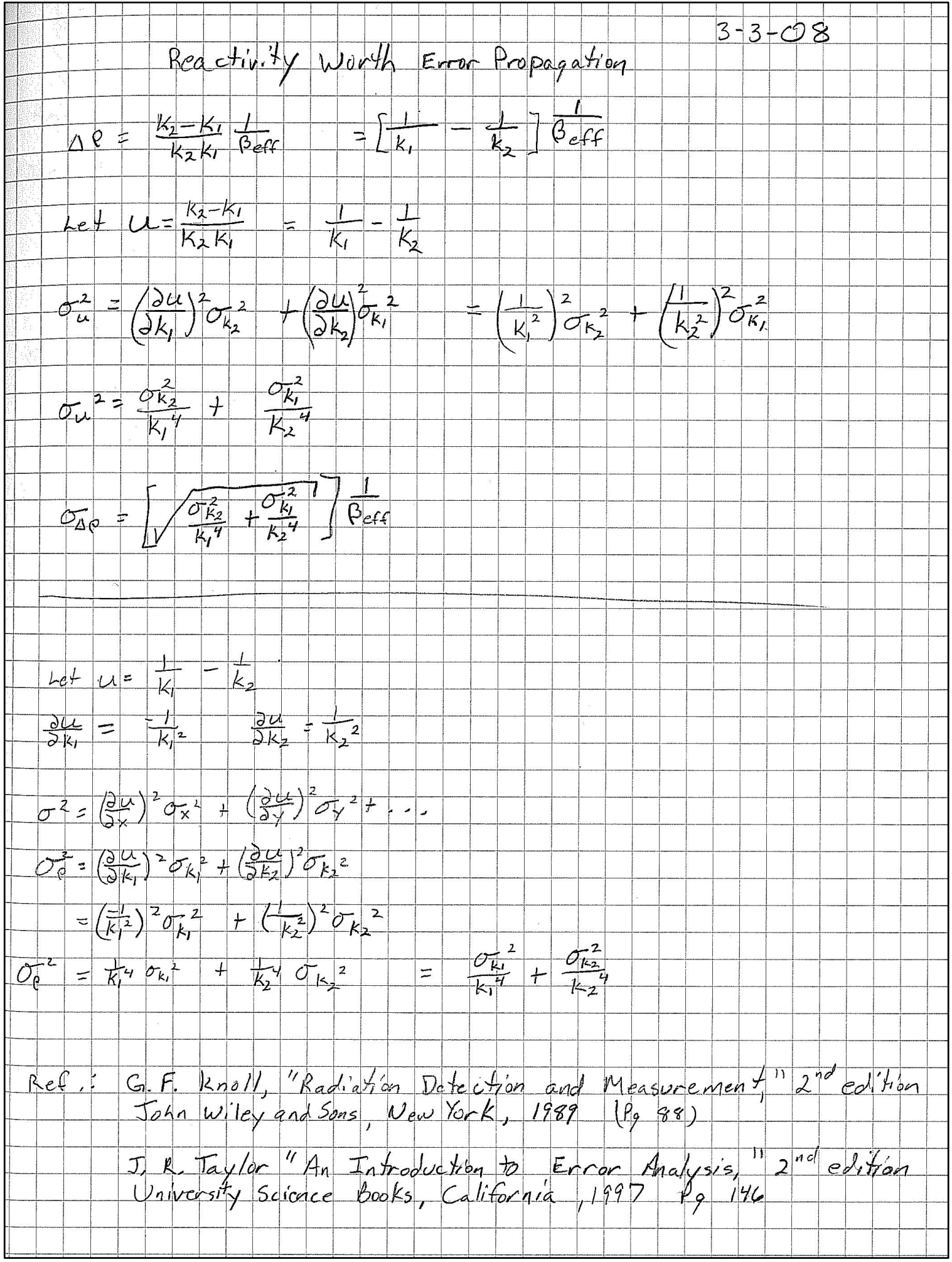




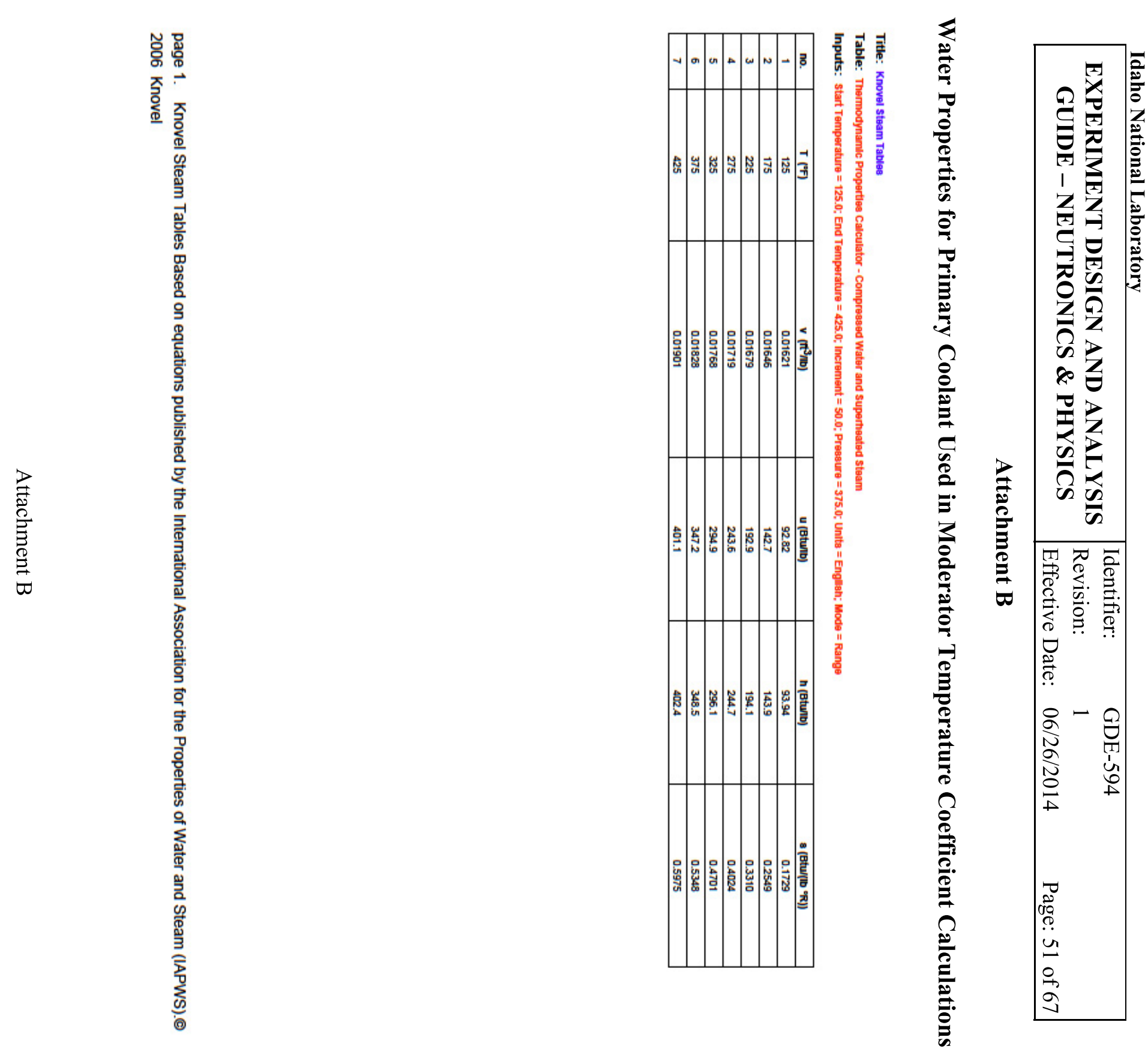




\begin{tabular}{|c|c|c|c|}
\hline $\begin{array}{l}\text { EXPERIMENT DESIGN AND ANALYSIS } \\
\text { GUIDE - NEUTRONICS \& PHYSICS }\end{array}$ & $\begin{array}{l}\text { Identifier: } \\
\text { Revision: } \\
\text { Effective Date: }\end{array}$ & $\begin{array}{l}\text { GDE-594 } \\
1 \\
06 / 26 / 2014\end{array}$ & Page: 52 of 67 \\
\hline
\end{tabular}

\section{Attachment C}

\section{Example of makxsf input file (specs)}

The makxsf input file (specs)

\#

\# test for new makxsf

\#

\#

\# old-xsdir new-xsdir

testdir1 testdir2

\#

\# copy selected xs-tables to testlib2, type2 atrhtmp 1

1001.11c 324.82 1001.70c 1001.71c $1001.12 \mathrm{c} 352.591001 .70 \mathrm{c} 1001.71 \mathrm{c}$ $1001.13 \mathrm{c} \quad 380.371001 .70 \mathrm{c} 1001.71 \mathrm{c}$ $1001.14 \mathrm{c} 408.151001 .70 \mathrm{c} 1001.71 \mathrm{c}$ $1001.15 \mathrm{c} \quad 435.931001 .70 \mathrm{c} 1001.71 \mathrm{c}$ $1001.16 \mathrm{c} \quad 463.711001 .70 \mathrm{c} 1001.71 \mathrm{c}$ $1001.17 \mathrm{c} \quad 491.481001 .70 \mathrm{c} 1001.71 \mathrm{c}$

atr70sab 1

lwtr.30t 324.82 lwtr.10t lwtr.11t lwtr.31t 352.59 lwtr.11t lwtr.12t lwtr.32t 380.37 lwtr.11t lwtr.12t lwtr.33t 408.15 lwtr.12t lwtr.13t lwtr.34t 435.93 lwtr.12t lwtr.13t lwtr.35t 463.71 lwtr.13t lwtr.14t lwtr.36t 491.48 lwtr.13t lwtr.14t

afipu 1

$92235.91 \mathrm{c} 41092235.12 \mathrm{c} 92235.13 \mathrm{c}$ $92235.92 \mathrm{c} 43392235.12 \mathrm{c} 92235.13 \mathrm{c}$ $92235.93 \mathrm{c} 45592235.12 \mathrm{c} 92235.13 \mathrm{c}$ $92235.94 \mathrm{c} 47892235.12 \mathrm{c} 92235.13 \mathrm{c}$ $92238.91 \mathrm{c} 41092238.12 \mathrm{c} 92238.13 \mathrm{c}$ $92238.92 \mathrm{c} 43392238.12 \mathrm{c} 92238.13 \mathrm{c}$ $92238.93 \mathrm{c} 45592238.12 \mathrm{c} 92238.13 \mathrm{c}$ $92238.94 \mathrm{c} 47892238.12 \mathrm{c} 92238.13 \mathrm{c}$ 


\begin{tabular}{|c|c|c|c|}
\hline $\begin{array}{l}\text { EXPERIMENT DESIGN AND ANALYSIS } \\
\text { GUIDE - NEUTRONICS \& PHYSICS }\end{array}$ & $\begin{array}{l}\text { Identifier: } \\
\text { Revision: } \\
\text { Effective Date: }\end{array}$ & $\begin{array}{l}\text { GDE-594 } \\
1 \\
06 / 26 / 2014\end{array}$ & Page: 53 of 67 \\
\hline
\end{tabular}

\section{Attachment D}

\section{Predicted CLP's from TEV-288}

Idaho National Laboratory

\begin{tabular}{c|l|ll|} 
METHODOLOGY FOR DETERMINING & Identifier: & TEV-288 & \\
ATR CENTER LOBE POWER FOR USE & Revision: & 1 \\
IN THE INTEGRATED STRATEGIC & Effective Date: & $06 / 22 / 11$ & Page: 13 of 13 \\
OPERATIONAL PLAN (ISOP) & & \\
\hline
\end{tabular}

Appendix D: Predicted Center Lobe Power for a Given Total Corner Lobe Power

\begin{tabular}{|c|c|c|}
\hline $\begin{array}{l}\text { Total } \\
\text { Corner } \\
\text { Lobe } \\
\text { Power }\end{array}$ & $\begin{array}{c}\text { Predicted } \\
\text { Nominal } \\
\text { Startup } \\
\text { Center } \\
\text { Power }\end{array}$ & $\begin{array}{c}\text { Predicted } \\
\text { Worst } \\
\text { Case } \\
\text { Startup } \\
\text { Center } \\
\text { Power }\end{array}$ \\
\hline 75 & 19.7 & 23.2 \\
\hline 76 & 20.6 & 24.1 \\
\hline 77 & 21.5 & 24.9 \\
\hline 78 & 22.4 & 25.8 \\
\hline 79 & 23.3 & 26.6 \\
\hline 80 & 24.2 & 27.5 \\
\hline 81 & 25.1 & 28.3 \\
\hline 82 & 26.0 & 29.2 \\
\hline 83 & 26.9 & 30.0 \\
\hline 84 & 27.8 & 30.9 \\
\hline 85 & 28.7 & 31.7 \\
\hline 86 & 29.6 & 32.6 \\
\hline 87 & 30.5 & 33.4 \\
\hline 88 & 31.4 & 34.3 \\
\hline 89 & 32.2 & 35.1 \\
\hline 90 & 33.1 & 36.0 \\
\hline 91 & 34.0 & 36.8 \\
\hline 92 & 34.9 & 37.7 \\
\hline 93 & 35.8 & 38.5 \\
\hline 94 & 36.7 & 39.4 \\
\hline 95 & 37.6 & 40.2 \\
\hline 96 & 38.5 & 41.1 \\
\hline 97 & 39.4 & 41.9 \\
\hline 98 & 40.3 & 42.8 \\
\hline 99 & 41.2 & 43.6 \\
\hline 100 & 42.1 & 44.5 \\
\hline 101 & 43.0 & 45.3 \\
\hline 102 & 43.9 & 46.2 \\
\hline 103 & 44.8 & 47.0 \\
\hline 104 & 45.7 & 47.9 \\
\hline 105 & 46.5 & 48.7 \\
\hline 106 & 47,4 & 49.6 \\
\hline 107 & 48.3 & 50.4 \\
\hline 108 & 49.2 & 51.3 \\
\hline 109 & 50.1 & 52.1 \\
\hline 110 & 51.0 & 53.0 \\
\hline
\end{tabular}




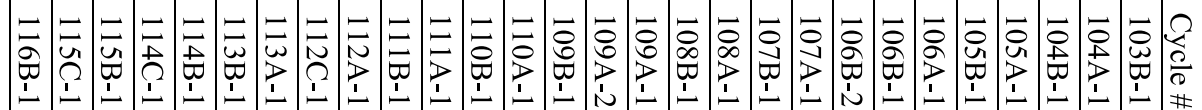

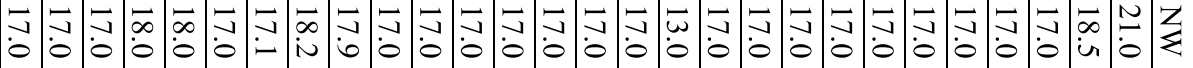

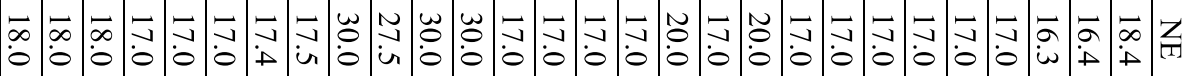

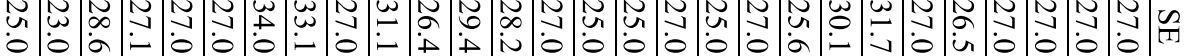

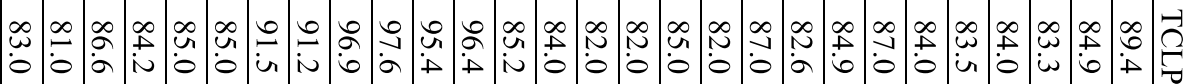

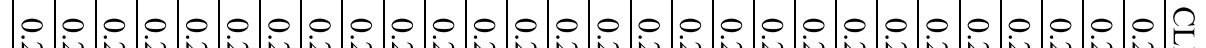

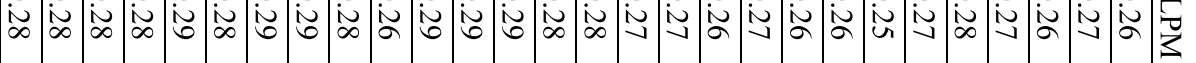

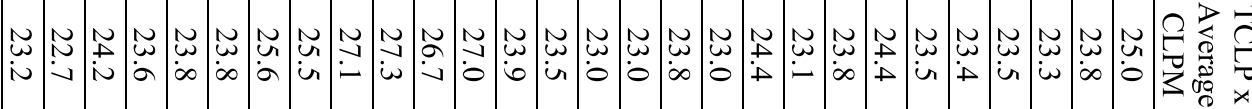

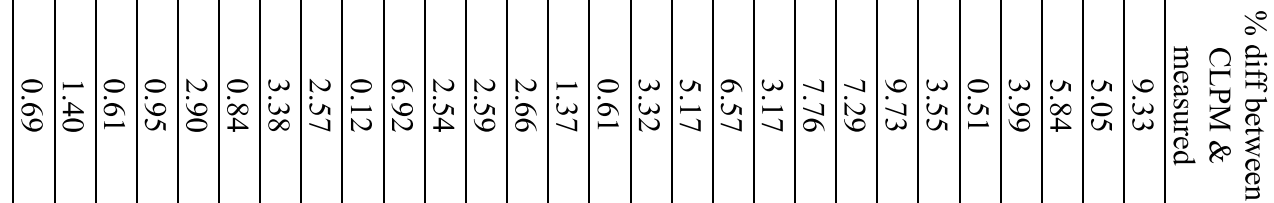

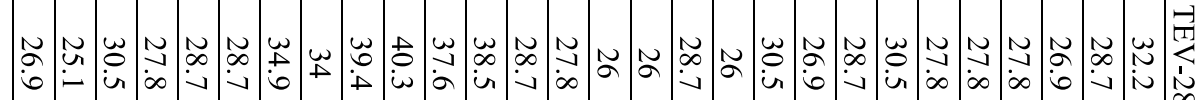

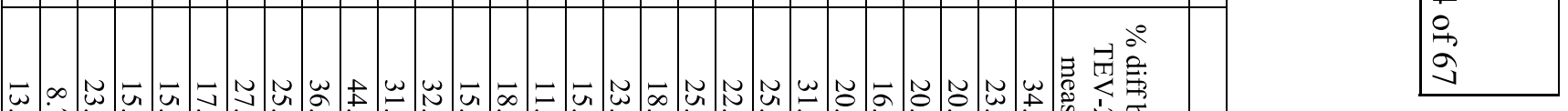

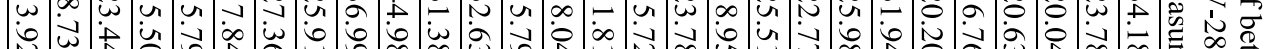

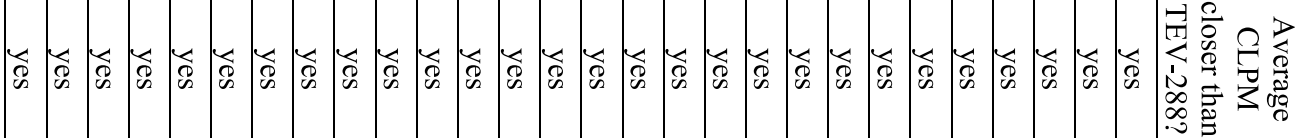




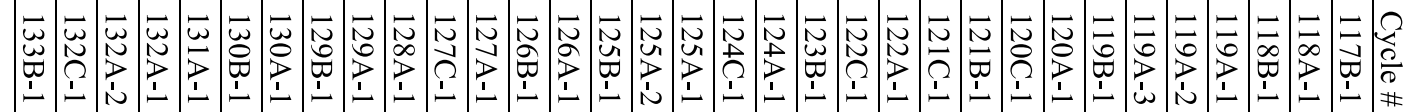

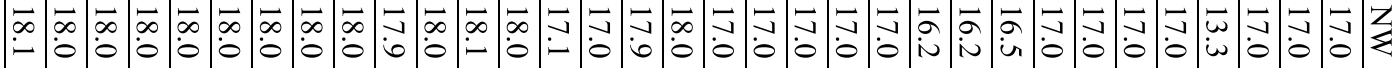

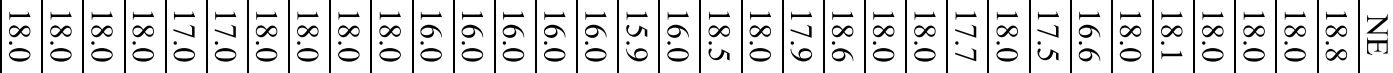

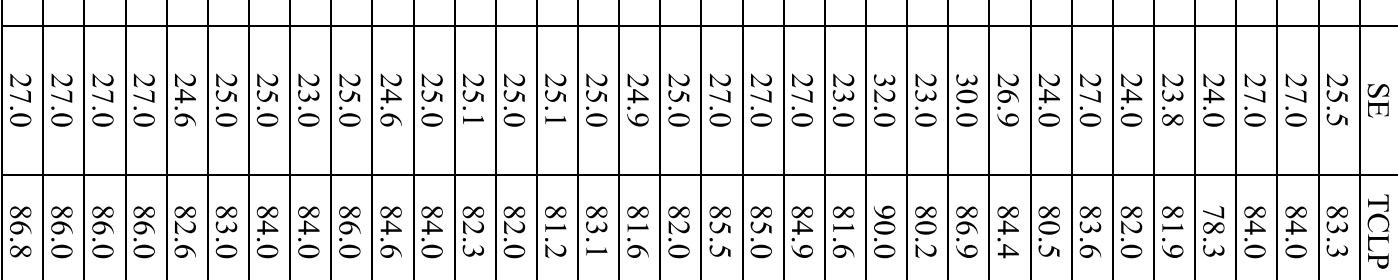

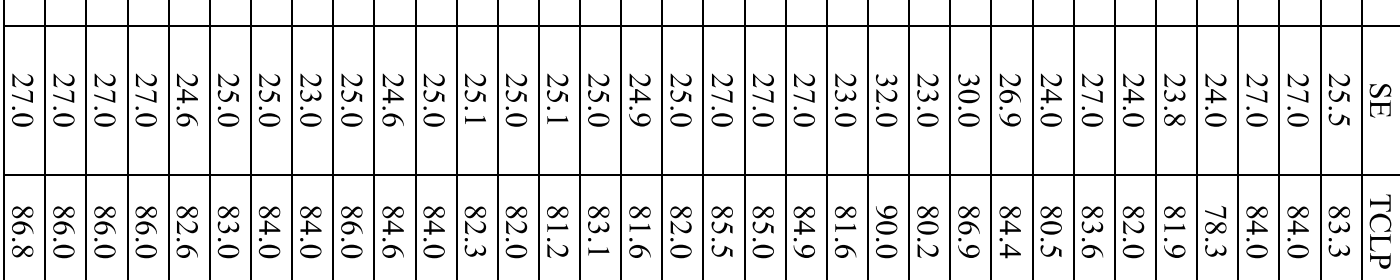

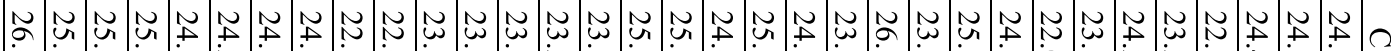

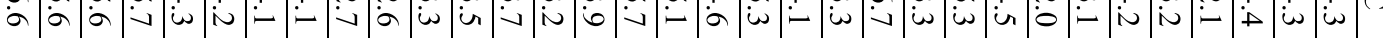

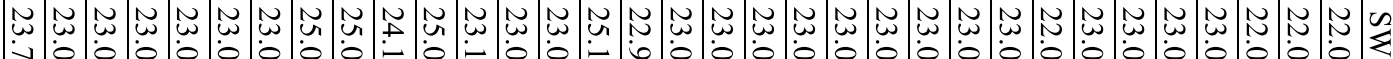

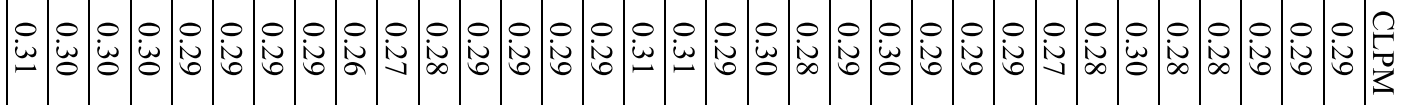

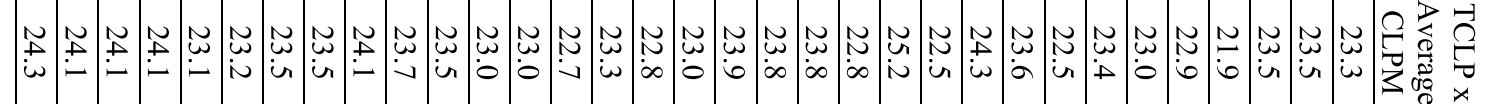

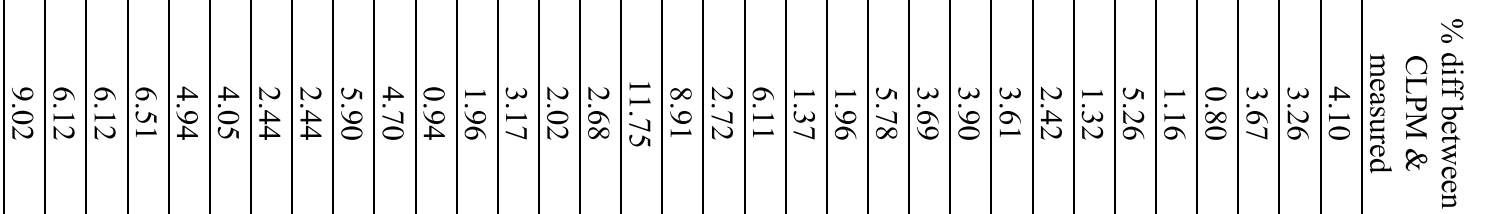

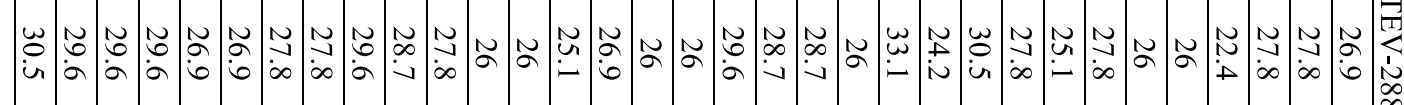

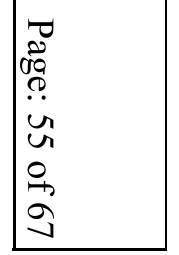

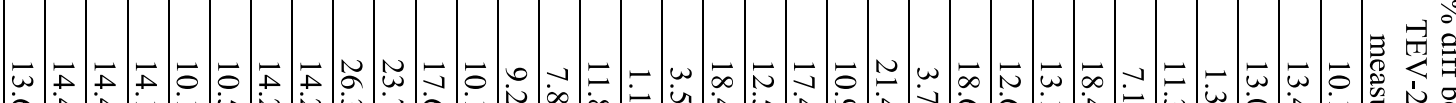

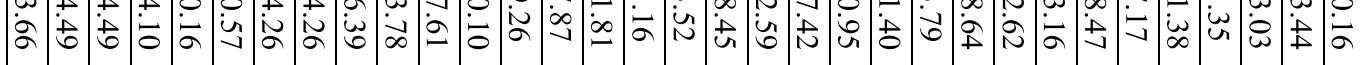

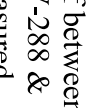

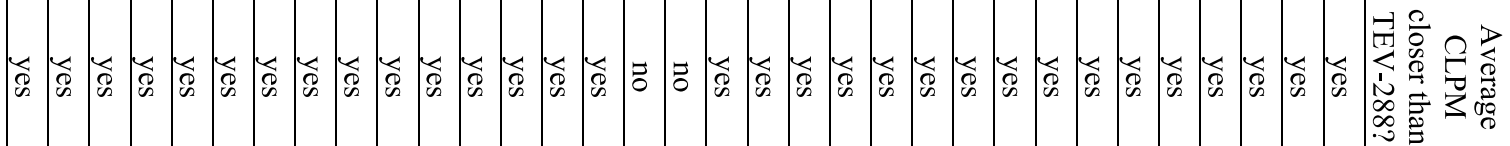




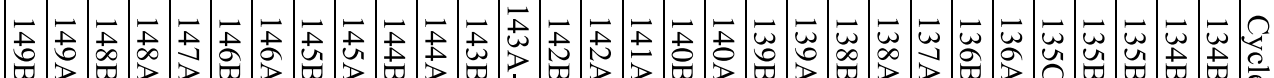

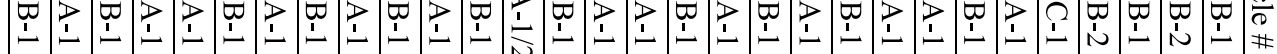

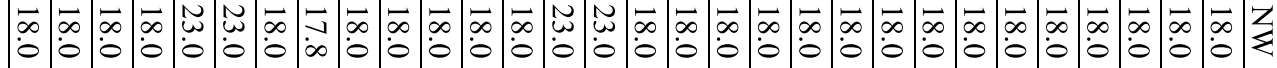

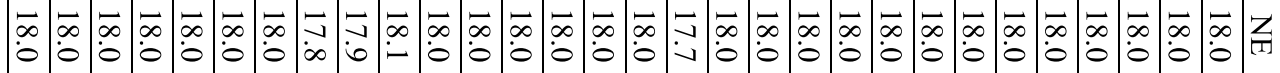

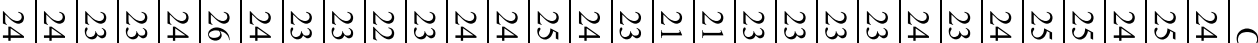

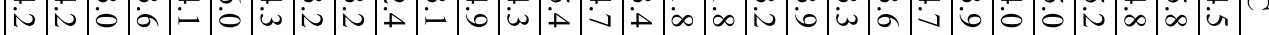

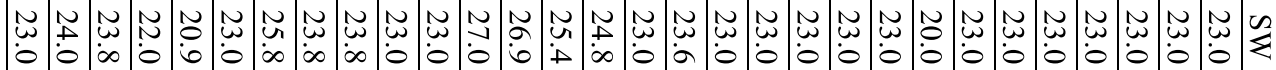

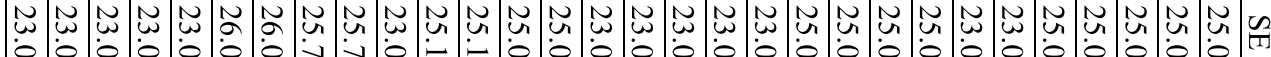

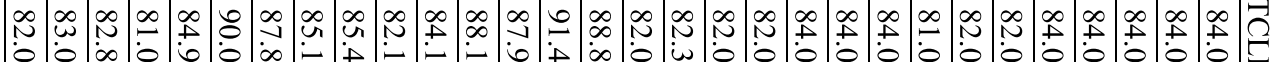

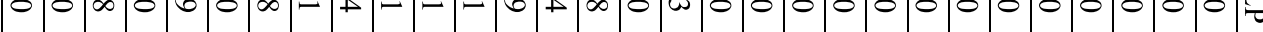

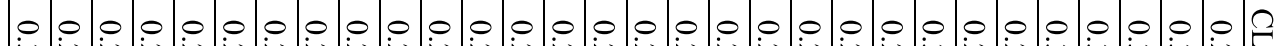

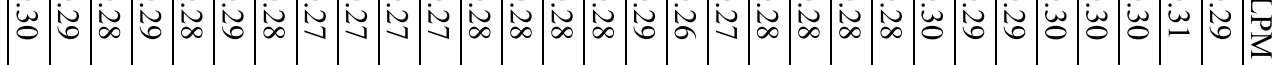

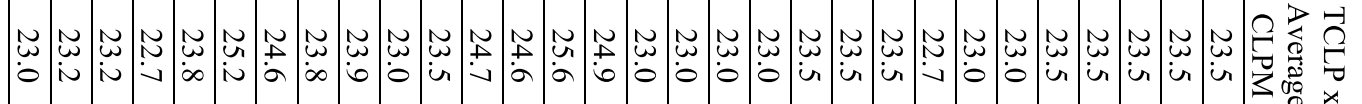

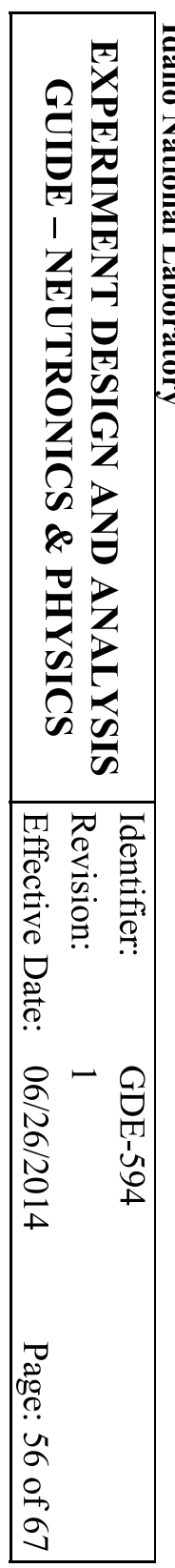

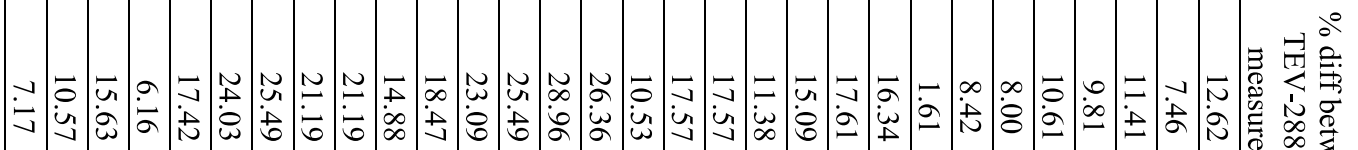

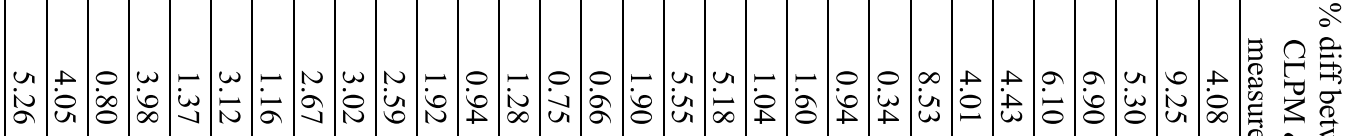

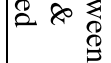

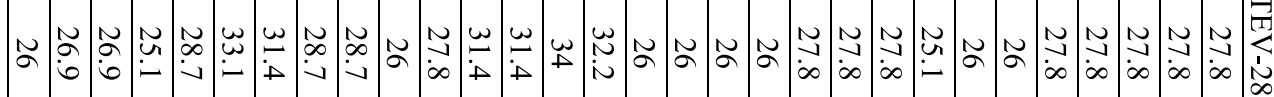




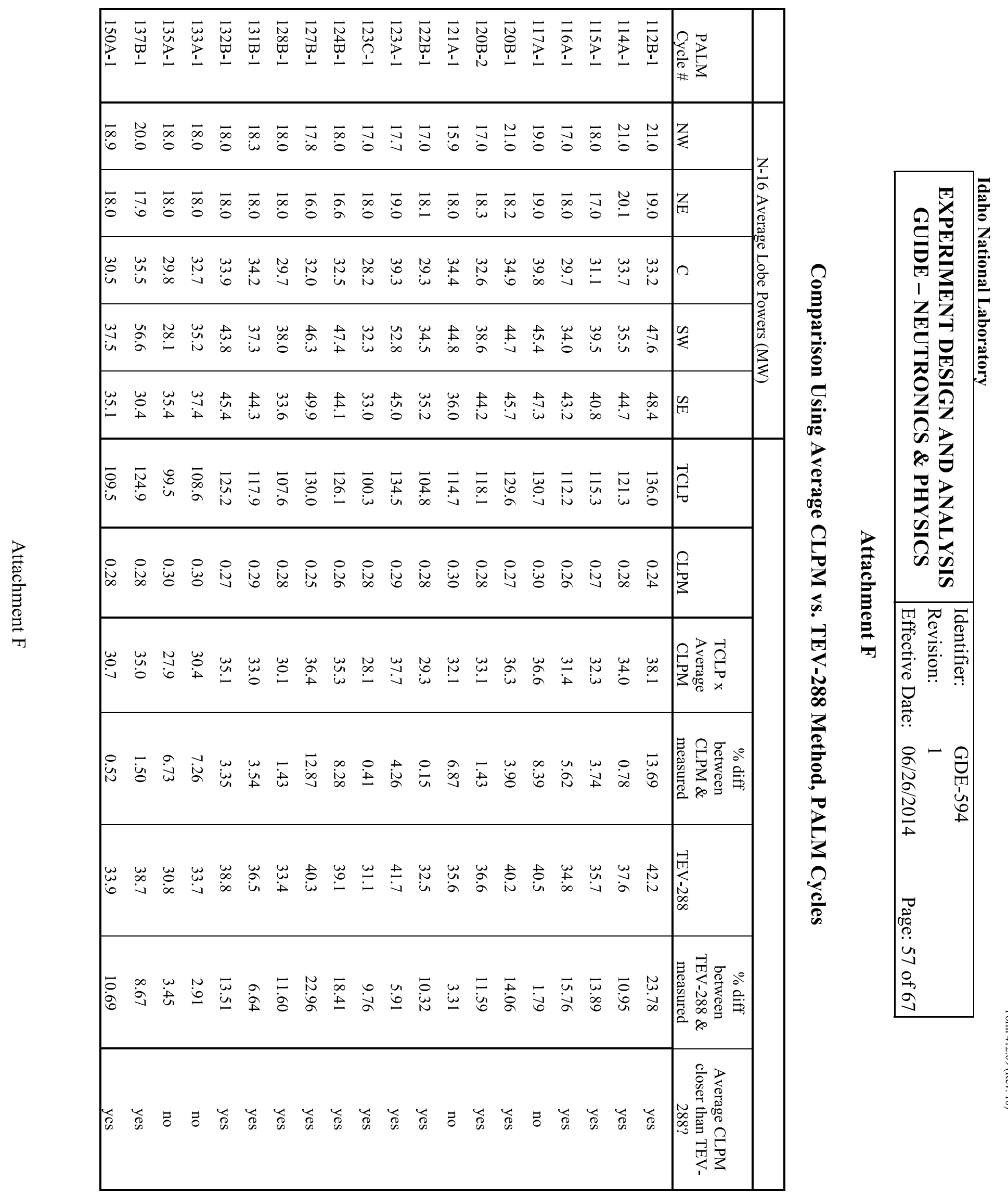




\begin{tabular}{|c|lll|}
\hline $\begin{array}{c}\text { EXPERIMENT DESIGN AND ANALYSIS } \\
\text { GUIDE - NEUTRONICS \& PHYSICS }\end{array}$ & Revision: & \multicolumn{1}{l|}{ GDE-594 } & \\
& Effective Date: & $06 / 26 / 2014$ & Page: 58 of 67 \\
\hline
\end{tabular}

\section{Attachment G}

\section{ATR Power History Through Cycle 133B-1, DEH-05-04}

Idaho National Engineering and Environmental laboratory
INTEROFFICE MEMORANDUM
Date: $\quad$ August 18,2004
$\begin{array}{llll}\text { To: } & \text { J. C. Chapman } & \text { MS } 7136 & 3-4450 \\ \text { From: } & \text { D. E. Hale } & \text { MS } 7136 & 3-4101\end{array}$

Subject: $\quad$ ADVANCED TEST REACTOR (ATR) POWER HISTORY THROUGH CYCLE 133B-1

References: (a) A. V. Briscoe letter to J. L. Durney, AVB-9-77, ATR Power History Through Cycle 34C-1, June 7, 1977

(b) C. C. Swanson letter to J. L. Durney, CAS-05-86, ATR Power History Through Cycle 72A-1, February 3, 1986

(c) L. S. Loret letter to E. C. Anderson, Sr., LSL-11-94, ATR Power History

Through Cycle 102B-1, February 28, 1994

Table 1 lists the ATR N-16 constrained power history data since the Beryllium V Core Internals Changeout (Cycle 103A-1) through Cycle 133B-1. The ATR power history prior to Cycle 103A-1 is presented in the references.

Table 2 lists the accumulated N-16 total lobe MWd and total core MWd as obtained from the ATR DAS for Cycle 103A-1 through 133B-1.

deh

Attachments:

As Stated

cc: J. D. Abrashoff, MS 7136

E. R. Carlson, MS 7129

G. S. Chang, MS 3885

D. L. Durocher, MS 7106

J. E. Dwight, MS 7117

K. R. Estes, MS 7101

R. C. Howard, MS 7101

C. C. Jensen, MS 7113

M. A. Lillo, MS 7136

C. C. McKenzie, MS 7136

G. A. Marts, MS 7101

R. K. Murray, MS 7111

R. C. Pedersen, MS 7101

T. E. Rahl, MS 3760

P. A. Roth, MS 7136

D. J. Schoonen, MS 7129

W. F. Steinke, MS 3407 


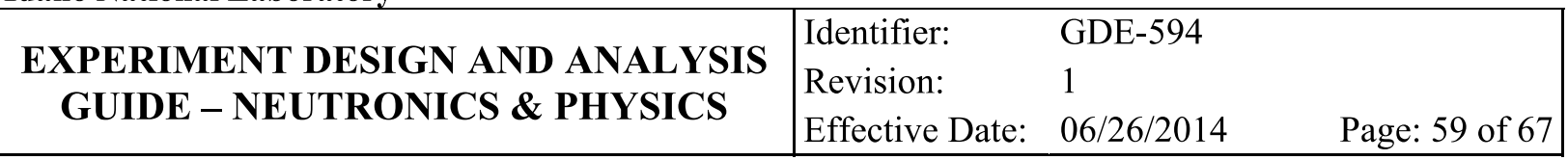

J. C. Chapman

Aügust 18, 2004

Page 2

D. V. Thomas, MS 7136

J. E. Wattenbarger, MS 7114

CSAP Surveillance File

D. E. Hale File (DEH-05-04)

Uniform File Code: 7304

Disposition Authority: A17-21-c

Retention Schedule: Destroy when 6 years old

NOTE: Original disposition authority, retention schedule, and Uniform Filing Code applied by the sender may not be appropriate for all recipients. Make adjustments as needed. 


\begin{tabular}{c|lll|} 
EXPERIMENT DESIGN AND ANALYSIS & Identifier: & GDE-594 & \\
GUIDE - NEUTRONICS \& PHYSICS & Revision: & 1 & \\
& Effective Date: & $06 / 26 / 2014$ & Page: 60 of 67
\end{tabular}

TABLE 1

SUMMARY OF ATR POWER HISTORY

\begin{tabular}{|c|c|c|c|c|c|c|c|c|c|c|c|c|}
\hline \multirow{2}{*}{$\begin{array}{c}\text { Cycle } \\
\text { No. } \\
\end{array}$} & \multicolumn{5}{|c|}{$\mathrm{N}-16$ Average Lobe Powers (MW) } & \multicolumn{6}{|c|}{$\mathrm{N}-16$ Lobe MWd } & \multirow[b]{2}{*}{ EFPD } \\
\hline & NW & $\underline{N E}$ & $\mathrm{C}$ & SW & $\underline{S E}$ & NW & $\underline{\mathrm{NE}}$ & $\mathrm{C}$ & $\underline{\text { SW }}$ & $\underline{S E}$ & Total & \\
\hline $103 \mathrm{~A}-1 / 6$ & --- & ---- & --- & -- & --- & 1 & 1 & 1 & 1 & 1 & 5 & --- \\
\hline 103B-1 & 21.0 & 18.4 & 22.8 & 23.0 & 27.0 & 830 & 726 & 902 & 908 & 1068 & 4434 & 39.5 \\
\hline $104 \mathrm{~A}-1$ & 18.5 & 16.4 & 22.6 & 23.0 & 27.0 & 803 & 711 & 981 & 996 & 1171 & 4660 & 43.4 \\
\hline 104B-1 & 17.0 & 16.3 & 22.0 & 22.9 & 27.0 & 773 & 739 & 1001 & 1040 & 1228 & 4781 & 45.5 \\
\hline $105 \mathrm{~A}-1$ & 17.0 & 17.0 & 22.6 & 23.0 & 27.0 & 744 & 744 & 989 & 1007 & 1181 & 4664 & 43.7 \\
\hline 105B-1 & 17.0 & 17.0 & 23.5 & 23.0 & 26.5 & 716 & 716 & 990 & 968 & 1118 & 4509 & 42.1 \\
\hline $106 \mathrm{~A}-1$ & 17.0 & 17.0 & 22.7 & 23.0 & 27.0 & 849 & 848 & 1134 & 1148 & 1347 & 5326 & 49.9 \\
\hline 106B-1 & 17.0 & 17.0 & 22.1 & 21.3 & 31.7 & 212 & 212 & 276 & 266 & 396 & 1362 & 12.5 \\
\hline 106B-2 & 17.0 & 17.0 & 22.1 & 20.8 & 30.1 & $\frac{109}{321}$ & $\frac{109}{321}$ & $\frac{142}{418}$ & $\frac{133}{399}$ & $\frac{193}{589}$ & $\frac{687}{2049}$ & $\frac{6.4}{18.9}$ \\
\hline 107A-1 & 17.0 & 17.0 & 21.4 & 23.0 & 25.6 & 718 & 717 & 902 & 971 & 1080 & 4388 & 42.2 \\
\hline 107B-1 & 17.0 & 20.0 & 23.6 & 23.0 & 27.0 & 843 & 993 & 1173 & 1142 & 1342 & 5494 & 49.7 \\
\hline $108 \mathrm{~A}-1$ & 17.0 & 17.0 & 21.5 & 23.0 & 25.0 & 727 & 727 & 923 & 985 & 1071 & 4433 & 42.8 \\
\hline 108B-1 & 13.0 & 20.0 & 22.6 & 25.0 & 27.0 & 563 & 864 & 978 & 1081 & 1169 & 4655 & 43.3 \\
\hline $109 \mathrm{~A}-1$ & 17.0 & 17.0 & 22.2 & 23.0 & 25.0 & 252 & 252 & 329 & 341 & 371 & 1546 & 14.8 \\
\hline $109 A-2$ & 17.0 & 17.0 & 23.1 & 23.0 & 25.0 & $\frac{544}{796}$ & $\frac{544}{796}$ & $\frac{740}{1069}$ & $\frac{736}{1077}$ & $\frac{800}{1171}$ & $\frac{3363}{4909}$ & $\frac{32.0}{46.8}$ \\
\hline 109B-1 & 17.0 & 17.0 & 23.2 & 23.0 & 27.0 & 720 & 721 & 984 & 974 & 1145 & 4544 & 42.4 \\
\hline $110 \mathrm{~A}-1$ & 17.0 & 17.0 & 24.5 & 23.0 & 28.2 & 681 & 680 & 980 & 921 & 1131 & 4393 & 40.0 \\
\hline 110B-1 & 17.0 & 30.0 & 27.7 & 20.0 & 29.4 & 660 & 1166 & 1077 & 777 & 1141 & 4822 & 38.8 \\
\hline $111 \mathrm{~A}-1$ & 17.0 & 30.0 & 27.4 & 22.0 & 26.4 & 600 & 1058 & 965 & 776 & 933 & 4332 & 35.3 \\
\hline 111B-1 & 17.0 & 27.5 & 25.5 & 22.0 & 31.1 & 244 & 395 & 366 & 316 & 446 & 1767 & 14.4 \\
\hline $112 A-1$ & 17.9 & 30.0 & 27.1 & 22.0 & 27.0 & 1032 & 1724 & 1556 & 1266 & 1553 & 7131 & 57.5 \\
\hline $112 \mathrm{~B}-1$ & 21.0 & 19.0 & 33.2 & 47.6 & 48.4 & 42 & 38 & 66 & 94 & 96 & 335 & 2.0 \\
\hline $112 \mathrm{C}-1$ & 18.2 & 17.5 & 26.2 & 22.4 & 33.1 & 902 & 868 & 1298 & 1112 & 1644 & 5823 & 49.6 \\
\hline $113 \mathrm{~A}-1$ & 17.1 & 17.4 & 26.5 & 23.0 & 34.0 & 733 & 742 & 1131 & 985 & 1452 & 5043 & 42.8 \\
\hline 113B-1 & 17.0 & 17.0 & 24.0 & 24.0 & 27.0 & 718 & 717 & 1011 & 1014 & 1141 & 4601 & 42.2 \\
\hline
\end{tabular}


EXPERIMENT DESIGN AND ANALYSIS GUIDE - NEUTRONICS \& PHYSICS
Identifier: Revision: Effective Date: 06/26/2014
Page: 61 of 67

Page 2 of 4

TABLE 1, Continued

SUMMARY OF ATR POWER HISTORY

\begin{tabular}{|c|c|c|c|c|c|c|c|c|c|c|c|c|}
\hline \multirow{2}{*}{$\begin{array}{c}\text { Cycle } \\
\text { No. } \\
\end{array}$} & \multicolumn{5}{|c|}{$\mathrm{N}-16$ Average Lobe Powers (MW) } & \multicolumn{6}{|c|}{$\mathrm{N}-16$ Lobe MWd } & \multirow[b]{2}{*}{ EFPD } \\
\hline & $\mathrm{NW}$ & $\mathrm{NE}$ & $\mathrm{C}$ & SW & $\underline{\mathrm{SE}}$ & NW & $\underline{\mathrm{NE}}$ & C & $\underline{\text { sw }}$ & $\underline{S E}$ & Total & \\
\hline $114 \mathrm{~A}-1$ & 21.0 & 20.1 & 33.7 & 35.5 & 44.7 & 42 & 40 & 67 & 71 & 89 & 310 & 2.0 \\
\hline 114B-1 & 18.0 & 17.0 & 24.5 & 23.0 & 27.0 & 920 & 869 & 1253 & 1177 & 1382 & 5603 & 51.1 \\
\hline $114 C-1$ & 18.0 & 17.0 & 23.8 & 22.1 & 27.1 & 779 & 735 & 1030 & 955 & 1171 & 4669 & 43.3 \\
\hline $115 A-1$ & 18.0 & 17.0 & 30.1 & 39.5 & 40.8 & 23 & 22 & 38 & 51 & 52 & 186 & 1.3 \\
\hline 115B-1 & 17.0 & 18.0 & 24.1 & 23.0 & 28.6 & 615 & 652 & 872 & 832 & 1037 & 4008 & 36.2 \\
\hline $115 \mathrm{C}-1$ & 17.0 & 18.0 & 23.0 & 23.0 & 23.0 & 823 & 873 & 1112 & 1112 & 1113 & 5034 & 48.4 \\
\hline $116 \mathrm{~A}-1$ & 17.0 & 18.0 & 29.7 & 34.0 & 43.2 & 218 & 231 & 382 & 436 & 554 & 1821 & 12.8 \\
\hline 116B-1 & 17.0 & 18.0 & 23.4 & 23.0 & 25.0 & 376 & 399 & 519 & 510 & 554 & 2358 & 22.2 \\
\hline $117 \mathrm{~A}-1$ & 19.0 & 19.0 & 39.8 & 45.4 & 47.3 & 269 & 268 & 562 & 642 & 669 & 2409 & 14.1 \\
\hline 117B-1 & 17.0 & 18.8 & 24.3 & 22.0 & 25.5 & 976 & 1079 & 1393 & 1262 & 1465 & 6175 & 57.4 \\
\hline $118 \mathrm{~A}-1$ & 17.0 & 18.0 & 24.3 & 22.0 & 27.0 & 821 & 869 & 1178 & 1065 & 1304 & 5238 & 48.4 \\
\hline 118B-1 & 17.0 & 18.0 & 24.4 & 22.0 & 27.0 & 618 & 654 & 885 & 800 & 981 & 3938 & 36.4 \\
\hline 119A-1 & 13.3 & 18.0 & 22.1 & 23.0 & 24.0 & 254 & 345 & 423 & 441 & 460 & 1924 & 19.2 \\
\hline 119A-2 & 17.0 & 18.1 & 23.2 & 23.0 & 23.8 & 42 & 45 & 58 & 57 & 59 & 26 & 1.5 \\
\hline $119 \mathrm{~A}-3$ & 17.0 & 18.0 & $\frac{24.2}{2.2}$ & $\frac{23.0}{n-10}$ & 24.0 & $\frac{389}{606}$ & $\frac{412}{902}$ & $\underline{554}$ & $\frac{527}{1025}$ & $\underline{550}$ & $\underline{2432}$ & $\underline{22.9}$ \\
\hline 119B-1 & 17.0 & 16.6 & 23.1 & 23.0 & 27.0 & 715 & 696 & 970 & 969 & 1137 & 4488 & 42.1 \\
\hline $120 \mathrm{~A}-1$ & 17.0 & 17.5 & 22.0 & 22.0 & 24.0 & 956 & 985 & 1236 & 1237 & 1349 & 5764 & 56.2 \\
\hline 120B-1 & 21.0 & 18.2 & 34.9 & 44.7 & 45.7 & 42 & 36 & 70 & 89 & 91 & $32 \mathrm{~s}$ & 2.0 \\
\hline 120B-2 & 17.0 & 18.3 & 32.6 & 38.6 & 44.2 & $\frac{24}{66}$ & $\frac{25}{62}$ & $\frac{45}{115}$ & $\frac{53}{143}$ & $\frac{61}{153}$ & $\frac{208}{537}$ & $\frac{1.4}{3.4}$ \\
\hline $120 \mathrm{C}-1$ & 16.5 & 18.0 & 24.5 & 23.0 & 26.9 & 560 & 613 & 832 & 783 & 916 & 3704 & 34.0 \\
\hline $121 \mathrm{~A}-1$ & 15.9 & 18.0 & 34.4 & 44.8 & 36.0 & 223 & 252 & 482 & 629 & 505 & 2091 & 14.0 \\
\hline 121B-1 & 16.2 & 17.7 & 25.3 & 23.0 & 30.0 & 750 & 821 & 1170 & 1064 & 1389 & 5194 & 46.3 \\
\hline $121 \mathrm{C}-1$ & 16.2 & 18.0 & 23.3 & 23.0 & 23.0 & 767 & 852 & 1101 & 1089 & 1089 & 4899 & 47.3 \\
\hline $122 \mathrm{~A}-1$ & 17.0 & 18.0 & 26.7 & 23.0 & 32.0 & 696 & 737 & 1093 & 942 & 1309 & 4777 & 40.9 \\
\hline 122B-1 & 17.0 & 18.1 & 29.3 & 34.5 & 35.2 & 21 & 22 & 36 & 43 & 44 & 167 & 1.2 \\
\hline $122 \mathrm{C}-1$ & 17.0 & 18.6 & 23.3 & 23.0 & 23.0 & 848 & 928 & 1161 & 1147 & 1146 & 5230 & 49.9 \\
\hline
\end{tabular}




\begin{tabular}{|c|c|}
\hline $\mathrm{C}$ & $\begin{array}{ll}\text { Identifier: } & \text { GDE-594 } \\
\text { Revision: } & 1 \\
\text { Effective Date: } & 06 / 26 / 2014\end{array}$ \\
\hline
\end{tabular}

Page 3 of 4

TABLE 1, Continued

SUMMARY OF ATR POWER HISTORY

\begin{tabular}{|c|c|c|c|c|c|c|c|c|c|c|c|c|}
\hline \multirow{2}{*}{$\begin{array}{c}\text { Cycle } \\
\text { No. } \\
\end{array}$} & \multicolumn{5}{|c|}{$\mathrm{N}$-16 Average Lobe Powers (MW) } & \multicolumn{6}{|c|}{$\mathrm{N}-16$ Lobe MWd } & \multirow[b]{2}{*}{ EFPD } \\
\hline & NW & $\underline{N E}$ & $\mathrm{C}$ & SW & SE & NW & NE & C & SW & SE & $\underline{\text { Total }}$ & \\
\hline $123 A-1$ & 17.7 & 19.0 & 39.3 & 52.8 & 45.0 & 226 & 243 & 502 & 675 & 576 & 2223 & 12.8 \\
\hline 123B-1 & 17.0 & 17.9 & 24.1 & 23.0 & 27.0 & 718 & 757 & 1015 & 972 & 1141 & 4603 & 42.2 \\
\hline $123 \mathrm{C}-1$ & 17.0 & 18.0 & 28.2 & 32.3 & 33.0 & 228 & 241 & 378 & 433 & 442 & 1722 & 13.4 \\
\hline $124 \mathrm{~A}-1$ & 17.0 & 18.0 & 25.3 & 23.0 & 27.0 & 977 & 1035 & 1453 & 1324 & 1553 & 6342 & 57.5 \\
\hline 124B-1 & 18.0 & 16.6 & 32.5 & 47.4 & 44.1 & 12 & 11 & 22 & 31 & 29 & 105 & 0.7 \\
\hline $124 \mathrm{C}-1$ & 17.0 & 18.5 & 24.6 & 23.0 & 27.0 & 681 & 740 & 986 & 922 & 1081 & 4411 & 40.1 \\
\hline $125 A-1$ & 18.0 & 16.0 & 25.1 & 23.0 & 25.0 & 575 & 510 & 800 & 734 & 798 & 3416 & 31.9 \\
\hline $125 A-2$ & 17.9 & 15.9 & 25.7 & 22.9 & 24.9 & $\frac{396}{971}$ & $\frac{351}{861}$ & $\frac{567}{1367}$ & $\frac{506}{1240}$ & $\frac{550}{1348}$ & $\frac{2371}{5788}$ & $\frac{22.1}{54.0}$ \\
\hline 125B-1 & 17.0 & 16.0 & 23.9 & 25.1 & 25.0 & 848 & 796 & 1195 & 1250 & 1249 & 5338 & 49.9 \\
\hline $126 A-1$ & 17.1 & 16.0 & 23.2 & 23.0 & 25.1 & 677 & 635 & 920 & 914 & 994 & 4140 & 39.7 \\
\hline 126B-1 & 18.0 & 16.0 & 23.7 & 23.0 & 25.0 & 890 & 789 & 1174 & 1136 & 1236 & 5225 & 49.4 \\
\hline $127 A-1$ & 18.1 & 16.0 & 23.5 & 23.1 & 25.1 & 1011 & 895 & 1313 & 1292 & 1404 & 5916 & 56.0 \\
\hline 127B-1 & 17.8 & 16.0 & 32.0 & 46.3 & 49.9 & 9 & 8 & 17 & 24 & 26 & 84 & 0.5 \\
\hline $127 \mathrm{C}-1$ & 18.0 & 16.0 & 23.3 & 25.0 & 25.0 & 905 & 803 & 1169 & 1256 & 1257 & 5389 & 50.3 \\
\hline $128 \mathrm{~A}-1$ & 17.9 & 18.0 & 22.6 & 24.1 & 24.6 & 1072 & 1079 & 1356 & 1442 & 1475 & 6423 & 59.9 \\
\hline 128B-1 & 18.0 & 18.0 & 29.7 & 38.0 & 33.6 & 262 & 261 & 432 & 553 & 488 & 1997 & 14.5 \\
\hline $129 \mathrm{~A}-1$ & 18.0 & 18.0 & 22.7 & 25.0 & 25.0 & 930 & 931 & 1174 & 1293 & 1293 & 5620 & 51.7 \\
\hline 129B-1 & 18.0 & 18.0 & 24.1 & 25.0 & 23.0 & 789 & 789 & 1056 & 1096 & 1008 & 4738 & 43.8 \\
\hline $130 \mathrm{~A}-1$ & 18.0 & 18.0 & 24.1 & 23.0 & 25.0 & 926 & 926 & 1243 & 1183 & 1284 & 5561 & 51.5 \\
\hline 130B-1 & 18.0 & 17.0 & 24.2 & 23.0 & 25.0 & 801 & 756 & 1077 & 1023 & 1113 & 4771 & 44.5 \\
\hline $131 \mathrm{~A}-1$ & 18.0 & 17.0 & 24.3 & 23.0 & 24.6 & 874 & 824 & 1176 & 1116 & 1195 & 5185 & 48.5 \\
\hline 131B-1 & 18.3 & 18.0 & 34.2 & 37.3 & 44.3 & 253 & 249 & 473 & 516 & 612 & 2103 & 13.8 \\
\hline $132 \mathrm{~A}-1$ & 18.0 & 18.0 & 25.7 & 23.0 & 27.0 & 420 & 420 & 600 & 537 & 631 & 2608 & 23.4 \\
\hline $132 \mathrm{~A}-2$ & 18.0 & 18.0 & 25.6 & 23.0 & 27.0 & $\frac{373}{793}$ & $\frac{373}{793}$ & $\frac{532}{1132}$ & $\frac{477}{1014}$ & $\frac{560}{1191}$ & $\frac{2315}{4923}$ & $\frac{20.7}{44.1}$ \\
\hline 132B-1 & 18.0 & 18.0 & 33.9 & 43.8 & 45.4 & 30 & 30 & 56 & 72 & 75 & 262 & 1.6 \\
\hline 132C-1 & 18.0 & 18.0 & 25.6 & 23.0 & 27.0 & 906 & 905 & 1288 & 1157 & 1359 & 5615 & 50.3 \\
\hline
\end{tabular}




\begin{tabular}{c|lll} 
EXPERIMENT DESIGN AND ANALYSIS & Identifier: & GDE-594 & \\
GUIDE - NEUTRONICS \& PHYSICS & Revision: & 1 & \\
& Effective Date: & $06 / 26 / 2014$ & Page: 63 of 67
\end{tabular}

Page 4 of 4

TABLE 1, Continued

SUMMARY OF ATR POWER HISTORY

\begin{tabular}{|c|c|c|c|c|c|c|c|c|c|c|c|c|}
\hline \multirow{2}{*}{$\begin{array}{c}\text { Cycle } \\
\text { No. }\end{array}$} & \multicolumn{5}{|c|}{$\mathrm{N}-16$ Average Lobe Powers (MW) } & \multicolumn{6}{|c|}{ N-16 Lobe MWd } & \multirow[b]{2}{*}{ EFPD } \\
\hline & NW & NE & $\mathrm{C}$ & SW & $\underline{\mathrm{SE}}$ & NW & NE & $\mathrm{C}$ & SW & SE & Total & \\
\hline $133 A-1$ & 18.0 & 18.0 & 32.7 & 35.2 & 37.4 & 234 & 234 & 425 & 458 & 487 & 1839 & 13.0 \\
\hline 133B-1 & 18.1 & 18.0 & 26.6 & 23.7 & 27.0 & 1113 & 1106 & 1632 & 1454 & 1658 & 6963 & 61.4 \\
\hline
\end{tabular}




\begin{tabular}{|c|c|c|c|}
\hline $\begin{array}{l}\text { EXPERIMENT DESIGN AND ANALYSIS } \\
\text { GUIDE - NEUTRONICS \& PHYSICS }\end{array}$ & $\begin{array}{l}\text { Identifier: } \\
\text { Revision: } \\
\text { Effective Date: }\end{array}$ & $\begin{array}{l}\text { GDE-594 } \\
1 \\
06 / 26 / 2014\end{array}$ & Page: 64 of 67 \\
\hline
\end{tabular}

\section{Attachment H}

ATR Power History Through Cycle 150B-1, Revision 1, DEH-05-11, Rev.1

\section{INTEROFFICE MEMORANDUM

Date: $\quad$ December 1, 2011

To: $\quad$ R. A. Jordan

From: D. E. Hale Bryon Curmatt for per telecon

Subject: $\quad$ ADVANCED TEST REACTOR (ATR) POWER HISTORY THROUGH CYCLE 150B-1, Revision 1

References: (a) A. V. Briscoe letter to J. L. Durney, AVB-9-77, ATR Power History Through Cycle 34C-1, June 7, 1977

(b) C. C. Swanson letter to J. L. Durney, CAS-05-86, ATR Power History Through Cycle 72A-1, February 3, 1986

(c) L. S. Loret letter to E. C. Anderson, Sr., LSL-1 1-94, ATR Power History Through Cycle 102B-1, February 28, 1994

(d) D. E. Hale letter to J. C. Chapman, DEH-05-04, Advanced Test Reactor (ATR) Power History Through Cycle 133B-1, August 18, 2004

Revision 0 of this document incorrectly applied the ATR N-16 unconstrained lobe powers. This revision lists and correctly applies the ATR N-16 constrained lobe powers.

Table 1 lists the ATR N-16 constrained power history data since the Beryllium VI Core Internals Changeout (Cycle 134A-1) through Cycle 150B-1. The ATR power history prior to Cycle $134 \mathrm{~A}-1$ is presented in the references.

Table 2 lists the accumulated N-16 total lobe MWd and total core MWd as obtained from the ATR DAS for Cycle 134A-1 through 150B-1.

DEH

cc: $\quad$ E. R. Carlson, MS 7101

G. S. Chang, MS 3870

J. C. Chapman, MS 7136

C. D. Cooper, MS 3407

B. J. Curnutt, MS 7136

C. A. Dahl, MS 3818

S. L. Drussel, MS 6110

K. R. Estes, MS 7130

R. L. Fulks, MS 7130

J. E. Giebel, MS 7104

G. C. Hawkley, MS 7136 


\begin{tabular}{|c|c|c|c|}
\hline $\begin{array}{l}\text { EXPERIMENT DESIGN AND ANALYSIS } \\
\text { GUIDE - NEUTRONICS \& PHYSICS }\end{array}$ & $\begin{array}{l}\text { Identifier: } \\
\text { Revision: } \\
\text { Effective Date: }\end{array}$ & $\begin{array}{l}\text { GDE-594 } \\
1 \\
06 / 26 / 2014\end{array}$ & Page: 65 of 67 \\
\hline
\end{tabular}

R. A. Jordan

December 1,2011

Page 2
R. Holtz, MS 7136
R. C. Howard, MS 7101
C. D. Jackson, MS 7106
C. C. Jensen, MS 7113
J. R. Jimenez, MS 7136
W. F. Jones, MS 3818
A. W. LaPorta, MS 7136
M. A. Lillo, MS 3870
S. G. Louk, MS 7111
M. D. Love, MS 7117
Z. S. Miller, MS 7136
M. K. Morrison, MS 7136
R. K. Murray, MS 7111
D. Ogden, MS 3818
S. K. Penny, MS 3835
J. R. Peters, MS 7103
P. A. Roth, MS 3425
C. J. Stanley, MS 7101
M. E. Stengel (2), MS 7103
K. D. Stueve, MS 7106
C. R. Tyler, MS 3835
D. J. Utterbeck, MS 3870
A. J. Vinnola, MS 3407
J. F. Williams, MS 7101
CSAP Surveillance File
D. E. Hale Letter File (DEH-05-1 1, Rev. 1)

Uniform File Code: 8153

Disposition Authority: A17-32-b-1

Retention Schedule: Destroy when 6 years old

NOTE: Original disposition authority, retention schedule, and Uniform Filing Code applied by the sender may not be appropriate for all recipients. Make adjustments as needed. 


\begin{tabular}{|c|lll|}
$\begin{array}{c}\text { EXPERIMENT DESIGN AND ANALYSIS } \\
\text { GUIDE - NEUTRONICS \& PHYSICS }\end{array}$ & Revision: & GDE-594 & \\
& Effective Date: & $06 / 26 / 2014$ & Page: 66 of 67 \\
\hline
\end{tabular}

Page 1 of 2

TABLE 1

SUMMARY OF ATR POWER HISTORY

\begin{tabular}{|c|c|c|c|c|c|c|c|c|c|c|c|c|}
\hline \multirow{2}{*}{$\begin{array}{c}\text { Cycle } \\
\text { No. } \\
\end{array}$} & \multicolumn{5}{|c|}{$\mathrm{N}$-16 Average Lobe Powers (MW) } & \multicolumn{6}{|c|}{ N-16 Lobe MWd } & \multirow[b]{2}{*}{ EFPD } \\
\hline & NW & $\underline{\mathrm{NE}}$ & C & $\underline{\text { SW }}$ & $\underline{S E}$ & NW & NE & $\mathrm{C}$ & SW & SE & $\underline{\text { Total }}$ & \\
\hline $134 \mathrm{~A}-1$ & ---- & ---- & ---- &.--- & $\cdots$ & 0 & 0 & 0 & 0 & 0 & 0 & ---- \\
\hline $134 A-2$ & --- & ---- & ---- & --- & $-\cdots$ & $\frac{0.2}{0.2}$ & $\frac{0.3}{0.3}$ & $\frac{0.4}{0.4}$ & $\frac{0.4}{0.4}$ & $\frac{0.4}{0.4}$ & $\frac{2.0}{2.0}$ & $\cdots$ \\
\hline 134B-1 & 18.0 & 18.0 & 24.5 & 23.0 & 25.0 & 452.8 & 452.2 & 615.5 & 578.5 & 628.6 & 2727.6 & 25.1 \\
\hline $134 \mathrm{~B}-2$ & 18.0 & 18.0 & 25.8 & 23.0 & 25.0 & $\frac{385.6}{838.4}$ & $\frac{385.8}{838.0}$ & $\frac{553.5}{1169.0}$ & $\frac{493.2}{1071.7}$ & $\frac{536.1}{1164.7}$ & $\frac{2354.2}{5081.8}$ & $\frac{21.4}{46.5}$ \\
\hline $135 \mathrm{~A}-1$ & 18.0 & 18.0 & 29.8 & 28.1 & 35.4 & 236.2 & 236.0 & 391.1 & 368.6 & 464.0 & 1695.8 & 13.1 \\
\hline 135B-1 & 18.0 & 18.0 & 24.8 & 23.0 & 25.0 & 458.3 & 458.4 & 630.8 & 585.3 & 636.5 & 2769.2 & 25.5 \\
\hline 135B-2 & 18.0 & 18.0 & 25.2 & 23.0 & 25.0 & $\frac{405.0}{863.3}$ & $\frac{405.7}{864.1}$ & $\frac{567.4}{1198.2}$ & $\frac{517.8}{1103.1}$ & $\frac{563.0}{1199.5}$ & $\frac{2458.9}{5228.1}$ & $\frac{22.5}{48.0}$ \\
\hline $135 \mathrm{C}-1$ & 18.0 & 18.0 & 25.0 & 23.0 & 25.0 & 729.9 & 729.7 & 1013.5 & 933.0 & 1013.9 & 4419.9 & 40.6 \\
\hline $136 \mathrm{~A}-1$ & 18.0 & 18.0 & 24.0 & 23.0 & 23.0 & 916.2 & 916.4 & 1218.9 & 1169.5 & 1170.2 & 5391.1 & 50.9 \\
\hline 136B-1 & 18.0 & 18.0 & 23.9 & 23.0 & 23.0 & 701.9 & 702.3 & 931.2 & 896.9 & 897.0 & 4129.4 & 39.0 \\
\hline 137A-1 & 18.0 & 18.0 & 24.7 & 20.0 & 25.0 & 975.4 & 974.8 & 1336.2 & 1083.2 & 1353.3 & 5722.8 & 54.1 \\
\hline 137B-1 & 20.0 & 17.9 & 35.5 & 56.6 & 30.4 & 242.0 & 217.0 & 429.6 & 685.4 & 367.6 & 1941.6 & 12.1 \\
\hline $138 \mathrm{~A}-1$ & 18.0 & 18.0 & 23.6 & 23.0 & 25.0 & 1046.9 & 1047.7 & 1370.7 & 1336.4 & 1453.5 & 6255.1 & 58.1 \\
\hline 138B-1 & 18.0 & 18.0 & 23.3 & 23.0 & 25.0 & 838.5 & 839.6 & 1084.8 & 1070.9 & 1164.6 & 4998.5 & 46.6 \\
\hline 139A-1 & 18.0 & 18.0 & 23.9 & 23.0 & 25.0 & 928.7 & 929.1 & 1231.1 & 1186.3 & 1289.5 & 5564.6 & 51.6 \\
\hline $139 \mathrm{~B}-1$ & 18.0 & 18.0 & 23.2 & 23.0 & 23.0 & 919.7 & 919.7 & 1187.5 & 1174.9 & 1175.0 & 5376.8 & 51.1 \\
\hline $140 \mathrm{~A}-1$ & 18.0 & 18.0 & 21.8 & 23.0 & 23.0 & 837.0 & 837.2 & 1012.9 & 1069.7 & 1069.4 & 4826.1 & 46.5 \\
\hline $140 \mathrm{~B}-1$ & 18.0 & 17.7 & 21.8 & 23.6 & 23.0 & 641.7 & 629.5 & 777.2 & 842.9 & 820.0 & 3711.3 & 35.7 \\
\hline $141 \mathrm{~A}-1$ & 18.0 & 18.0 & 23.4 & 23.0 & 23.0 & 583.3 & 583.1 & 756.8 & 745.1 & 745.5 & 3413.7 & 32.4 \\
\hline $142 \mathrm{~A}-1$ & 23.0 & 18.0 & 24.7 & 24.8 & 23.0 & 1104.9 & 864.8 & 1186.0 & 1192.5 & 1104.0 & 5452.2 & 48.0 \\
\hline 142B-1 & 23.0 & 18.0 & 25.4 & 25.4 & 25.0 & 1196.9 & 936.7 & 1323.4 & 1322.5 & 1298.7 & 6078.2 & 52.0 \\
\hline $143 \mathrm{~A}-1 / 2$ & 18.0 & 18.0 & 24.3 & 26.9 & 25.0 & 880.0 & 882.5 & 1187.7 & 1315.4 & 1223.1 & 5488.7 & 48.9 \\
\hline 143B-1 & 18.0 & 18.0 & 24.9 & 27.0 & 25.1 & 1032.1 & 1032.6 & 1423.5 & 1543.7 & 1435.0 & 6466.9 & 57.3 \\
\hline $144 \mathrm{~A}-1$ & 18.0 & 18.0 & 23.1 & 23.0 & 25.1 & 787.0 & 787.0 & 1006.7 & 1004.5 & 1093.4 & 4678.6 & 43.7 \\
\hline 144B-1 & 18.0 & 18.1 & 22.4 & 23.0 & 23.0 & 932.3 & 933.4 & 1155.7 & 1190.7 & 1190.9 & 5403.0 & 51.7 \\
\hline
\end{tabular}




\begin{tabular}{|c|lll|}
$\begin{array}{c}\text { EXPERIMENT DESIGN AND ANALYSIS } \\
\text { GUIDE - NEUTRONICS \& PHYSICS }\end{array}$ & Revision: & GDE-594 & \\
& Effective Date: & $06 / 26 / 2014$ & Page: 67 of 67 \\
\hline
\end{tabular}

Page 2 of 2

TABLE 1 SUMMARY OF ATR POWER HISTORY

\begin{tabular}{|c|c|c|c|c|c|c|c|c|c|c|c|c|}
\hline \multirow{2}{*}{$\begin{array}{c}\text { Cycle } \\
\text { No. }\end{array}$} & \multicolumn{5}{|c|}{$\mathrm{N}-16$ Average Lobe Powers (MW) } & \multicolumn{6}{|c|}{$\mathrm{N}-16$ Lobe MWd } & \multirow[b]{2}{*}{ EFPD } \\
\hline & NW & NE & $\mathrm{C}$ & SW & SE & NW & NE & $\mathrm{C}$ & SW & $\underline{S E}$ & Total & \\
\hline $145 \mathrm{~A}-1$ & 18.0 & 17.9 & 23.2 & 23.8 & 25.7 & 983.0 & 980.9 & 1267.3 & 1299.5 & 1407.8 & 5938.4 & 54.7 \\
\hline 145B-1 & 17.8 & 17.8 & 23.0 & 24.6 & 25.8 & 1020.5 & 1020.0 & 1321.4 & 1407.8 & 1478.3 & 6247.9 & 57.3 \\
\hline $146 \mathrm{~A}-1$ & 18.0 & 18.0 & 24.3 & 25.8 & 26.0 & 906.8 & 906.8 & 1225.7 & 1300.0 & 1312.6 & 5651.9 & 50.5 \\
\hline 146B-1 & 23.0 & 18.0 & 26.0 & 23.0 & 26.0 & 903.7 & 707.1 & 1021.6 & 903.9 & 1021.0 & 4557,2 & 39.2 \\
\hline $147 \mathrm{~A}-1$ & 23.0 & 18.0 & 24.1 & 20.9 & 23.0 & 1156.9 & 904.4 & 1208.4 & 1049.4 & 1155.2 & 5474.3 & 50.2 \\
\hline $148 \mathrm{~A}-1$ & 18.0 & 18.0 & 23.6 & 22.0 & 23.0 & 856.0 & 855.8 & 1121.4 & 1043.8 & 1093.6 & 4970.6 & 47.5 \\
\hline 148B-1 & 18.0 & 18.0 & 23.0 & 23.8 & 23.0 & 927.5 & 926.7 & 1181.6 & 1224.0 & 1185.0 & 5444.8 & 51.5 \\
\hline $149 \mathrm{~A}-1$ & 18.0 & 18.0 & 24.2 & 24.0 & 23.0 & 662.5 & 662.7 & 891.3 & 883.3 & 846.8 & 3946.5 & 36.8 \\
\hline 149B-1 & 18.0 & 18.0 & 24.2 & 23.0 & 23.0 & 964.4 & 964.5 & 1297.8 & 1231.6 & 1230.8 & 5689.0 & 53.6 \\
\hline 150A-1 & 18.9 & 18.0 & 30.5 & 37.5 & 35.1 & 233.4 & 221.6 & 375.9 & 462.7 & 432.6 & 1726.2 & 12.3 \\
\hline 150B-1 & 19.9 & 18.0 & 24.2 & 23.0 & 23.1 & 832.8 & 754.7 & 1014.6 & 964.9 & 966.0 & 4533.0 & 41.9 \\
\hline
\end{tabular}

